\title{
Enabling the potential of Mission-led Research in New Zealand: Conceptualisations, Structures, and Relationships in the National Science Challenges
}

\author{
By
}

James Brathwaite

Submitted to the Victoria University of Wellington in partial fulfilment of the requirements for the degree of Masters of Commerce (Management)

Victoria University of Wellington

2019 


\section{Abstract}

Addressing the Grand Challenges of the world requires a mode of research that can mirror their scale and complexity. Traditional investigator- and industry-led research frameworks, although useful in their own right, fail to capture the collaborative, transdisciplinary approach that can both generate the necessary knowledge and apply research outcomes on the scale needed to resolve the 'big picture' problems. Mission-led research provides a framework that attempts to strike that balance of knowledge generation and application; and New Zealand's National Science Challenges (NSCs) provide a representation of missionled research that may exemplify the relationships and processes needed to enact it. This thesis aims to understand how the relationships and processes designed to facilitate mission-led research in the NSCs impacts their ability to achieve their missions.

Research was undertaken through semi-structured interviews with participants from two NSCs, representing four of the key stakeholder perspectives: Management, Researchers, Industry, and Māori. These interviews sought to understand how different stakeholder groups conceptualised mission-led research itself, the processes within it, and their relationships with other stakeholder groups. The results demonstrated that stakeholders perceived mission-led research in four interdependent ways, driven by a core concept of 'Big Picture' problems. These problems were seen to necessitate 'Transdisciplinarity' in their resolution, that research would be 'Long-term/Strategic', and that research outcomes would have a 'Collective Benefit'. Alignment between conceptualisations of mission-led research and how closely processes and stakeholder groups adhered to those conceptualisations was central to positive engagement and collaboration.

Alignment between stakeholders was seen to occur through three modes: Conceptual, Structural, and Relational. Conceptual alignment promoted a common understanding of the mission; Structural alignment ensured research practices reflected mission-led values; and Relational alignment improved stakeholder understanding of diverse expectations and motivations amongst other worldviews. Successful NSCs used the three modes of alignment to improve transdisciplinary collaboration while maintaining diversity of worldviews and skillsets, enabling them to more effectively address their missions. 


\section{Acknowledgements}

Thank you to everyone who supported me during this thesis - and in the years before. Many of you will have no idea how much of a difference you made.

Thank you first, to Urs; your guidance and supervision was invaluable, as well as your patience; and to SfTI, whose scholarship enabled me to focus on my research.

Thank you to the Tribe, who've stuck with me so long and with so much love; and to Bellbird's the Word, without whom university would have been much less fun.

To the Honours Crew, I would hardly have survived last year without you keeping me on track; to everyone at DOC, your support and friendship gave me some welcome escape.

To the Homoljas, Kelsey, Na, Rebecca, and Kate, who gave all the support and love I could ever have asked for;

To Hege, our procrastination collaboration was the best thing I never needed;

And to Sach, our dare-fuelled study sessions were what really got me to the end.

To all my family, who I could never acknowledge enough; thank you for all your love and dedication, patience and support.

Jamie

*Slaps knee* - Hot Damn! 


\section{Contents}

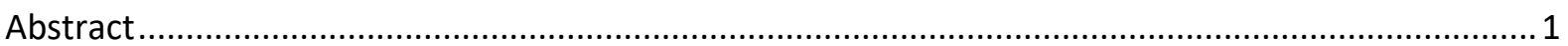

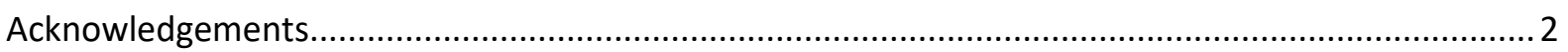

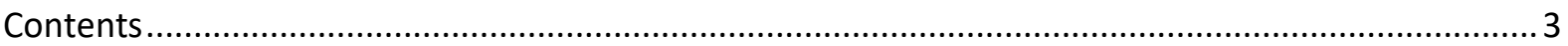

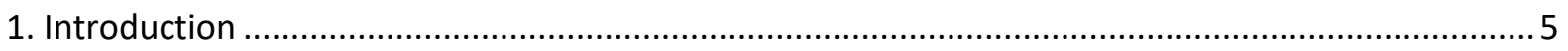

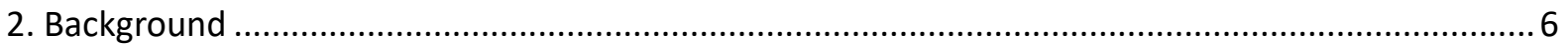

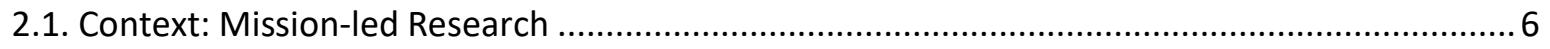

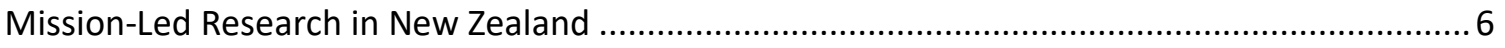

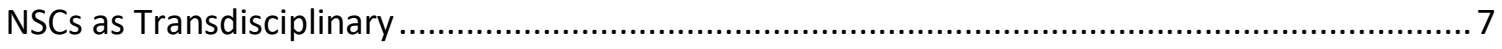

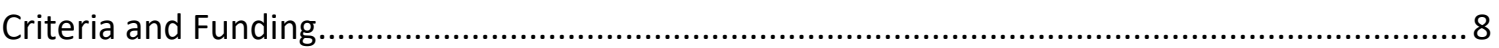

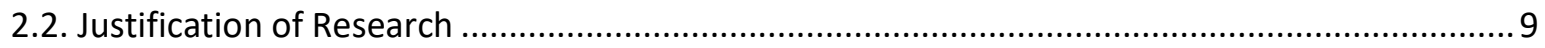

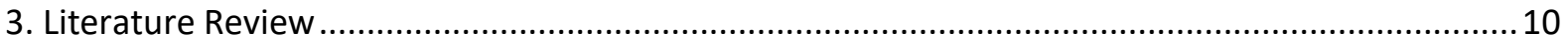

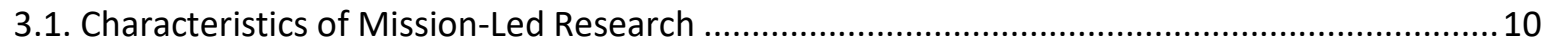

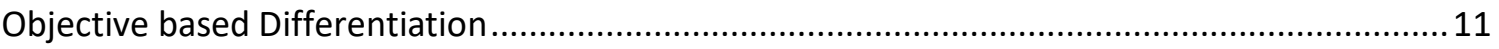

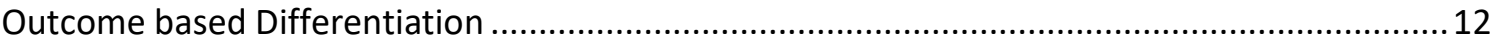

Funding Mechanism based Differentiation .......................................................................... 14

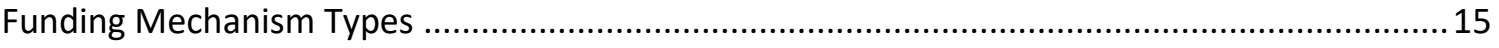

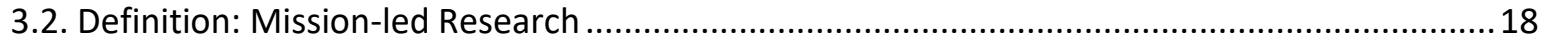

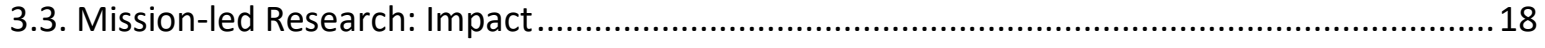

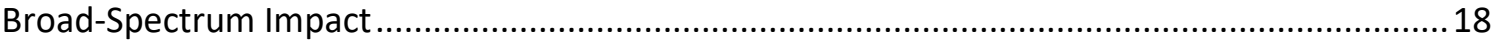

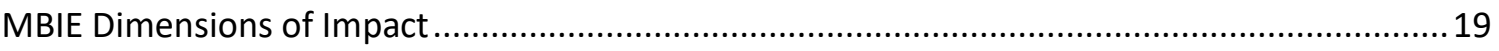

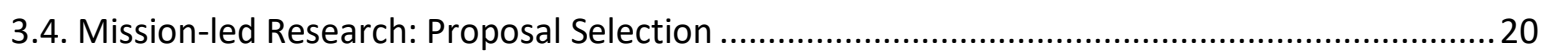

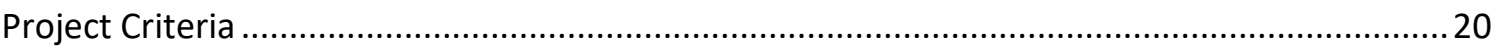

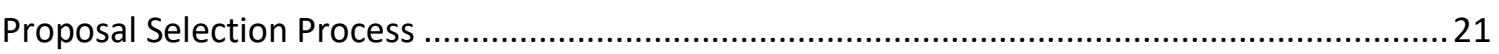

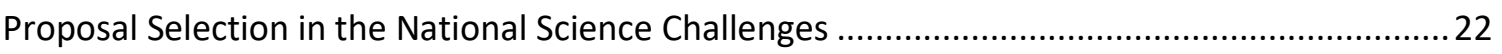

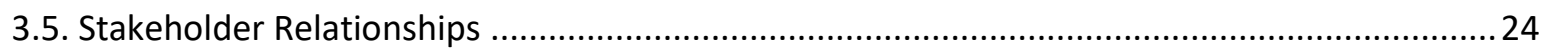

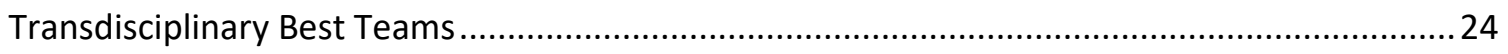

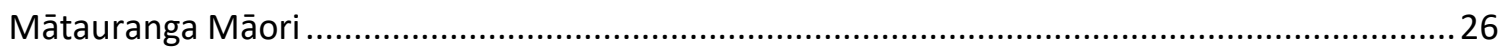

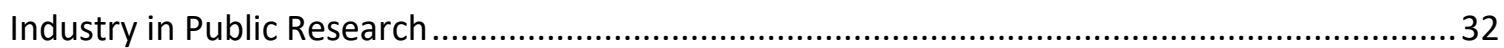

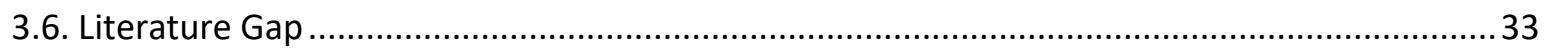

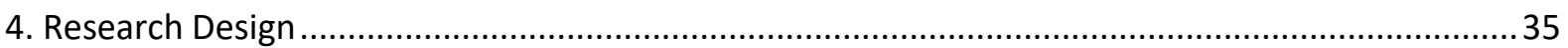

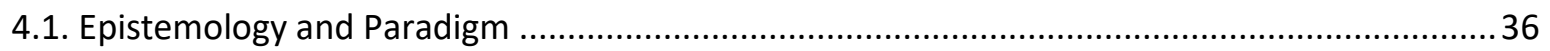

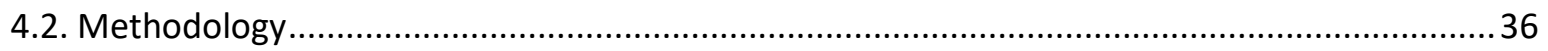

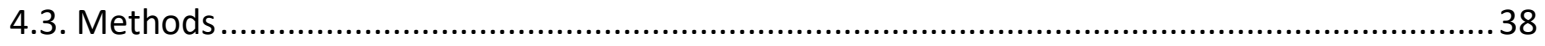

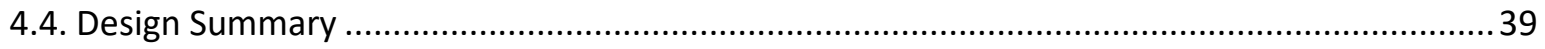

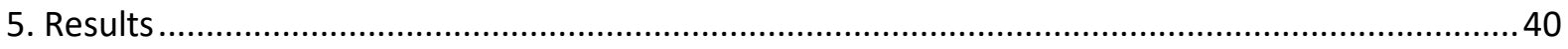




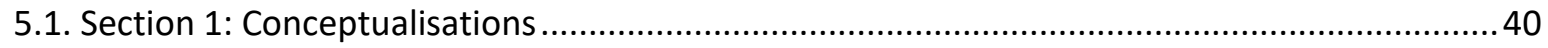

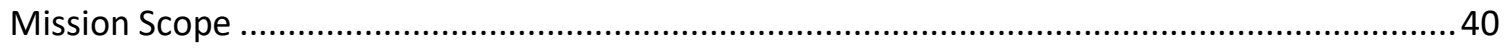

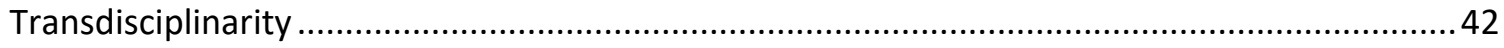

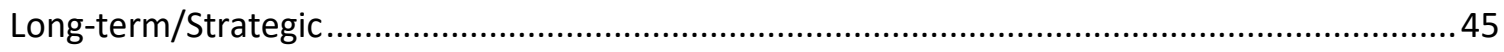

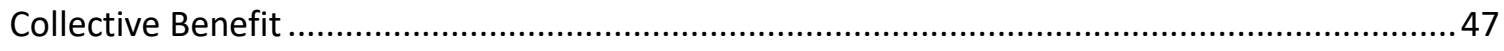

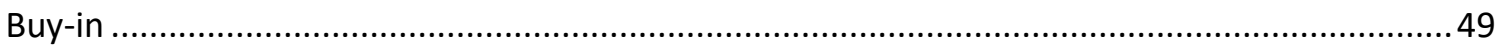

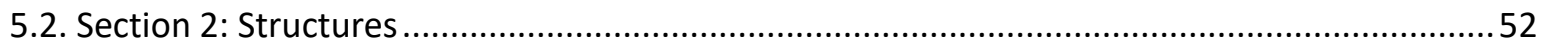

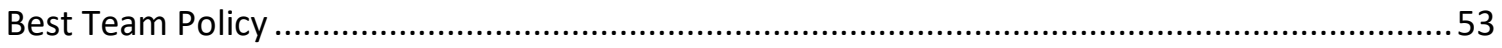

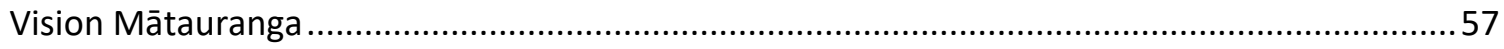

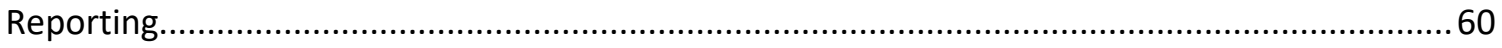

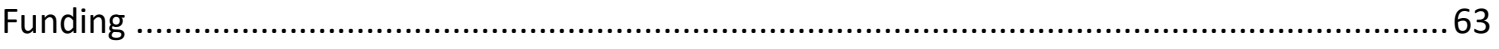

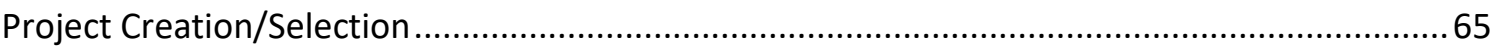

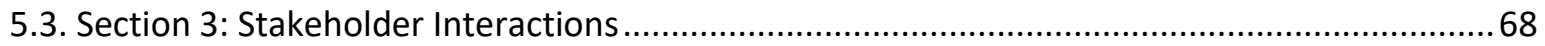

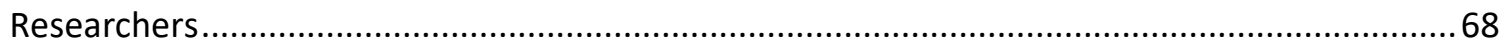

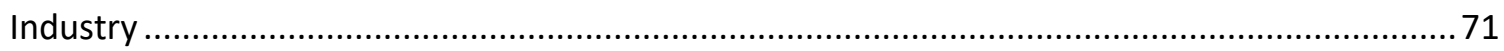

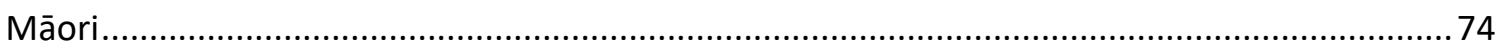

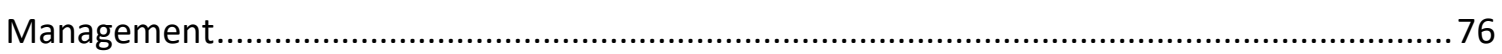

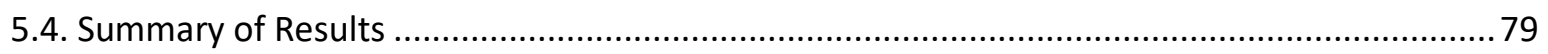

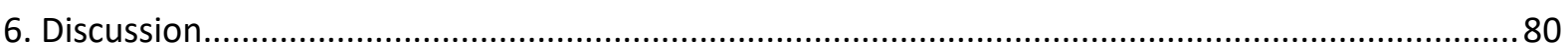

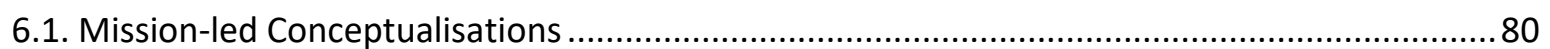

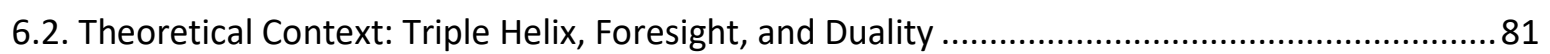

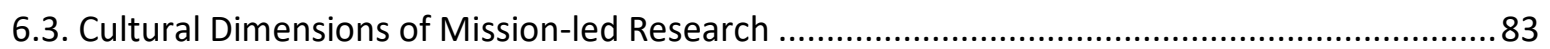

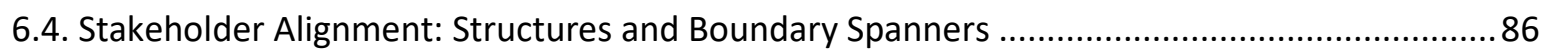

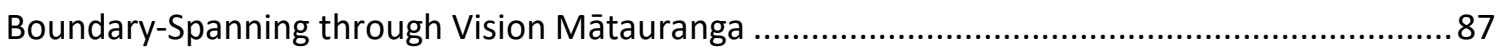

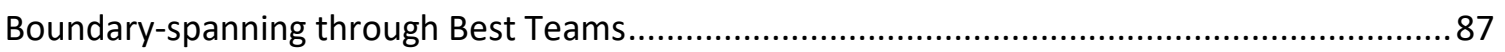

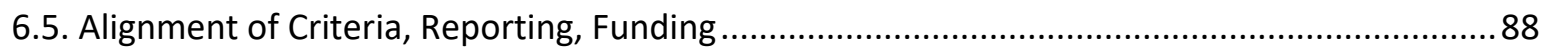

6.6. Theoretical Contribution and Research Question ................................................................ 90

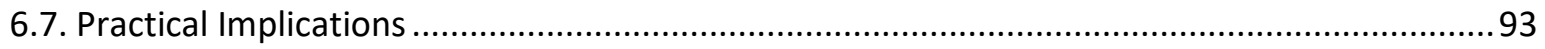

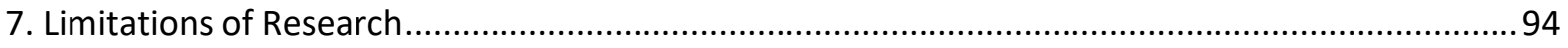

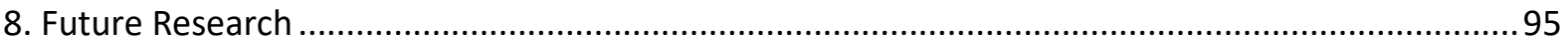

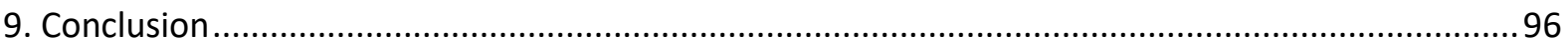

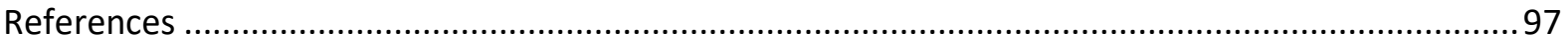

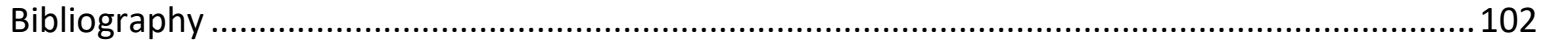




\section{Introduction}

The National Science Challenges (NSCs) are a New Zealand framework for the implementation of mission-led research. The NSCs are the most recent example of a mission-led framework in New Zealand, and create an opportunity to examine how research can be undertaken to resolve complex, large-scale problems that are becoming increasingly recognised in the political arena. The resolution of these problems poses a challenge to typical research and science systems; their nature as "Grand Challenges" (Kuhlmann \& Rip, 2014) entails a level of complexity that traditional innovator-led and industry-led systems struggle to address. The NSCs should have the potential to present a structure that is better equipped to acknowledge and address these challenges on the scale needed to progress toward their resolution. Understanding how to enact a positive, collaborative interaction between stakeholders in the NSCs is a critical component of addressing their missions. This thesis aims to understand how the structures and relationships that underpin the NSCs operate to help them achieve their missions, asking the question:

\section{How do stakeholder relationships, funding mechanisms, and selection processes that facilitate mission-led research impact the ability of the National Science Challenges to achieve their objectives?}

Selecting the NSCs and 'mission-led research' as a thesis topic was personally driven by a desire to see the world saved; or, at least, to understand what the tools that might save it could look like. The NSCs, those missions to overcome massive societal problems, represent the most deliberate, direct effort by New Zealand policy makers to do so; but in early readings it became immediately apparent the scale of the problems the NSCs would themselves need to overcome. The most urgent of these problems I saw to be the need for transdisciplinary research, where stakeholder groups with divergent motivations and expectations would need to find a common orientation in an unfamiliar framework. Understanding how successful examples of mission-led research in the NSCs achieve that collaboration seemed the key to knowing how transdisciplinary collaboration could be applied, and whether there was a realistic route to mission-led research as a long-term framework by which the massive problems of the world can be challenged and overcome. 


\section{Background}

\subsection{Context: Mission-led Research}

Mission-led, publicly funded R\&D is a phenomenon strongly influenced by global sociopolitical context. Its role has been relatively constant; it addresses major societal challenges where traditional market forces fail to tackle them (Mazzucato, 2017). These "Grand Challenges" (Kuhlmann \& Rip, 2014) or "grand societal challenges" (Boon \& Edler, 2018; Mazzucato, 2017) are those gaps in knowledge, technology, or process that present significant risk or opportunity to society. George, Howard-Grenville, Joshi and Tihanyi (2016, p. 1881) provide a useful definition, with Grand Challenges as "specific a critical barrier(s) that, if removed, would help solve an important societal problem with a high likelihood of global impact through widespread implementation". Historical American 'mission-oriented' research includes the Apollo and Manhattan projects (Kuhlmann \& Rip, 2014). These projects addressed challenges that no other research paradigm might address and are typical of a 'mission-oriented' concept but are much more limited than the 'Grand Challenge' concept by targeting a specific, clearly defined end-goal (Kuhlmann \& Rip, 2014) contextualised by the socio-political environments of their time. Modern mission-oriented research fulfils a similar role, addressing societal challenges where the market has failed, but the challenges are characterised by open-ended, complex, and multi-dimensional problems that lack clarity of what entails 'success', contrasting with early mission-oriented research where ideas of success and impact were more clearly defined. Many of these challenges have superseded the national context and become "global in scope" (Foray, Mowrey \& Nelson, 2012; George, Howard-Grenville, Joshi \& Tihanyi, 2016), transcending political, geographical, and disciplinary borders. The result is that these broad-scale challenges cannot be addressed with mission-oriented frameworks reflecting a historical or national context in terms of funding mechanisms, selection processes, and stakeholder relationships, and likely require the introduction of new frameworks and institutions designed to meet them.

\section{Mission-Led Research in New Zealand}

In New Zealand, mission-led research is addressed through three frameworks by the Ministry of Business, Innovation and Employment (MBIE). These are the MBIE Contestable Fund, Crown Research Institute (CRI), and the National Science Challenges (NSCs) (MBIE, 2015a). Each framework addresses societal problems on a broad-scale, but are 
differentiated through their individual strategic directions and funding mechanisms. The Contestable Fund is resourced through a mechanism referred to as "Contestable funding", the CRIs through 'Institutional', and the NSCs through 'Negotiated/On-demand' (MBIE, 2015a). These are not strictly exclusive; where a particular project's objectives are aligned with the mission of another framework, resources may be pooled (MBIE, 2015a, p. 28). The strategic approach of the different institutions to implementing Mission-led research is summarised by MBIE (2015a, p. 28), where it indicates that the Contestable Fund emphasises the use of competition among researchers, while the NSCs are described as a "collaborative mechanism", although both refer to long-term research on a national scale. The CRIs are different again by taking the form of "Crown-owned companies" (MBIE, 2017b, p. 24), with each company aligning itself with a sector of the New Zealand economy.

The mission-led context provides a unique challenge to funding mechanisms. Because of the open-ended, broad-scale nature of the problems that they are attempting to address, there is no readily apparent measurement by which success can be judged, complicating the use of traditional investment tools such as Cost Benefit Analyses and making the allocation of resources based on those tools more difficult.

\section{NSCs as Transdisciplinary}

As the newest mission-led approach, the NSCs provide an interesting take on mission-led research in New Zealand. While all three frameworks attempt to address complex societal issues, the NSCs have several unique characterisations that make them of interest to an investigation of mission-led research. Primary among these is the composition and interaction of four key stakeholders that influence the research process; these reflect a similar composition of industry, academia, and government suggested by Leydesdorff \& Meyer (2006) in the Triple Helix Model, although the New Zealand context introduces a fourth overlaying perspective that introduces further diversity into the trio of perspectives: Māori. Academia, the fundamental producers of knowledge that might address the issues presented, act under a "best team" policy. This reflects what MBIE documents (MBIE, 2015a; 2017a) refer to as "multidisciplinary" research required to address complex problems, with leading researchers from several disciplines engaged to resolve an issue. Industry acts as a second stakeholder perspective, with a level of input toward the contribution of specialist knowledge, funding, and as likely end users of the research 
outputs. The third stakeholder is MBIE, as the primary funding agency (MBIE, 2015a) and the producer of key guidelines. It also assesses the progress of the individual Challenges, ensuring they are producing the expected level of research outcomes and addressing their intended missions. Māori then act as a fourth stakeholder perspective through the NSC's deliberate incorporation of Mātauranga Māori throughout the research process (MBIE 2015a; Prussing and Newbury, 2016). The interaction of these four stakeholders goes beyond what MBIE has identified as multidisciplinary, and becomes transdisciplinary (Maasen, Lengwiler and Guggenheim, 2006); this implies a meaningful transfer of knowledge not just between academic disciplines, but across sectors, and presents key challenges and opportunities to the successful operation of the NSCs. Understanding how this transdisciplinary interaction takes place within successful Challenges will help to inform future mission-led research structures.

\section{Criteria and Funding}

Beyond the stakeholder interactions within the NSCs, two key processes influence the potential outcomes of mission-led research. These are the funding mechanisms that provide the resources needed for mission-led institutions and research projects to operate, and the processes by which research proposals are created and judged for funding allocation. An interrelationship between all three factors supports their consideration as a group, rather than as separate contributors to the success of projects. For example, the setting of criteria is heavily influenced by the background of those involved in their creation; field of expertise, experience in different sectors, and demographics of decision makers all place frames on the criteria setting process. Particularly for broad-scale, societal objectives typical of mission-led research, projects that can act in a truly transdisciplinary way will have a greater chance of fulfilling their objectives (Dhansay, Serper, Linol, Ndluvo, Perumal, \& De Wit, 2015).

The funding mechanism is the third component to be considered because of the dependency of successful research on an effective funding framework, and MBIE's use of a 'negotiated' funding mechanism (MBIE, 2015a, p. 26). Because of mission-led research's long-term nature, there is a need for a funding mechanism that is robust enough to assess and provide resources for incomplete projects to deliver on their mission; necessitating the use of criteria for success and progress. These criteria are created within limitations of 
knowledge that exist within decision-maker groups, resulting in criteria that are influenced by the composition and strength of stakeholder relations. An additional complication is the direct impact of stakeholder relationships on funding; particularly in the nature of proposal selection. The typical nature of the research proposal process is competitive; researchers, or groups thereof, apply to a limited pool of funding and seek to have their proposal selected above the others. The competitive grant process has several implications that are particularly disadvantageous for mission-led research; particularly where it "may stifle collaboration" (Kubler, 2013, p. 3) and "can be time-consuming and expensive" (Materia, Pascucci \& Kolympiris, 2015, p. 88). In addition, issues of bias in assessment of funding may be present in peer review processes (Kubler, 2013, p. 12) where funding decisions reflect the values of decision makers.

\subsection{Justification of Research}

Understanding the relationships between stakeholders and the structures within which they operate is crucial to establishing how mission-led research, with its particular characteristics, can be best managed to improve its success. This research seeks to examine those relationships in an example of successful mission-led research implementation. Mission-led research presents a variety of challenges unique to its structure, but by its very nature can deliver long-term, broad scale benefits to a uniquely inclusive set of beneficiaries. However, implementation of mission-led research must be effectively managed in order to realise those benefits. Poor stakeholder relations, unrealistic or poorly set criteria, or ineffectively allocated funding can result in a failure to successfully deliver the research objectives. Recent trends toward an increase in global use of mission-led research, including in Europe (European Commission, 2012), the USA (Mowery, Nelson \& Martin, 2010), and New Zealand all provide examples of an increased urgency to address societal challenges, and benefit from doing so. For New Zealand, the NSCs (MBIE, 2015a) provide the best representation of mission-led research, and an opportunity to examine how the processes that operate at a practical level are implemented in successful projects. Because of the common features of mission-led research within the NZ context, particularly within the NSCs, an understanding of these processes can be used to inform the successful management of future projects. 


\section{Literature Review}

\subsection{Characteristics of Mission-Led Research}

Mission-led Science is one of three research types identified by MBIE (2015a) in their National Statement of Science Investment, contrasting with industry-led and investigatorled research. The concept of Mission-led Science has become a prominent one in the New Zealand research space, constituting a total investment approximating \$400 million NZD (MBIE, 2015a, p. 28) through various sources of funding. As a research investment typology 'mission-led' is not a new concept, identified by Bozeman (2000, p. 631) as salient in United States policy from 1945-1965 and 1992-present, and now influential in global science policies (Mazzucato, 2017; Boon \& Edler, 2018). However, the research literature has until recently failed to provide a useful definition for mission-led research, and it is only rarely discussed explicitly as a distinct investment type. Thus, studies of mission-led science have not been well integrated and there is only a limited foundation to build from.

A brief definition of mission-led research is provided by MBIE in the New Zealand Gazette (2014 p. 286), describing it as "the funding of research, science, or technology or related activities directed at achieving a specific outcome", a definition mirrored by Mazzucato's (2017) “mission-oriented' for its aim to achieve specific objectives”. Although this definition is useful in providing broad guidance to policy decisions, it can be generalised to include any research that is both funded and has a specific objective. A more useful definition can be found in Kelman and Cook's (1996) definition of mission-linked research, which they describe as targeting "current and emerging problems, and may be basic or applied". This earlier definition encompasses two key ideas: an orientation toward future problems, and the inclusion of both blue-skies and applied research. Bozeman's characteristics of a "mission technology paradigm" (2000, p. 632) provide some additional context as to the type of problems to be addressed; generally long-term, national-level issues such as "energy production and conservation, medicine and public health". Bozeman also recognises the public sector as an influential body, able to coordinate resources and exert influence across multiple stakeholder groups to enable cross-sector collaboration. 
Mission-led research in New Zealand exists in a policy environment that also recognises investigator-led and industry-led research. Their different roles are broadly defined in MBIE's National Statement for Science Investment (2015a) as in Diagram 1, but require conceptual distinction in order to understand the place of mission-led research in the science landscape. These distinctions can be based on three components: objectives, outcomes, and funding mechanisms.

\section{Content unavailable.}

\section{Please refer to print version for access.}

\section{Diagram 1: Investment in Research. MBIE, 2015a, pg. 26}

\section{Objective based Differentiation}

NZ's Ministry of Business, Employment and Innovation (MBIE) identifies Mission-led science as research "undertaken toward a particular policy aim or goal" (MBIE, 2015a, p. 28). These goals typically constitute broad-spectrum objectives aimed at providing public benefit, exemplified by the objective of MBIE's Contestable fund to deliver "long-term, transformative impact for New Zealand" (MBIE, 2015a, p.28), and the National Science Challenge, to address "complex, long term, national-scale issues for New Zealand". Both frameworks adhere to Bozeman's (2000) characteristics of mission-led science as oriented 
toward long-term public good, coordinated by government to address issues unlikely to be delivered through private sector research, known as "Market Failure" (Mazzucato, 2017).

Comparison of the goals of mission-, industry-, and investigator-led science provides some delineation of the paradigm structures. Where the primary focus in mission-led science might be summarised as broad-scale impact, MBIE (2015a, p. 27) identifies investigator-led science as primarily for the purpose of knowledge acquisition, as directed by researchers. This is evidenced in the objectives of the Marsden Fund, a major mechanism for the funding of investigator-led research in New Zealand, constituting \$54 million as of 2015 (MBIE, 2015a, p. 26). Those objectives specify that the purpose of research should significantly focus on "enhancing the quality of research in New Zealand" and supporting the "advancement of knowledge in New Zealand", both goals centred in the creation of knowledge through exploratory research (Marsden Fund Council, 2017).

Industry-led research focuses on the application of research and knowledge in practical ways to achieve measurable outcomes (MBIE, 2015a, p. 28). This emphasis creates three broad categorisations of research model based on their primary purpose: broad-spectrum impact (Mission-led), knowledge creation (Investigator-led), and practical application (Industry-led). Some degree of overlap between categorisations is to be expected; for example, industry-led research intending to create new systems of manufacturing may have a prerequisite need for subject-specific knowledge creation. Identification of the primary purpose for which the research is being undertaken provides a preliminary means of delineating the research types, and incorporation of other characteristics such as outcomes and funding mechanisms can offer further clarification.

\section{Outcome based Differentiation}

The outcomes of mission-led science are characterised by the specific goals of the individual projects. However, the National Science Challenges (MBIE, 2015b) provide an example of the outcomes mission-led science can be expected to achieve in various contexts of research. The varied nature of the different Challenges has necessitated the adoption of formal guidelines broad enough to cover a range of possible research contexts, allowing the adoption of those outcome guidelines as a framework for identifying mission-led research in 
general. The outcomes described occur across three specified timeframes: short term (1-3 years), medium term (4-7 years), and long term (8-10 years) (MBIE, 2015b, p. 11). Short term impacts focus on awareness of the research among the scientific community, considering changes in "knowledge, attitude and behaviour" as measures of high awareness. Medium term impacts target adoption of outcomes by "research users", considering incorporation of ideas, processes, techniques or products by "adopters and influencers" into their operations as measures of successful research outcomes. Long term impacts are more ambiguously measured, identifying concepts of impact and change in the context of both the mission of the research and external factors. Questions of what long term difference the research has made for "economic, cultural, social, health, or environmental outcomes" (MBIE, 2015b, p. 11) provide some indication of the national scale at which the research is expected to impact, and mirrors the 'broad-spectrum impact' goal that characterises the objective setting component of mission-led research. Some questions remain, however, about the key assumptions about what mission-led implies that are embedded in these broad guidelines.

Comparison with investigator-led research in the Marsden Fund portrays a similar set of expected outcomes to those of mission-led, though differentiated by context. Outcomes expected within the context of the Marsden Fund reflect the knowledge oriented goals of investigator-led research: scientific publications, conferences, and "scholarly impact" (Marsden Fund Council, 2017) exemplifying measures of success. Longer term outcomes are also identified, particularly "application beyond research" and "economic, social, cultural, environmental, health" impacts, a set of measurements thematically identical to the long term outcomes expected of mission-led. Importantly, however, these impacts are not core to the outcomes of investigator-led research and not considered as critical assessment criterion when funding them, whereas these broad-impact focused outputs are central to the outcomes of mission-led research.

Industry-led research is strongly differentiated from investigator-led research, and is expected to "result in measurable benefits to firms and the economy" (MBIE, 2015a, p. 28). The outcomes specifically act to improve industry's ability to compete and generate profit, with a general view of enabling a strong, innovative economy. MBIE specifies that industry- 
led is focused on the "practical development of new materials, products, processes, systems or services", tending toward research which is "close to market", allowing rapid commercialisation and realisation of value. Importantly, industry's role as the source of funding is the critical differentiator between industry-led and the other paradigms, although the research work itself is sometimes performed externally to business. Of the $\$ 1.068$ billion of R\&D funded in 2014, approximately $10 \%$ of funding was contracted to government research institutes and 3\% to universities, with the remaining $87 \%$, a value of $\$ 927$ million, performed internally by businesses (MBIE, 2015a, p. 28).

The difference in expected outcome between the research types is most apparent between industry- and investigator-led; industry expecting rapidly applicable, practical development to benefit the economy, and investigator expecting scholarly impact largely focused on knowledge production. Mission-led spans across both groups, but over a longer time-frame; expecting knowledge generation in the short and medium term, and practical application in the long-term, emphasising that the key differentiator between frameworks is in the timeframe of outcomes more than their nature.

\section{Funding Mechanism based Differentiation}

The differences in funding mechanisms between mission, investigator, and industry-led research are represented by the type and objective of the funding institution. Mission-led research in New Zealand is generally funded by government departments, primarily MBIE; although the Departments of Conservation and Primary Industries, and the Ministry for the Environment, are also noted as providing \$58 million in contestable funding (MBIE, 2015a, p. 26). The result is that all major forms of mission-led research in the New Zealand context are funded through government departments, reflecting the willingness of public institutions to provide for research with broad-spectrum impact which would be otherwise unlikely to secure funding independently by research institutions or the private sector as a result of Market Failure (Mazzucato, 2017). This pattern may be explained by characteristics of industries acting within the context of a 'societal challenge', or of mission-led science itself. Industries such as agriculture may be characterised by numerous smaller businesses, which lack the capacity to fund major research projects (Materia, Pascucci, \& Kolympiris, 2015), creating a failure of the market to address projects of that scale and necessitating 
input either in direct resourcing or resource coordination from the public sector. Mission-led research also has a high perceived risk to the private sector owing to some of the components that facilitate its function, such as its tendency toward interdisciplinarity. An interdisciplinary approach to research is generally accepted as required to address the long term, national scale issues that define the objectives of mission-led research (Bromham, Dinnage, \& Hua, 2016) but typically struggles to obtain funding from academic research institutions because "academic institutions' budgets, governance and promotion arrangements are usually organised around single disciplines, as are processes at many granting bodies and journals" (Rylance, 2015, p. 314). Additionally, while industry-led research has a degree of interdisciplinarity incorporated where necessary for the desired outputs, the outputs themselves are limited in potential impact. The publicly funded mission-led paradigm therefore provides a means by which interdisciplinary research might reliably acquire investment without the associated narrow scope of industry-led research, given the alignment between the objectives of mission-led research and the capabilities of interdisciplinary research to meet those objectives.

\section{Funding Mechanism Types}

The different research investment paradigms are largely defined by the sectors and organisations which provide their funding. Investigator-led research tends to be funded by tertiary research institutions, or the Royal Society in the case of the Marsden Fund (MBIE, 2015a, p. 26); industry-led through the Callaghan Innovation fund's business R\&D grants and the business sector (MBIE, 2015a, p. 28); and mission-led through public funding by government departments, particularly MBIE. In each research type, MBIE recognises three formal routes of funding allocation: Contestable, Negotiated, and Institutional (MBIE, 2015a, p. 26). In the context of mission-led science, all three are represented (MBIE, 2015a, p. 28): Contestable in the MBIE Contestable fund, recently renamed the Endeavour Fund (MBIE, 2017c); Negotiated in the National Science Challenges; and Institutional in the Crown Research Institute (CRI) core funding. The purpose of each funding type in relation to mission-led research is differentiated based on the way in which they aim to achieve common mission-led objectives, while generally reflecting a desire to support research that will have a significant impact on New Zealand's economic performance, environment, and society. The Endeavour Fund, representative of Contestable Funding, is one of MBIE's main 
mission-led funding mechanisms (MBIE, 2017c, p. 6). It was valued over the 2015-16 period at $\$ 182.7$ million, and will increase to $\$ 243$ million in $2020 / 21$ (MBIE, 2017c, p. 4), and is characterised by its use of 'competition for funding' between scientists to drive "excellent, higher risk research" in areas of significant potential impact. These aims are reiterated in the guidance supplied for the creation of research proposals: Excellence, where science is progressed and new knowledge disseminated through a team with the necessary, complementary skillsets, knowledge and resources to deliver the desired results; and Impact, where a credible potential benefit to New Zealand is demonstrated, with implementation pathways not limited to a single end user (MBIE, 2017c, p. 18). The competitive nature of the fund is intended to complement Negotiated and Institutional funding mechanisms, primarily by supporting the development of CRI capabilities and investing in research relevant to NSC projects but external to their specific objectives (MBIE, 2017c, p. 8).

The primary Negotiated funding mechanism of mission-led science in New Zealand is enacted through the National Science Challenges. The concept of Negotiated Funding is understood here as "funding for projects that will be negotiated using a best team approach, in which a project team will be asked to submit a project proposal that addresses the project brief" (Sustainable Seas, 2018, p. 5). The model is designed around an understanding that the types of challenges that are intended to be addressed in the National Science Challenge framework require a collaborative approach to research, with a diverse knowledge base amongst participants and flexibility in the resources supplied to them. A negotiated basis of resource distribution incorporating the input of multiple stakeholder groups with a high level of subject expertise provides an opportunity to establish a funding schedule for research projects based on the criteria and resource base of the users and funders, as well as the capabilities and requirements of the research team. Some weaknesses in the negotiated process have been noted in the power dynamic of negotiations (Boon \& Edler, 2018), with conflicting stakeholder expectations creating a degree of dissatisfaction with the process if a particular group's expectations aren't satisfactorily addressed. This is more likely when there are multiple stakeholders with divergent expectations, making it difficult to negotiate a compromise that meets the needs of all groups. 
Institutional funding is enacted through three mechanisms of Government expenditure (MBIE, 2015a): the PBRF Fund, valued at $\$ 300$ million, Crown Research Institute (CRI) core funding valued at \$145 million, and Callaghan Innovation Services, valued at \$68 million. The CRI core funding is the only example of an institutional and mission-led fund, and is the largest valued mission-led fund (MBIE, 2016a). It also provides funding toward other mechanisms, such as the National Science Challenges, where research aligned between the two systems accounts for $25 \%$ of the CRI's core funding application (MBIE, 2016a, p. 13). Aligned research is considered to be that which is "consistent with the CRI's SCP (Statements of Core Purpose) and the NSC research strategy" (MBIE, 2016a), highlighting the strategic nature of funding allocation. The collaboration is flexible, and dependent on continued alignment between CRI and NSC outcomes - this introduces a degree of uncertainty toward funding security in the NSCs as objectives shift with research contexts. As a concept, institutional funding is generally recognised as a means of facilitating the research capabilities of universities and public research organisations by improving funding security and institute autonomy (MBIE, 2016a). It is generally provided to the institute, rather than teams or individuals, allowing a longer term, more strategic fund to be established based on performance and agreed upon criteria for funding distribution.

An important contextual note to be considered regarding the different funding mechanisms is that the broad categories of "Institutional" "Industrial" and "Negotiated or On-Demand" (MBIE, 2015a) only apply to the institution applying for funding directly from MBIE, and not necessarily to the internal processes of the organisations that subsequently distribute the funding. For example, the mission-led NSCs have typically engaged in a proposal selection process that follows the competitive grant archetype, typical of an innovator-led framework; this generally involves a call for proposals, which is expected to be met by research teams acting competitively to acquire the available funding - similar to the mechanisms of investigator-led research. This has been the assumed format of proposal selection in the NSCs, with MBIE (2015a, p. 11) referring to assessment of "individual competing proposals"; although there is a general recognition of the for mechanisms which "encourage collaboration" (MBIE, 2015a, p. 28) The framework of negotiated funding 
therefore may only apply to the National Science Challenges as an institution, and not necessarily to individual research projects.

\subsection{Definition: Mission-led Research}

Mission-led research can then be considered for our purposes here as: A policy framework which supports research designed to address national-scale issues of public interest. Objectives will be set to achieve long-term, transformative impact at a broad-scale, including economic, social, cultural, health, or environmental concerns. Desired outcomes may be achieved at three time-scales: short term improved researcher community awareness, medium-term adoption of outcomes by the researcher community, and longterm, broad-scale impacts contextualised by the research mission. The research is primarily funded through public investment in the form of Contestable, Negotiated, or Institutional funding, compensating for a market failure.

An additional characteristic of a 'best team' research approach is not necessarily, but has been adopted in NZ owing to its practical benefits in the mission-led context. A best team approach features collaborative research practices, incorporating transdisciplinary research teams. The aim is to acquire the best available knowledge required to address the issue at hand, which may be of a diverse range owing to the broad nature of mission-led research (MBIE, 2015b).

\subsection{Mission-led Research: Impact}

One of the core challenges in assessing the public benefit and industry applicability of Mission-led research, particularly in the context of the NSCs, is the scope of intended impact that the research might cover. The desired outcomes in economic, cultural, social, health, or environmental fields (MBIE, 2015b, p. 11) are necessarily broad, incorporating the variety of possible projects the different Challenges might pursue; this is reflected in the recognition of 'broad-spectrum impact' as a likely outcome of mission-led research.

\section{Broad-Spectrum Impact}

The range of components included within 'broad-spectrum impact' is advantageous for outcome measurement particularly where the alternatives, such as those with a predominantly economic basis, fail to recognise outcomes that might eventuate from 
mission-led type research. For example, economic outputs are balanced against criteria such as social, cultural, and environmental outcomes, which represent a greater consideration for the potential impacts of Mission-led research. This helps to contextualise the research for stakeholder communications, acknowledging and formalising a more diverse set of potential outcomes that reflect the diversity in motivations and expectations held by stakeholders. The disadvantages of a broad-spectrum impact criteria are in providing an easily communicable, quantitative measure of impact, particularly where economic outcomes may not be relevant to the research being done.

Although broad-spectrum impact recognises a broad sphere of research, it results in the subsequent adoption of the advantages and disadvantages associated with each individual measure of impact; particularly those with a more qualitative focus. Common among these is an inherent difficulty in measurement, particularly for criteria with a social, cultural, or environmental basis, which can require the adoption of potentially unrealistic assumptions (Bozeman, Rimes \& Youtie, 2015, Table.1, p. 37) where their impact on economic impact is used as a criteria for measuring technology transfer. The result is that many of the outcomes described by the NSC programme are inherently difficult to quantify in a way that provides a meaningful measure of whether the project can be considered to have met the NSC's overall objectives. However, Bornmann (2013) identifies some components of 'broadimpact' criteria that improves both their specificity and quantification, without losing the benefits of a generalizable criterion in a mission-led context. These include: how well discovery or understanding is advanced; participation of underrepresented groups; to what extent research infrastructure is enhanced through facilities, instrumentation, networks, or partnerships; the scale of results dissemination; and benefits delivered (Holbrook, 2010). Most of these are reflected in the desired outcomes of the NSC, with "Scientific Community Awareness" (MBIE, 2015b) functionally similar to advancement of understanding, and "Adoption of Outputs" reflected in research infrastructure enhancement. In general, they can be seen to reflect a broader range of outcomes then simply economic.

\section{MBIE Dimensions of Impact}

The National Statement of Science Investment identifies their own impact framework, specifying some of the dimensions that publicly funded, mission-led research is expected to 
adhere to (Table 2). The dimensions of impact described by MBIE (2015a) reflect the diversity of outcomes the literature suggests mission-led research should account for; including non-economic, qualitative criteria, including specific dimensions for the inclusion of Vision Mātauranga. These suggest that MBIE has recognised the broad-spectrum impact types that mission-led outcomes are likely to encompass and given them a weighting aligned with their context.

Table 2: Dimensions of Impact (MBIE 2015a)

\section{Content unavailable. Please refer to print version for access.}

\subsection{Mission-led Research: Proposal Selection \\ Project Criteria}

The New Zealand Gazette (2017) provides the primary criteria by which proposals to the National Science Challenges are to be assessed. These are: 6.1(a) The proposal is collaborative and responds to the most important, national-scale issues for New Zealand and the Challenge objective: 6.2(a) The research, science, and technology will be excellent 
quality; 6.2(b) The proposal is focused on delivering impact; 6.2(c) Decision-making and accountability arrangements are sound and enduring. These three criteria are supported by a series of sub-criteria and guidance; all, for example, contain a sub-criteria of how the proposal will "give effect to the Vision Mātauranga policy". The criteria are extremely broadly defined, allowing a significant level of interpretation by individual Challenges; this provides the flexibility they require to address a diverse range of issues.

\section{Proposal Selection Process}

The proposal selection process in frameworks of Mission-led research is variable, and dependent upon the institution implementing it. Proposal selection is a critical component of ensuring the assigned 'mission' of a project is achieved, but the selection of proposals is known to be influenced by a wide range of factors. Some have strong relevance to research outcomes, such as scientific merit and suitability of the research topic, while others have little or no influence on outcomes as in gender, age, and academic affiliation of both applicants (Materia, Pascucci \& Kolympiris, 2015) and the review panel.

The type of proposal selection mechanism can have a considerable influence on the outcome of proposal appraisal and should be built on the needs of the institution, its framework for research, and the type of mission being targeted. For example, Materia, Pascucci and Kolympiris (2015, p. 88) describe peer-reviewed competitive grants as "usually oriented toward short-term (3-5 years) projects". This suggests that for research institutions with a Mission-led framework, focused on the long-term delivery of broad-spectrum benefits, a peer-reviewed competitive grant program might not necessarily select proposals with the greatest potential to deliver on their mission. The peer-reviewed process itself is a "cornerstone of science" (Bornmann, Wallon \& Ledin, 2008), based on the assessment of a piece of scientific work by subject matter experts, but its validity in proposal assessment is occasionally controversial. Cole, Cole and Simon (1981) describe the evaluation of proposals by the National Science Foundation's (NSF) peer review process as ascribing only half of a given proposal's 'score' to its scientific merit, and half to external factors, including the attributes of the review panel members. They attribute this variation to discrepancies in opinion of the reviewers regarding what is considered "good science" and different 
interpretation of scoring values, highlighting the need for consistent understanding among both the review panel and applicants regarding the criteria for proposal selection.

\section{Proposal Selection in the National Science Challenges}

The National Statement of Science Investment (MBIE, 2015a) recognises and attempts to address the weaknesses of the peer-review process noted in the literature, by specifying that there are to be "clear criteria for excellence and impact". Dimensions of impact are identified in Table 3, while the understanding of excellent science is described in three parts: The Best People, A Rigorous Approach, and Optimum Results (MBIE, 2015a. p. 13). "Best people" refers to the participants in the research, specifying that they be "sufficiently skilled", "sought-after practitioners", have "reputations for high-quality work" and are "linked domestically and internationally". The acquisition and retention of researchers with these characteristics is influenced by the funding mechanism of the program, particularly where competitive processes are applied.

The concept of a "competitive" grant is well-established in scientific communities, and can be summarised as the allocation of funding to scientists through research institutions based on peer review of scientific merit in a competition amongst multiple proposals (Este, Rentocchini, Grimaldi \& Manjarrés-Henríquez, 2013). The Contestable Fund mechanism established by MBIE (2015a), under which the mission-led Endeavour Fund operates, is a prime example of the use of competitive funding. Competitive funds are useful frameworks for enabling researchers "to follow a curiosity-driven research agenda" (Este, Rentocchini, Grimaldi \& Manjarrés-Henríquez, 2013, p. 1536), particularly emphasising research outcomes with "scientific excellence". But its effectiveness in producing high-quality outcomes is confounded by unintended features of the process: competitive funding applications disproportionately consume the time resources of researchers, which may increase the likelihood of "better researchers withdrawing from the process" (Tisdell, 1997) owing to high opportunity cost of involvement. Additionally, the "cumulative advantage" of past performance means that proposals from established researchers with high academic output are more likely to be selected in a competitive environment (Grimpe, 2012). The combined impact results in new researchers potentially opting for alternative career options without the risks associated with engaging in competitive funding processes. This reduces 
the pool of potential highly-skilled candidates and is particularly significant in frameworks such as the NSCs, which aim to collate a "best research team" as a core performance area (MBIE, 2015b).

The National Science Challenges have implemented a process of proposal selection that may both provide the benefits of competitive processes, and bypass the negative aspects. The call for proposals essentially reflects a typical competitive process, with the "best proposal" winning the funding allocation to perform research. However, the NSC specifically encourages the use of a collaborative approach in proposal creation (MBIE, 2013) in order to generate "best teams", significantly reducing the risk to individual researchers of failing to acquire funding and wasting resources in doing so. This in turn reduces the risks of experienced researchers withdrawing from the process, enhancing the available knowledge pool of candidates and improving the potential quality of proposals and the 'excellence' of research outputs. Additionally, there is an expectation of the National Science Challenges that they will invest in new "emerging talent" (MBIE, 2015b), and allow for the "dynamic introduction of new capability, research, and researchers" (MBIE, 2017a) - a formalised strategy built into proposal selection criteria that actively encourages the incorporation of emerging researchers without the "cumulative advantage" (Grimpe, 2012) of previous academic work. In this way the NSCs have introduced adaptations to the proposal selection process that can both encourage highly-skilled researchers with attractive alternatives to engage in the proposal submission process, and improve the ability of new researchers to break into the process.

Understanding the perceptions of research participants regarding the proposal selection process is a critical issue for mission-led research programmes. To ensure that core performance areas are met, particularly those targeting high quality research outputs and stakeholder engagement (MBIE, 2015b), various stakeholder expectations must be met. The case of the NSCs provides a group of diverse stakeholders with contrasting expectations: public institutions, private organisations, Māori, and researchers. Ensuring that proposal selection criteria reflects the expectations of each of these groups, without confounding the ability of each to deliver their contribution to the research process, is a key challenge to implementing a successful mission-led programme. 


\subsection{Stakeholder Relationships}

The concept of a "best research team" (MBIE, 2015b) is a key performance area identified for the NSCs that presents several challenges to researchers, highlighting concepts of interdisciplinary research practices and inter-stakeholder relations that must be addressed in order for a mission-led research program to be successful.

\section{Transdisciplinary Best Teams}

Differentiating between multidisciplinary, interdisciplinary, and transdisciplinary research is a complex and evolving issue (Pregernig, 2006). Rasmussen, Andersen and Borch (2010) provide a useful separation for the purpose of this thesis. They consider multidisciplinary study to be the maintenance of mono-disciplinary distinctions within a common project, with tasks separated and only minimal interaction between the different disciplines. Interdisciplinary practice is then the interaction and cooperation between disciplines within a highly formalised structure, requiring a "cognitive coupling" and knowledge transfer between disciplines to allow for a synergetic effect. Transdisciplinary research is described by Maasen, Lengwiler and Guggenheim (2006), who describe the practice as building on interdisciplinary concepts of knowledge transfer, as well as the inclusion of "non-scientists in the production and/or evaluation of knowledge" and the orientation of knowledge production around problems generated from "pressures, 'applications' or from societal stakeholders" external to 'science'. The NSC context then lends itself strongly to the transdisciplinary definition, owing to a) its broad-scale, mission-led objectives; and b) its potential for inclusion of non-scientist actors in the production, evaluation, and implementation of knowledge produced. However, interdisciplinary concepts still apply within the transdisciplinary context, and will be drawn on where appropriate.

The intended broad-scale impacts of mission-led research are multi-faceted, with a single research project having the potential to affect multiple impact variables. This targeting of "large and complex issues" (MBIE, 2015b) is noted as requiring the input of scientists from "different research institutions and across disciplines" (MBIE 2015a, p. 58) in order to achieve the intended objectives. The implication is that for a key performance area such as "best research team collaboration" (MBIE, 2015b) top researchers from multiple disciplines are expected to collaborate toward a common end-goal, the "challenge objective" in the context of NSCs. Additional performance areas of Stakeholder Engagement, Māori 
involvement and Mātauranga, and Public participation (MBIE, 2015b) indicate the expectation that Challenges will incorporate non-scientist (Maasen, Lengwiler \& Guggenheim, 2006) knowledge in formulating the problem to be solved, generating knowledge and solutions toward achieving the objective, and in implementing new processes and tools in practical application of the research outcomes. This makes the NSCS an explicitly transdisciplinary framework, reflecting the general acceptance of transdisciplinary processes as a critical component to resolving complex and broad-scale issues (Pregernig, 2006; Rasmussen, Andersen \& Borch, 2010; DeTombe, 2001, 2017; (Bromham, Dinnage \& Hua, 2016). However, research projects incorporating transdisciplinary processes introduce novel challenges. One of the critical challenges is in maintaining an interdisciplinary knowledge exchange during research; Pregernig (2006) identifies the risk of transdisciplinary projects failing to live up to "normative expectations" as a result of task separation into familiar disciplines, which reduces the project from 'transdisciplinary' to 'multidisciplinary', and the benefits of transdisciplinary practices aren't realised. Sievanen, Campbell, and Leslie (2012) identify two further categories of challenge that interdisciplinary projects face: structural, such as in communication between disciplines and practical integration of data types; and conceptual, such as conflicting expectations regarding research outcomes, roles, and social contexts of research. While their challenges specify scientists as the level of challenge, these are also applicable at the level of scientist and non-scientist interface. For example, a key communication challenge is one of language: Rasmussen, Anderson and Borch (2010) identify the lack of common language between disciplines as a key barrier, one which a facilitator would need to overcome through familiarisation with each discipline involved. This challenge would similarly apply across the academia/policy/industry/culture boundaries, and must be addressed if transdisciplinary benefits are to be realised.

Resolving the challenges of transdisciplinary research projects is complex, and there are multiple strands of thought in the current literature (Rekers \& Hansen, 2015). Rosenberg (2009) for example, suggests that interdisciplinary projects are too complex and subtle to be successful through deliberate planning, and that organic emergence of ideas flowing through a basic understanding of different disciplines is more likely to deliver the desired benefits. Contrastingly, Rasmussen, Andersen, and Borch (2010) suggest the need for 
"strategic foresight" as an explicit management tool for transdisciplinary research, suggesting the anticipation of benefits, areas of discipline interaction as "boundary objects", and realisation of findings. One commonality between the different schools of thought is the benefit of facilitators, or boundary-spanning individuals. A new role in the form of Principal Investigators (PIs) is suggested by Mangematin, O'Reilly, and Cunningham (2014) as one way in which boundary-spanning can occur in a transdisciplinary context, facilitating communications between not only research disciplines, but academia, private sectors, and policy makers. The PI role suggested is comprehensive, including that of lead researcher, project manager and administrator, requiring them to take on a multitude of varying tasks, such as "articulating objectives, time frames, logics and cultures", creation of dialogue between disciplines, and combining different approaches toward achieving objectives. An alternate to a single boundary-spanning individual is suggested by Brown, Deletic, and Wong (2015), describing five steps to successful interdisciplinary research: forge a shared mission; development of "T-shaped researchers"; nurture constructive dialogue; give institutional support; bridge research, policy, and practice. The underlying theme is one of unified understanding of research objectives, discipline capability and interaction, and ongoing communication supported by a broader institutional framework.

The NSCs have several of the characteristics Brown, Deletic, and Wong (2015) describe as important to successful interdisciplinary research. An explicit shared mission, institutional support and a bridging between research, policy and practice are all apparent. Practices that are not immediately apparent require evaluation, however - particularly regarding researcher development in multiple disciplines, common language development, and presence of facilitators or boundary spanners (Mangematin, O'Reilly \& Cunningham, 2014). Examining the perception of participants in NSC programs would provide an indication of how well transdisciplinary practice is genuinely being implemented in mission-led frameworks, and what might be done to improve the benefits realised from its implementation.

\section{Mātauranga Māori}

Understanding Mātauranga Māori is a key component in interpreting its interaction with 'Western' science. For our purposes, this thesis will recognise the definition provided by MBIE (2015a, p. 6), as theirs is the context for this research. The definition supplied by MBIE 
is that Mātauranga Māori "is a body of knowledge first brought to New Zealand by Polynesian ancestors of present-day Māori. Mātauranga Māori can exist, and be understood and applied, at various levels, including: broadly by Māori across New Zealand; or at regional, tribal, and whānau levels. Mātauranga Māori can also include the processes for acquiring, managing, applying and transferring that body of knowledge." While this will be this thesis' primary reference for interpreting Mātauranga Māori, further interpretations provide some acknowledgment of broader meanings. Sadler (2007, p. 34) considers Mātauranga Māori as an epistemology or "knowledge tradition" that has been developed to meet the needs of people and remain compatible with the local environment. The epistemology is enacted within a paradigm of "Rangahau" (Sadler 2007, p. 36), which emphasises a search "for connectiveness, Whanaungatanga looking for relationships that connect all phenomena whether animate or inanimate". This is described as a form of knowledge acquisition with a tendency toward holistic, integrated perspectives.

\section{Mātauranga Māori in Western Science}

The interaction between Mātauranga Māori and typical 'Western' science is frequently referred to as an 'interface' (Durie, 2004) between the two paradigms. A degree of similarity in their processes, allows the two to exist simultaneously and integrate their ways of knowing to provide novel insight - although integration has typically proven difficult to meaningfully achieve. Prussing and Newbury (2016) examine the attempt made by the National Science Challenges to adopt Mātauranga Māori and conclude that the effect was one of "neoliberal multiculturalism", with marked distinctions made between Māori and non-Māori knowledge that moved to "visibly recognise while not substantively including" (Prussing \& Newbury, 2016, p. 58) Māori knowledge. Input of Māori into the research process are made through "highly selective terms" that restrict their ability to influence the outputs of the Challenges, allowing focus to remain on "MBIE's economic and political goals". Prussing and Newbury's (2016) research demonstrates the potential for frameworks to apply a dual mode of operation with regard to indigenous knowledge, and that apparent recognition may not reflect meaningful input. In the mission-led context of the National Science Challenges, maintaining 'best team' benefits through transdisciplinary practice requires the meaningful integration of the varying ways of knowing, including that of Mātauranga Māori; inhibition of this integration reduces the potential benefits that might be otherwise realised. 


\section{Mātauranga Māori in the National Science Challenges}

One of the primary concepts that the NSCs engage with on a transdisciplinary level is the concept of Mātauranga Māori. Engagement occurs primarily through "Vision Mātauranga”, which is described as "an MBIE policy framework whose mission is to unlock the science and innovation potential of Māori knowledge, resources and people to assist New Zealanders to create a better future" (MBIE, 2015a, p. 6). MBIE expands on the purpose of VM through a Ministry of Research, Science and Technology (2005, p. 4) booklet that describes its purpose as relating to four distinct themes: "Indigenous Innovation: Contributing to Economic Growth through Distinctive R\&D”; "Taiao: Achieving Environmental Sustainability through Iwi and Hapū relationships with land and sea"; "Hauora/Oranga: Improving Health and Social Wellbeing"; "Mātauranga: Exploring indigenous Knowledge and RS\&T". These themes, and a purpose of "Realising the Innovation Potential" (MRST, 2005) provided the basis of VM's strategic direction and guidance for funding. MBIE's adoption of this interpretation of Mātauranga Māori reflects strongly on the requirements they present to the National Science Challenges, with all four of the 'themes' identified in the National Statement of Science Investment (MBIE, 2015a) as in Table 2.

Many of the individual Challenges go on to specify their own "Vision Mātauranga" (Table 3). SfTI, BioH, Aging Well, and Sustainable Seas Challenges provide variable examples of how VM is intended to be incorporated into the Challenge. Each identifies a mode of incorporating VM reflecting different levels of what Prussing and Newbury (2016) might have identified as visible recognition, with SfTI and BioH presenting the most comprehensive apparent incorporation. However, it is important to distinguish again between this visible recognition and substantive inclusion of Mātauranga Māori. Determining the level to which Māori knowledge has genuine impact on the outputs of the NSCs will provide a representation of one of the key transdisciplinary relationships the NSCS should be aiming to achieve; an indication of which is likely to be supplied by identifying differential beliefs regarding effectiveness of integration between cultural groups within the NSC research processes themselves. 


\begin{tabular}{|c|c|c|}
\hline Challenge & Challenge Presentation of Vision Mātauranga & Source \\
\hline $\begin{array}{l}\text { Science for } \\
\text { Technology and } \\
\text { Innovation (SfTI) }\end{array}$ & $\begin{array}{l}\text { Principles: } \\
\text { - Kia kōtahi mai: holism and consideration of society beyond the Challenge } \\
\text { - Rapua te pae tāwhiti atu - looking beyond the horizon } \\
\text { - Kia whakapakari mai - developing and strengthening people, particularly the next generation } \\
\text { - Munhononga - integration of people and processes } \\
\text { - Mana whakahaere - empowered leadership. } \\
\text { Intended Outcomes: } \\
\text { - An international exemplar of two-way exchange of knowledge systems between Te Ao Māori ("the Māori } \\
\text { - world") and western science and innovation } \\
\text { - Realising the potential of the Māori value chain (its businesses and assets) to grow the New Zealand } \\
\text { economy }\end{array}$ & SfTI, 2018a \\
\hline $\begin{array}{l}\text { New Zealand's } \\
\text { Biological } \\
\text { Heritage }\end{array}$ & $\begin{array}{l}\text { Structures: } \\
\text { - Kahui Māori: a strategic conduit to engage with iwi and Māori organisations on the Challenge as a whole } \\
\text { and provide input on Māori research priorities and delivery of outcomes. } \\
\text { - Kaihautu: Presenting Mātauranga Māori perspectives to Project teams; } \\
\text { Influencing scoping and planning of research directions and budgets; } \\
\text { Informing teams on potential issues with data storage and sovereignty; } \\
\text { Using networks to introduce iwi and Marae-based groups and Mātauranga practitioners. }\end{array}$ & BioH, 2018a \\
\hline
\end{tabular}




\begin{tabular}{|c|c|c|}
\hline & $\begin{array}{l}\text { Vision Mātauranga Classifications: In order for the BioHeritage Challenge to consider providing a } \\
\text { 1. Research with no specific Māori component } \\
\text { 2. Research specifically relevant to Māori } \\
\text { 3. Research involving Māori } \\
\text { 4. Māori-centred research } \\
\text { 5. Kaupapa Māori research }\end{array}$ & \\
\hline Aging Well & $\begin{array}{l}\text { Acknowledges } \\
\text { - The current burden of poor ageing falls disproportionately on Māori populations and communities both } \\
\text { in urban and rural areas } \\
\text { - Within Māori communities there are a number of formal and informal processes, services and practices } \\
\text { to support older people to age positively in place and learnings about those pathways have the potential } \\
\text { to benefit all New Zealanders } \\
\text { - Iwi and hapū, urban Māori organisations, Māori businesses, and Māori individuals have long been service } \\
\text { providers in social service and health service provision to older people, as well as in the provision of } \\
\text { older people's housing solutions } \\
\text { Strategic Direction } \\
\text { - The Kāhui has a formative (not post-hoc) role in - Determining the strategic direction of the research } \\
\text { program - Identifying what issues are important to Māori - Determining processes for engagement with } \\
\text { Māori stakeholders }\end{array}$ & $\begin{array}{l}\text { National Science } \\
\text { Challenge: Aging } \\
\text { Well, } 2013 . \\
\text { National Science } \\
\text { Challenge: Aging } \\
\text { Well, } 2018 .\end{array}$ \\
\hline
\end{tabular}




\begin{tabular}{|c|c|c|}
\hline Sustainable Seas & 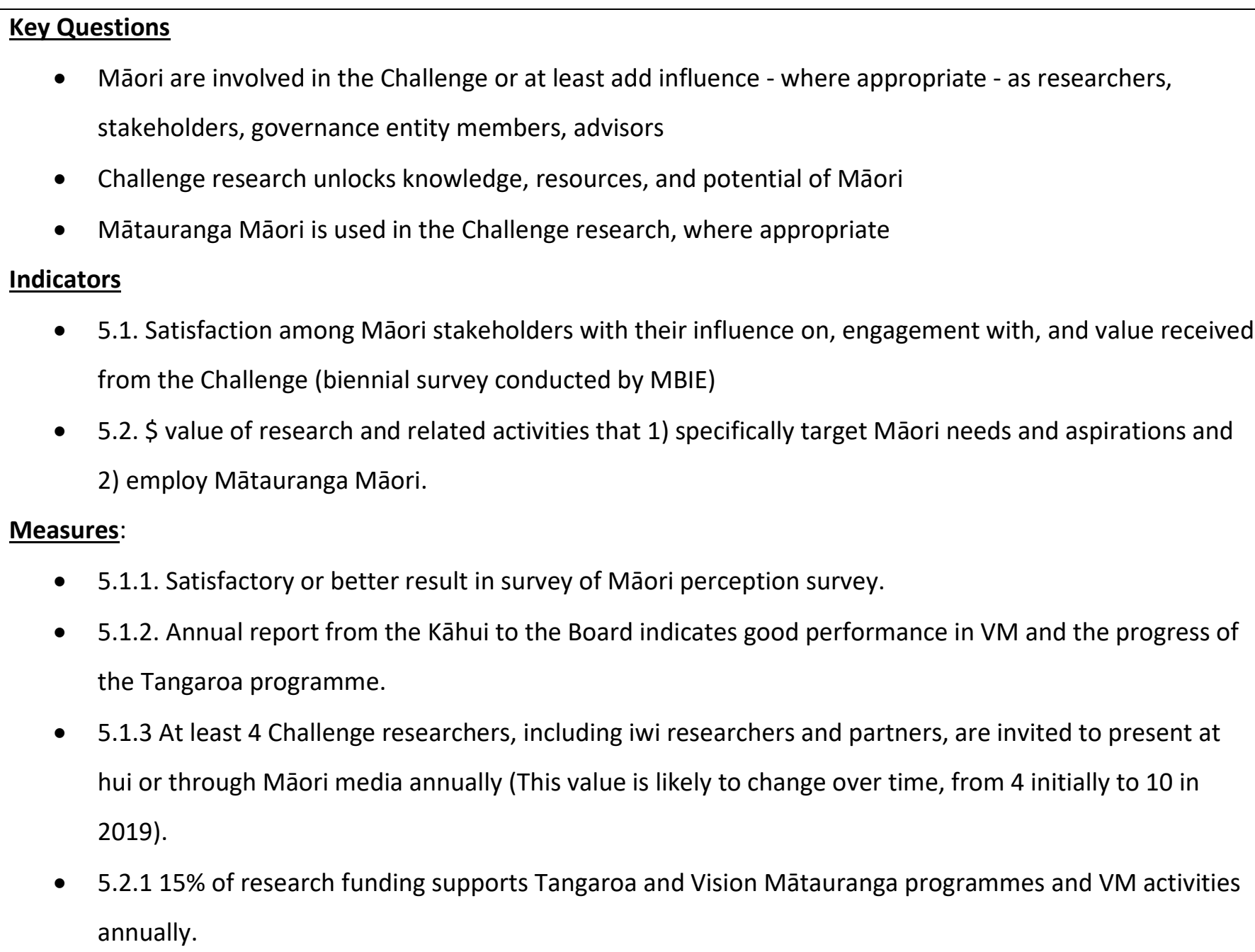 & $\begin{array}{l}\text { National Science } \\
\text { Challenges: } \\
\text { Sustainable Seas. } \\
2017 .\end{array}$ \\
\hline
\end{tabular}

Table 3: Incorporation of Vision Mātauranga in NSCs. 


\section{Industry in Public Research}

The involvement of industry in research is particularly applicable to the context of missionled research because of the prominence of industry involvement in enacting research outputs. The National Statement of Science Investment (MBIE, 2015a) emphasises at multiple points the involvement of Industry in research as a key predictor of "excellent" science, and as a key source of funding for 'close to market' research, assisting in the transformation of researcher or mission-led research outputs into applicable and relevant products that can have a practical impact. This is a deliberate strategy employed by MBIE in their overall strategy for the improvement of science excellence and impact, specifying the role of industry in "leveraging proven ideas" (MBIE, 2015a, p. 7). MBIE's (2016b) principles of development and implementation for the Challenges recognise a dual role of "end users" of research outputs of the Challenges, both in the practical application of outputs and in provision of investment "where appropriate". This describes the expansive engagement expected of 'end users', and in combination with other documents (MBIE, 2015a, 2016a) suggests that input from industry could include both expertise and financial resources.

The majority of the literature investigating the interaction between industry and researchers refers to the dynamic between industry and university-based researchers rather than researchers in general - interactions are somewhat generalisable however, particularly where they describe inter-organisational risks and benefits not specific to a university context. The cooperative interaction between industry and research institutions is generally recognised as a mutualistic relationship, with both sectors provided with valuable opportunities - research institutes gain specialist knowledge and IP that can be transformed into revenue, while research institutions gain a source of funding and improved interdisciplinary relationships (Perkmann \& Walsh, 2009). Morandi (2013) describes further benefits in complementary access to resources and achieving "critical mass for innovation". However, the type of research being performed can alter the benefits derived for the different parties. Blue-sky, or 'basic' research tends to produce more "academically valuable knowledge" (Perkmann \& Walsh, 2009), while applied research yields greater practical applications and benefits to industry as end-users, as well as interdependency between partners and can provide benefits typical of interdisciplinary or transdisciplinary practice. 
Morandi (2013) propose some of the critical dynamics that might drive successful collaborative practice between academia and industry. The most relevant of these for our purposes describe the planning practices frequently employed in collaborative research. For example, explicit plans are not as useful as those based on "mutual adjustment" and ongoing information exchange and negotiation. This is accentuated by the deliberate lack of appointed project managers and leaders; instead, individuals holding high formal power in positions of liaison as "boundary-spanners" (Lundberg, 2013) enable cooperative processes with simple, informal practices. Boundary-spanners are frequently referred to as a key group in the successful collaboration between industry and academia, reflecting a similar role in the use of interdisciplinary research (Mangematin, O'Reilly, and Cunningham, 2014). The importance of individuals capable of communicating across multiple 'boundaries' demonstrates the need for clear, well-managed communication channels both between and within, stakeholder groups.

\subsection{Literature Gap}

The literature concerning mission-led research is characterised by the effective examination of individual concepts, but poor integration of those components in a broad framework. While literature often refers to concepts which operate within mission-led processes, such as transdisciplinarity (Rasmussen, Anderse, \& Borch, 2010) broad-spectrum impact (Bornmann, 2013), and funding and selection processes (Materia, Pascucci, \& Kolympiris, 2015), there is a dearth of literature that addresses the combination of these concepts as they relate to mission-led research. Additionally, literature that specifically addresses mission-led tends to focus on its application and outputs (Mazzucato, 2017), and doesn't address how the concept of mission-led research is understood by those engaged in it. Lastly, the New Zealand context of mission-led research is unique in its inclusion of Māori perspectives; while there has been some literature produced in regard to the experience of Māori in the National Science Challenges, these have focused on the dynamic neoliberalism and indigenous knowledge (Prussing and Newbury, 2016), but have not contextualised it with the underlying principles of mission-led research.

This thesis will attempt to address these gaps by asking: How do stakeholder relationships, funding mechanisms, and selection processes that facilitate mission-led processes impact the ability of the National Science Challenges to achieve their objectives? Answering this 
question will provide insight into how the different components that make up the missionled framework interact to enable effective mission-led outcomes. 


\section{Research Design}

Answering this question requires an in-depth understanding of two core processes of the mission-led research framework and their transdisciplinary context. The first is that of project selection: how criteria are selected and prioritised in order to both attract proposals that will address the mission objective and discern the proposal(s) with the greatest potential to realise benefits. Secondly, the specific funding mechanisms of the framework, specified for MBIE's National Science Challenges as a "Negotiated Funding" (MBIE, 2015a, p. 26) scheme must be understood at two basic levels: those of policy, and implementation. Gaining insight into selection and funding processes intended to enable mission-led research and their operation in a specifically mission-led framework will help to inform an understanding of how those processes impact the achievement of mission objectives. However, project selection and funding processes exist in a context of transdisciplinary, collaborative stakeholder relations, complicating the processes of project creation and prioritisation. Understanding how these multiple perspectives are reconciled, both in the proposal selection and funding process and in the interpretation of MBIE's broad objectives into specific 'missions', will help to build an understanding of the relationship dynamic that operates within mission-led research processes, and provide a more holistic perspective on the mission-led format.

For the NSCs, the primary influential stakeholders can be summarised as Management, Researchers, Industry advisors, and Māori. Management direct the greater Challenge operations to represent the objectives of MBIE, as interpreted in the context of the Challenge. The views of Researchers are present at both an implementation level as primary investigators, and a functional level, as Management often incorporate those who have previously held researcher roles. Industry advisors may hold several roles, including shaping research proposals and providing resources and expertise toward the achievement of mission objectives, and are the likely end users of research outcomes. Finally, Māori perspectives are a critical worldview in the New Zealand context of mission-led research, with Mātauranga Māori repeatedly emphasised in policy literature as a component in decision making at all stages of the research process. Obtaining an understanding of these stakeholder perspectives regarding how effectively mission-led frameworks incorporate transdisciplinary practice in their processes will build understanding around the effective 
use of mission-led frameworks and how well the structures intended to facilitate it are practically applied.

\subsection{Epistemology and Paradigm}

A post-positivist epistemology will be adopted for this research. The general framework intends to emphasise the importance of personal insights, and the impacts of framing and biases (O'Leary, 2014). As data will be primarily collected through interviews examining the interacting perspectives of stakeholders, recognising the application of frames and subsequent biases is crucial in understanding how the different views are formed. In order to build sufficient understanding of the practical application of mission-led concepts from the perspectives of multiple stakeholder groups, a qualitative paradigm will be used. This intends to acknowledge the distinct realities that exist within the framework from each stakeholder group, and to examine areas in which the different perspectives agree or disagree on practical and conceptual points. This paradigm aligns with the concepts of an ethnographic study (O'Leary, 2014), examining the distinctions and commonalities between 'cultural groups'; though the group distinctions in this case are made on the specific scale of New Zealand based, mission-led research frameworks. The groups are not necessarily distinct, as noted above, with some having overlapping connections to different stakeholders focused on here.

\subsection{Methodology}

Data will be collected by examining two examples within a specific mission-led research framework: the National Science Challenges. These will be the Science for Technological Innovation (SfTI) Challenge, and the Biological Heritage (BioH) Challenge. The SfTI Challenge provides a useful perspective on an exemplar of mission-led frameworks in NZ because of key characteristics: it has the greatest level of government funding of the 11 Challenges (MBIE, 2017a) at \$106 million over the ten years to June 2024; it has explicit Vision Mātauranga (VM) principles (SfTI, 2018a), and has a high number of partner organisations (12) compared to the other challenges (SfTI, 2018b). These characteristics are likely to provide an environment that includes many of the points this research seeks to address; the interaction between multiple stakeholders, allocation of funding, and project selection are likely to be particularly apparent where more stakeholders are involved, VM is explicit, and funding is substantial. The BioH Challenge will also be used as an exemplar of mission-led 
research. It exists in the same basic framework of the National Science Challenge as SfTI, and shares many characteristics with SfTI that make it a potentially useful point of comparison. It has a relatively high allocation of government funding at $\$ 63.7$ million until June 2024, actively incorporates Vision Mātauranga (BioH, 2018a) and has 18 listed parties and affiliates (BioH, 2018b). The only immediately apparent differences that may influence their implementation of mission-led research are their broad fields of research and the lack of an explicit human and relational capacity development programme in $\mathrm{BioH}$ to contrast SfTI's (SfTI, 2018c). The result is an ability to investigate SfTI as a primary example of mission-led research in New Zealand, and to use BioH as a point of comparison and diversity of perspective. The use of only two of the Challenges does introduce some limitations; particularly in understanding how different contexts might influence the dynamic of relationships and processes; particularly where Challenges don't exhibit the characteristics common between SfTI and BioH, such as a strong presentation of Vision Mātauranga and high numbers of partner organisations. However, the need to obtain interviews from each stakeholder group within the Challenges, as well as practical limitations of time and access make the use of $\mathrm{SfTI}$ and BioH a pragmatic solution while maintaining data integrity.

Semi-structured interviews will be held with Challenge members in roles that reflect different perspectives: Challenge Director and Theme Leaders will address managerial perspectives, project leaders and researchers for research perspectives, and Industry advisors will provide industry perspective. Māori perspective will be sought at each level from individuals with Māori background. For individuals with multiple or ambiguous perspectives, clarification will be sought from interviewees on what perspective, or combination of, they believe to be most appropriate to them. Semi-structured interviews have been chosen to provide an appropriate level of flexibility in the interview process, allowing points of interest to be followed up and re-ordering of questions if it becomes contextually appropriate (Robles, 2014). They also allow subsequent analysis to identify themes and use of dialogue that would be more limited in interviews with stricter structures, allowing more accurate identification of personal values and expression of "experiential data" (Parker, 2015). Interviews with 3-4 representatives of each stakeholder group across each Challenge will be sought, with some overlap of perspectives expected. Interviews will be held in BioH for two purposes: first, to provide an alternative source of 
data if particular perspectives aren't sufficiently represented within SfTI; and second, to provide some ability to compare experiences of mission-led frameworks external to SfTI's specific context, with different configurations of funding and selection processes. These interviews should provide two fundamental understandings: perspectives on the practical implementation of selection and funding processes; and the nature of stakeholder relationships within a mission-led framework. A broad representation of each group will be sought where possible, enabling generalisations of group perspectives and meaningful comparison between them. One possibility that is considered is the existence of boundaryspanners that occupy multiple perspectives, either through previous experience or owing to their current role - for example, the strategic incorporation of Mātauranga Māori at all levels of the research process suggests that Māori perspectives will exist within researchers, management, and industry. Because of this, data analysis will prioritise the identification of convergent or divergent themes primarily, and will recognise divergence based on perspective only where evident.

\subsection{Methods}

Interviews will be recorded and transcribed to the degree required to capture sufficient richness of data and context to support analysis. Summaries will include information required to identify interviewee values and perspectives, supported by relevant quotes, in detail sufficient to identify points of possible convergence or divergence between participant perspectives. The interviews will then be analysed using a thematic dialogue analysis (Mills, Durepos \& Wiebe, 2010, p. 926). Occurring concurrently with data collection, interview summaries will be coded according to relevance of responses toward different themes (Maguire \& Delahunt, 2017). Coding will follow a grounded theory approach (Given, 2008; Belgrave \& Seide, 2018), intending to initially allow themes and relevant coding to be emergent, rather than pre-determined on a theoretical basis (Maguire \& Delahunt, 2017, p. 3355). Coding will occur as soon as is practicable following interviews, to allow emergent themes to be identified and discussed as appropriate with subsequent interviewees.

Prominent or recurrent themes will be identified for individuals and mapped, allowing the comparison of common or divergent themes between participants. Emphasis will be placed on areas of convergence or divergence, particularly where these might identify key strengths or weaknesses in the mission-led framework that could enable or inhibit the 
achievement of mission objectives. An alternative means of analysis that was also considered was that of Narrative Analysis; this would have provided a more comprehensive understanding of how each perspective might have been influenced by specific events that might occur over the course of their experience in the NSCs, but limited the ability to make meaningful comparisons between groups if their experiences lacked significant common events. This was a likely scenario owing to the divergent management strategies between Challenges and, to a degree, between different portfolios and projects within Challenges. Additionally, the focus of this research is less on the cause of perspective differentiation and more on the nature of that differentiation, making a thematic analysis much more appropriate. Content analysis and conservational analysis may also have been appropriate for this focus, but would provide a level of detail not necessarily useful for purpose, and may have limited the generalisability of data to stakeholder groups. This would have necessitated subsequent theme analysis regardless in order to achieve the goal of the research (O'Leary, 2014, p. 315).

Interviews will be carried out primarily through electronic means owing to the geographic distribution of Challenge participants, preferably using audio/visual software; though faceto-face meetings will be used where possible and appropriate. Ethical considerations were covered through SfTI HEC approval, with consent obtained from interviewees as data was collected. Interviewee information will be confidential, and participants will not be identified in any research report where possible, with response data being ascribed as: NSC name (SfTI, BioH), role (Management [Mgmt], Researcher [Res], Māori [Māori], or Industry advisor [Ind]) and a number; e.g. SfTI Mgmt 2. Where individuals hold multiple perspectives they will be identified with each perspective, e.g. SfTI Mgmt/Res/Māori 1.

\subsection{Design Summary}

The research design of this thesis intends to achieve an understanding of how processes and relationships within the NSCs interact to achieve successful research outcomes. The design's intention is to meaningfully incorporate the perspectives of different stakeholders on those processes and relationships, and integrate them in a way that reflects the reality of their dynamic. The use of semi-structured interviews, grounded theory, and a post-positivist epistemology aim to allow flexibility during the research process, while recognising the legitimacy of the various perspectives. 


\section{Results}

This Chapter establishes the perspectives of the stakeholder groups, and is structured to reflect the interaction of contextual, structural, and relationship components that became evident in the data collection process. The first section details perceptions of stakeholders toward the concept of Mission-led research, identifying prominent themes associated with it. The second section will then examine how interviewees identify those conceptualisations and experiences as represented in the structures of the NSCs; for example, Best Teams, VM, and Project Funding and Selection. The final section will present descriptions of relationship dynamics and points of significant interest to stakeholder groups, specifically in areas of conflict or collaboration, differences in expectations and motivations, and willingness or capability to engage in Mission-led research.

\subsection{Section 1: Conceptualisations}

This section will address the conceptualisations of different stakeholder groups regarding mission-led research. It identifies four emergent themes: Big Picture mission scope, Transdisciplinarity, Long-term/Strategic research, and Collective Benefit. It also addresses the buy-in of stakeholders to the concept of mission-led research, in the context of the NSC.

\section{Mission Scope}

Table 4: Conceptualisation of mission scope

\begin{tabular}{|l|l|}
\hline Theme & Representative Quotes \\
Mission: Big & "Thinking about big wicked problems that humanity faces." (BioH \\
Picture & $\begin{array}{l}\text { Mgmt/Res/Māori 1) } \\
\text { "For us it meant putting out a really big goal, and goals actually, big ideas }\end{array}$ \\
& $\begin{array}{l}\text { "Basically have these high level missions and they try to get science } \\
\text { coordinated that focuses on these missions" (BioH Ind 1) }\end{array}$ \\
& $\begin{array}{l}\text { "Mission-led research is obviously about the outcome, about the mission } \\
\text { you're trying to achieve" (BioH Mgmt/Māori 1) }\end{array}$ \\
\hline
\end{tabular}




\begin{tabular}{|l|l|}
\hline "some research we can do that could build that mission toward...a broad \\
need that could have commercial opportunities in the future." (SfTI \\
Mgmt 2) \\
"It's trying to solve the broader, widely applicable problems" (SfTI Res 1)
\end{tabular}

The primary characteristic by which mission-led research was conceptualised, and essentially the driver of each subsequent conceptualisation and the eventual relational dynamics between stakeholders, was that of being "big picture". Variants of 'big picture' were brought up by all stakeholders; reference to goals, high-level missions, and widely applicable problems characterise the 'big picture' concept.

I know there's narrower definitions of missions, additionality, vision, outcomes and outputs and objectives, but to me Mission-led is a big picture. (BioH Mgmt/Res/Māori 1)

The quote above illustrates the prioritisation of 'big picture' as an understanding of missionled research; other definitions and variants are recognised and understood as relevant to the mission-led framework, but they exist within the overarching big picture conceptualisation. However, there is some variation in the perception of a 'big picture' between mission contexts; BioH tend to refer more to a 'big idea', rather than an explicit goal, while SfTI perspectives interpret 'big picture' more as a composition of smaller challenges that together address a specific 'big' problem, as below.

\section{So, to me, Mission-led means that there are a series of problems or issues that need to be resolved and once they're resolved that's mission completed. (SfTI Mgmt/Māori/Res 1)}

This variation in the meaning of 'big picture' between Challenges exemplifies the possible diversity in understanding of similar concepts. It is also acknowledged that understanding within Challenges may vary, although there is seen to be confidence in having a common understanding within the management team in SfTI:

If you take our Challenge Management Team I think everyone's on the same page as to what it is we're trying to do and what mission-led research 
means. I think understanding beyond [management] is mixed and I suspect that would actually be the case right across the science community. (SfTI Mgmt 3)

This risk of divergent conceptualisation was not supported by the other data collected, but presents a possibility of a misaligned understanding of mission-led research within organisations which should be recognised. BioH, however, tended to reflect a common understanding of 'big picture' as a largely abstract concept which would become more specific as applied in the context of particular missions:

Our mission is that end-point of reversing the decline of NZs biological heritage, so that's our mission, that's our end-point; so that definition of what a Mission is, the end-point. (BioH Mgmt/Res/Māori 1)

This quote from also emphasises an understanding of 'big picture' mission scope as explicitly focused on the output and end-point of the mission. This indicates that 'big picture' concepts are broadly applicable as a mission-led concept that can be understood as output focused within project contexts.

\section{Transdisciplinarity}

Table 5: Transdisciplinary Conceptualisations

\begin{tabular}{|c|c|}
\hline Theme & Representative Quotes \\
\hline Transdisciplinarity & $\begin{array}{l}\text { "big wicked picture problems that are clearly gonna be trans- } \\
\text { discipline or inter-discipline" (BioH Mgmt/Res/Māori 1) } \\
\text { "we actually use the term integration a lot too, in recognition that } \\
\text { we really are striving for inter and even transdisciplinary research." } \\
\text { (BioH Mgmt 1) } \\
\text { "different ethnicities, different demographics, so you're gonna have } \\
\text { to have all sorts of disciplines working together...to solve some of } \\
\text { these issues." (BioH Mgmt/Res/Māori 1) }\end{array}$ \\
\hline
\end{tabular}




\begin{tabular}{|l|l|}
\hline "it will have a lot of complexities, and it's only through a joint effort \\
that you can actually achieve those complexities." (SfTI \\
Mgmt/Res/Māori 1) \\
"the Challenge understands that businesses are important and a lot \\
of the activities...have been in consultation with businesses and what \\
do businesses think is the future." (SfTI Mgmt/Māori 1) \\
"those moments of translation are the moments of innovation" (SfTI \\
Res/Māori 1)
\end{tabular}

Across the interviews, the concept of transdisciplinary research was another common conceptualisation across world-views, although the details of its application varied between the SfTI and BioH Challenge. The transdisciplinary concept was often suggested as a necessary aspect of mission-led, research specifically because of the "big picture" conceptualisation:

\section{If you're going to have big picture science problems, to deliver big picture solutions for problems, and social scientists if you like - even Predator Free 2050, how will we do that? It's not just the science, it's the public and community, it's the people who have to work together to achieve Predator Free 2050, it's really important to have those connections. (BioH Mgmt/Res/Māori 1)}

This provides a useful indication of how participants understand the need for the research to be transdisciplinary as a result of the complexities of "big picture" missions. A differentiation between $\mathrm{SfTI}$ and BioH suggests that perception of transdisciplinary research is partly based in the research context; specifically that of the broad area of research and the context of the 'mission'. The BioH mission of reversing biodiversity decline provides a broader context, and requires a knowledge pool that includes multiple technical disciplines and industry, but also necessitates inclusion of Mātauranga Māori and social scientists. SfTI, on the other hand, has a mission which specifies 'economic development' as a key goal. To 
achieve that part of the mission, the knowledge pool required is seen as extending predominantly between technical research disciplines, government, and industry:

I think for mission-led research you do need external input. I think that's part of the nature of it...that might be industry, it might be government, it might be sector bodies providing that input as to what the major problems or opportunities are. (SfTI Mgmt 2)

Similarly to the 'big picture' conceptualisation, understanding of transdisciplinarity is variable between individuals. While the overarching concept is applied by all stakeholder groups, there are distinctions made in its application within Challenges that suggest a divergent understanding of the level of diversity which should be included; for example, some perspectives aspire to a greater inclusion of community perspectives in research processes, particularly those of project creation:

How many community members, not specialists, Al specialists, this kind of specialist were around the table at the mission labs; what would it mean to take our hui idea, what would it mean to take the mission-led concept out into communities, what would they say? (SfTI Res/Māori 1)

The different understandings of the scope of transdisciplinary research within SfTI don't necessarily conflict as much as they infer a variety of prioritisation. Perspectives which emphasised the need to incorporate industry and government didn't dismiss the involvement of communities, but their priority was towards the more traditional organisational stakeholders.

Overall, as with the 'big picture' theme and essentially driven by the recognition of transdisciplinary research as crucial to addressing 'big picture' problems, transdisciplinarity is a commonly held conceptualisation of mission-led research with some variations in the understanding of its effective application. 
Long-term/Strategic

Table 6: Long-term/Strategic Conceptualisations

\begin{tabular}{|c|c|}
\hline Theme & Representative Quotes \\
\hline $\begin{array}{l}\text { Long } \\
\text { Term/ } \\
\text { Strategic }\end{array}$ & $\begin{array}{l}\text { "SfTI overall is a Mission...to fund research projects that will eventually give } \\
\text { some economic benefits to NZ. So it's long term research." (SfTI Mgmt 4) } \\
\text { "one of the things that distinguishes the Challenges...is that these are longer } \\
\text { term, more strategic" (SfTI Mgmt 3) } \\
\text { "balance between short term short sharp projects vs longer term, stretchy, } \\
\text { spearhead type projects...I think that's been done well." (SfTI Mgmt/Ind 1) } \\
\text { "This is what we know is a problem now, but it's also; it's the future } \\
\text { engineering of that so that you have a future focused vision" (SfTI Res/Māori } \\
\text { 1) } \\
\text { try it for another month and if nothing's happening we're out" (SfTI } \\
\text { Māori/Ind 1) } \\
\text { "Some of what we're doing... will not pay the dividends or have the output } \\
\text { for the Mission for some considerable time." (BioH Mgmt/Res/Māori 1) } \\
\text { "what's the benefit for NZ that we want to achieve...in the science system } \\
\text { we are just not set up well to do that. MBIE...they do not have the strategic } \\
\text { view point." (BioH Mgmt } 1 \text { ) }\end{array}$ \\
\hline
\end{tabular}

The third conceptualisation of mission-led research is that of long-term, strategic research. Similar to transdisciplinarity, this is derived from the conceptualisation of mission-led as addressing 'big picture' problems. Both SfTI and BioH recognise that 'long term' research is a distinguishing feature of the Challenges; although the scale of 'long-term', is understood in the context of specific missions: 
BioH is in ecological, ecosystem resilience science as well; a lot of our systems, if you imagine measuring a Kauri system, a millennial ecosystem. Some of what we're doing even ecologically will not pay the dividends or have the output for the mission for some considerable time. So it doesn't have to be just a social benefit or social framework but an ecological, longterm science for climate change scientists. (BioH Mgmt/Res/Māori 1)

This view of long-term impact is held similarly in SfTI, despite the significant differences in fields of research and Challenge mission:

While the intent is to develop new technologies, that may not actually happen within the purview of the project or within the lifetime of the project (SfTI Mgmt 3)

However, it is generally recognised that 'big picture' problems can only be solved with directed, strategic research, which requires a degree of prediction to determine the likely nature of a project's 'future focus'. This long-term, strategic understanding, though, could conflict with the context of industry, who refer to their competitive context and 'commercial reality' as a practical impediment to the 'long-term' conceptualisation. This conflict in perspective is summarised below:

So industry is like a race car. It's moving real quick down the track, and they move outcomes tomorrow. Cos they've got other drivers, which are profit. Research is like a school bus, just chugging along slowly trying to get stuff done. (BioH Mgmt/Māori 1)

The implication is that the conflicting nature of mission-led research as future focused and the competitive context of industry can create tension between industry and the remaining perspectives on the conceptualisation of mission-led research as long-term and strategic. Despite this, industry still conceptualise the mission-led framework as long-term; the misalignment is a result of the perceived inappropriateness of long-term research in particular contexts:

So the SfTI ones, which are looking at $\mathbf{1 0}$ year time frames - research that will be relevant in the science and tech space in ten years' time is pretty much unpredictable. (SfTI Māori/Ind 1) 
As a result, all perspectives conceptualise mission-led research as long-term and strategic; similarly to the other conceptualisations, divergence is in the usefulness of its application rather than an inherent disagreement in understanding.

\section{Collective Benefit}

Table 7: Collective Benefit Conceptualisations

\begin{tabular}{|l|l|}
\hline $\begin{array}{l}\text { Theme } \\
\text { Benefit }\end{array}$ & $\begin{array}{l}\text { Representative Quotes } \\
\text { interests and endeavours, and that goes for us as scientists as well as sort of } \\
\text { individual companies" (SfTI Mgmt 3) }\end{array}$ \\
$\begin{array}{l}\text { "Science Challenges are deliberately designed to be bigger than any one } \\
\text { organisation." (BioH Mgmt 1) }\end{array}$ \\
$\begin{array}{l}\text { "we need research that we can scale to the degree that a small country like } \\
\text { ours can scale and produce." (SfTI Māori/Ind 1) } \\
\text { "Mission-led, it's aspirational, it's a mission per se, and it's having a collective } \\
\text { aspiration of our stakeholders, communities, Māori industry and scientists." } \\
\text { (BioH Mgmt/Res/Māori 1) }\end{array}$ \\
$\begin{array}{l}\text { "It's trying to solve the broader, widely applicable problems, not [solely on] } \\
\text { individual problems" (SfTI Res 1) }\end{array}$ \\
just in your project." (SfTI Mgmt 1)
\end{tabular}

The final conceptualisation of mission-led research is as targeting a collective benefit, again reflecting the idea of 'big picture' problems. Collective benefit suggests that the outputs of a mission-led project should have a broader impact than the interests of individual stakeholders:

Mission-led science and research should...transcend individual's particular research interests and endeavours, and that goes for us as scientists as well 
as sort of individual companies or other entities, so it should be bigger than an individual's interests. (SfTI Mgmt 3)

The scale of the impact is often referred to in context of communities and the New Zealand context, with both $\mathrm{SfTI}$ and BioH perspectives referring to a form of social responsibility that the NSCs hold to deliver outcomes that benefit 'New Zealand':

These are New Zealand's Science Challenges. They're for New Zealand, and that's a big part of the mission - is that you are supposed to work outside your institution, and you are supposed to involve community. (BioH Mgmt/Māori 1)

The SfTI perspective applies a similar theme of social responsibility to deliver collective benefit, but has more explicitly contextualised their responsibility in terms of their mission of economic development - this reflects the economic criteria put on SfTI:

There is an expectation that the output will align with economic development in this country, and that...the taxpayer gets a return on their investment. (SfTI Māori/Ind 1)

The general alignment between stakeholders on the conceptualisation of collective benefit again is influenced by the individual contexts of the stakeholders involved; the reference in SfTI perspectives to the economic benefit is not present in the BioH perspectives. It should also be noted that the scope of 'collective' benefit is generally referenced in terms of a national setting, with a focus on the New Zealand public, economy, and ecology as the beneficiaries in the context of $\mathrm{SfTI}$ and $\mathrm{BioH}$. Some conflict between stakeholders is also apparent where projects have an output of Intellectual Property (IP) that has been generated through Mātauranga Māori. Industry perspectives expect to be able to utilise IP as a benefit of their engagement with the NSCs, but exclusive ownership of IP generated using Mātauranga Māori creates a conflict between the two stakeholders:

We'll see that kind of conflict in our Challenge, especially as we start to use Māori knowledge...We'll have this tension where industry expectations are 'you've created the solutions that now we can turn into a product', and 


\section{Māori will be like 'but you've created this solution out of our knowledge so you don't own it, no one can own it'. (BioH Mgmt/Māori 1)}

The Collective benefit concept is a common conceptualisation of mission-led research, between all of the perspectives considered. As with the other concepts, its specific definition is based on the context of each perspective, with the types of benefits expecting to be delivered contextualised by the mission of research projects and the expectations of stakeholder groups.

\section{Buy-in}

Table 8: Buy-in

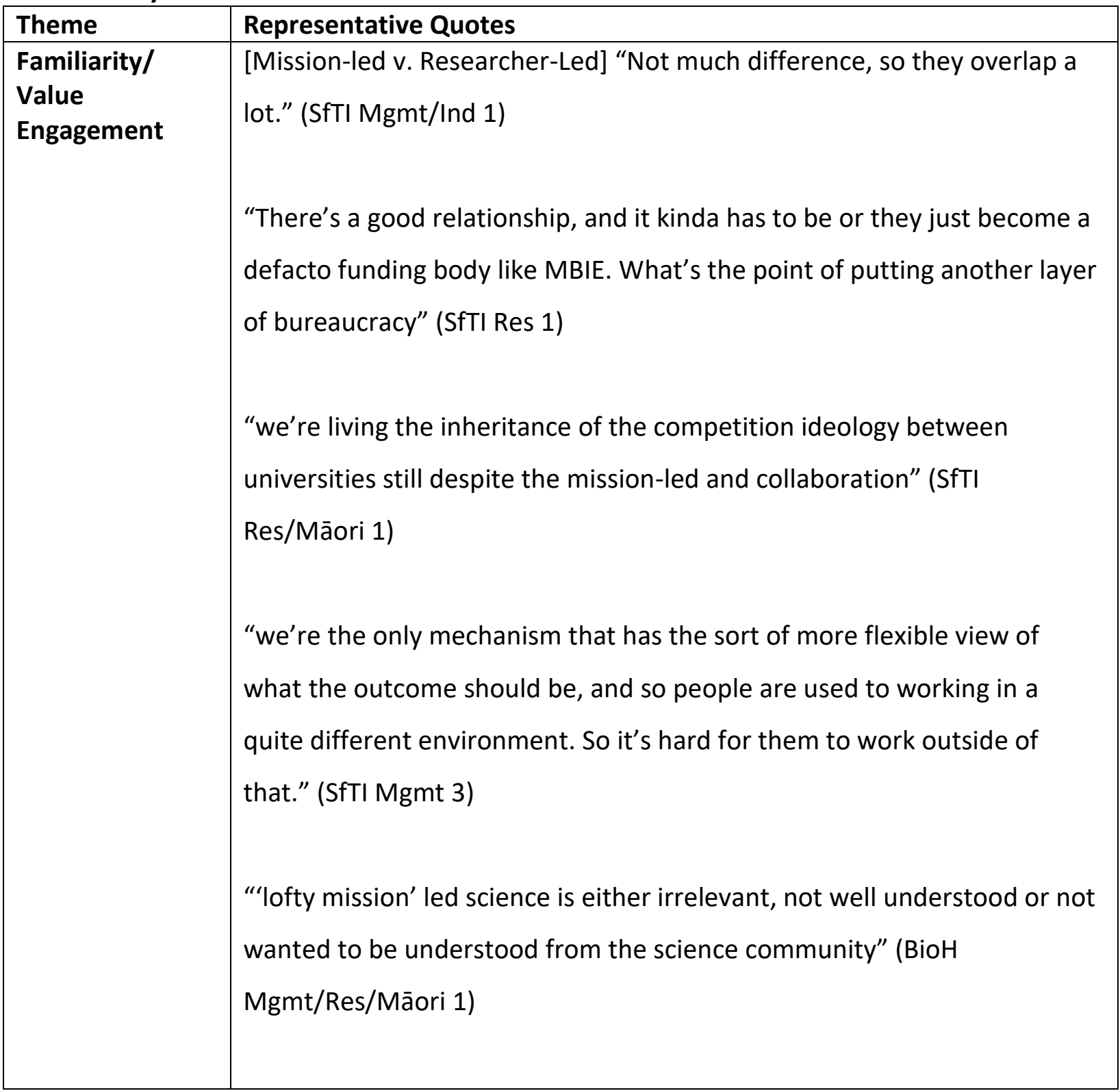




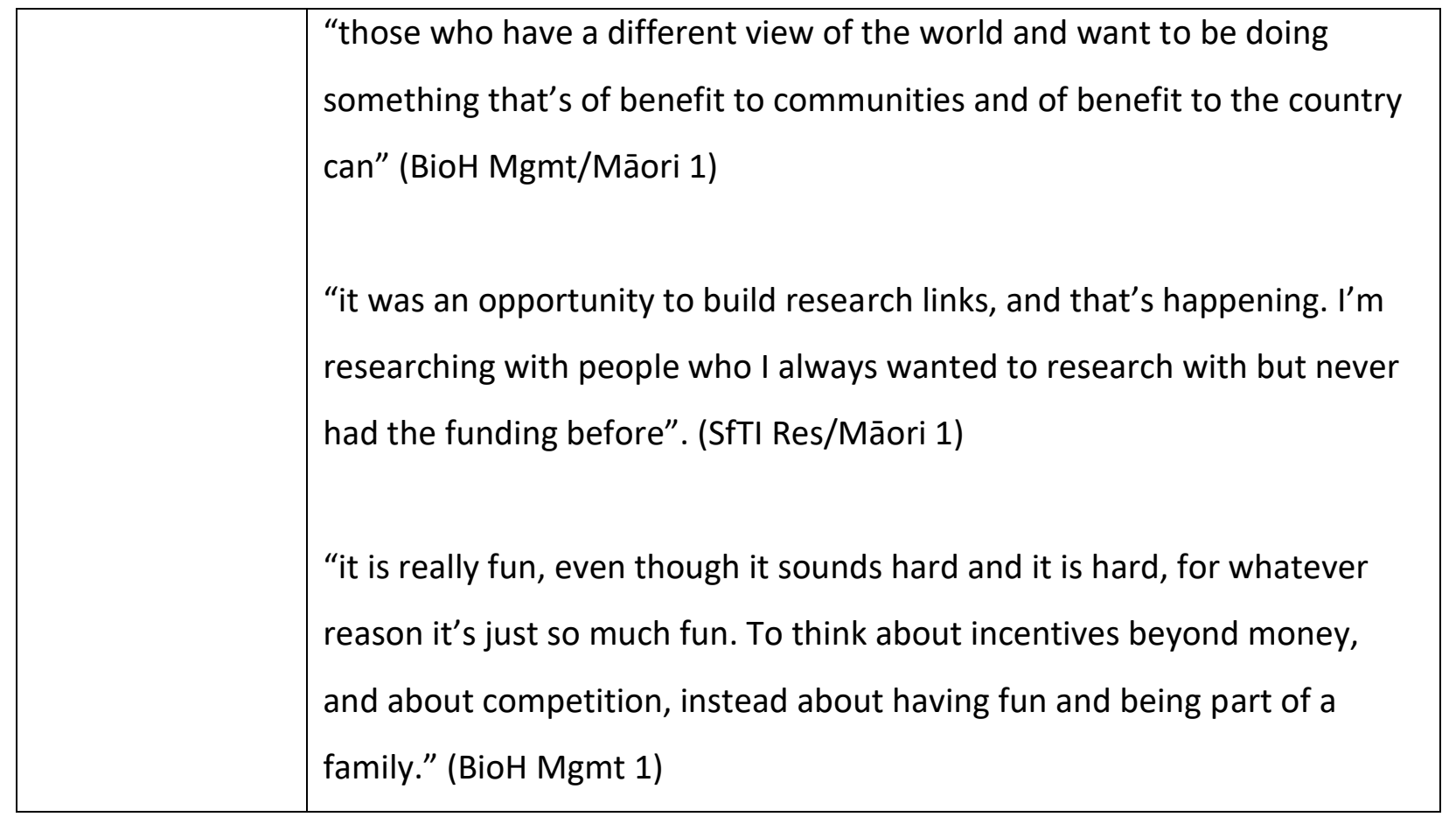

Buy-in to mission-led research is perceived as variable, and closely related to the conceptualisations of mission-led research. Misunderstanding of conceptualisations, or a value alignment that doesn't reflect them, both negatively impact buy-in from different stakeholders. For example, stakeholders who are unfamiliar with the NSCs and mission-led are seen as more likely to resist engaging:

There were...resistance to some of the Challenges, by some of the scientists and academics because of their early experiences with them, or they don't have any experiences with them. (BioH Mgmt/Res/Māori 1)

This contrasts individuals who may understand mission-led frameworks similarly to some aspects of the generally held conceptualisations above, but who have a value set that conflicts with one or more of those conceptualisations. The quote below suggests that researchers may understand the 'big picture' and strategic aspects of mission-led research, but prefer to act independently, negatively affecting their buy-in.

Most are happy to buy in but there's a proportion of scientists who...would say part of $\mathrm{my}$ job is to investigate questions that are of interest to me, so I don't necessarily want to be told or even guided as to what research I should do (SfTI Mgmt 3) 
Unfamiliarity with mission-led challenges, and a broader research environment that has been characterised as competitive and individualistic has driven a perception of engaging with the NSCs as an activity that increases risk to individuals who are already successful in other funding mechanisms. This manifests itself through a suggestion that the typically competitive science environment in NZ creates a 'scarcity mentality', where individuals who have already secured funding from other sources are unwilling to risk that security:

It's always all of us caught up in the science system, we're kind of caught up in this competitive way of working, it's a bit of a scarcity mentality. And so therefore that makes you quite risk averse and not willing to try new things. (BioH Mgmt 1)

Value engagement, however, is a considerable source of buy-in for the Challenges. Values of challenging work, relationship building, and having fun are all cited as motivators for individual engagement in the Challenges. Transdisciplinarity and collaboration is seen as providing opportunities and access to resources that aren't available in frameworks without a collaborative focus:

I enjoy the actual research side of things, and discussing ideas, linking in to other researchers. And we're coming to a point in the next couple of months where I'm going to get a hold of datasets and techniques that l'd have taken ages to come up with myself, so it's actually gonna short-cut a lot of my research, which is going to be really good. (SfTI Res 1)

The conceptualisations of 'big picture' problems and collective benefit provide additional incentives for individuals who want to have a positive impact in a broad sense this is generally supported by comments from researcher groups. However, there is a perspective that priorities for researchers can be divergent; some researchers are seen to do research primarily for the enjoyment of undertaking research, where the potential for impact and collective benefits are of a lower priority:

Researchers do research 'cos they enjoy it but a lot of the time they don't really care, the enjoyment of the research is the first thing and the development of the world is a secondary thing. (SfTI Mgmt/Māori) 
Lastly, the work of management to improve the engagement and buy-in, particularly of researchers, is seen as a key challenge. Several perspectives refer to the importance of moving the focus away from financial incentives, both due to the need to conserve financial resources and a perception that incentivisation through money encourages the engagement of individuals with a misaligned value set to the conceptualisations of mission-led research. This is particularly relevant where a large proportion of researchers engage with the Challenges because of their aligned conceptualisations and values:

Funding or money always seems to attract the worst in people. You take money out of the equation, you're just there for the kaupapa, you're always getting much better people. (SfTI Mgmt/Māori 1)

The industry context presents an additional challenge to buy-in. Their divergent conceptualisations of mission-led research, particularly those of collective benefit, are driven by a set of motivations that all perspectives recognise as significantly divergent from those of the other stakeholders. Where researcher motivations in the Challenges are largely aligned with ideas of collective, long term, big picture impacts, or in undertaking novel research, industries motivations are set in the commercial context:

For me and for the industry people I talk to the motivations for research are often around finding ways to improve the commercial output from the companies, keep people in jobs, compete, those kinds of things. (SfTI

\section{Māori/Ind 1)}

The degree of buy-in to the NSCs are highly variable; unfamiliarity, divergent values, or different motivations will decrease buy-in from stakeholders; an understanding of missionled concepts and a value alignment with those concepts will improve buy-in.

\subsection{Section 2: Structures}

The conceptualisations of mission-led research represent the basic views that different perspectives have toward mission-led research. While these are consistent in general, there are apparent divergences in the understandings of how concepts are applied and implemented. The three conceptualisations of transdisciplinarity, long-term/strategic, and collective benefit were strongly represented in discussion of the structures of the NSCs, with links made between the structures and how they aligned with the understandings of 
mission-led conceptualisations. This alignment was described as influencing engagement with the NSCs, stakeholder relations, and how the basic processes of criteria, reporting, and funding were enacted by management.

\section{Best Team Policy}

Table 9: Perspectives of Best Teams

\begin{tabular}{|c|c|}
\hline Theme & Representative Quotes \\
\hline $\begin{array}{l}\text { Transdisciplinary/ } \\
\text { Right Teams }\end{array}$ & $\begin{array}{l}\text { "diversity in skills within the team, people who think } \\
\text { differently...the researcher and technical skills, because science is } \\
\text { equally about project management, equally about } \\
\text { communication, equally about translation" (BioH Mgmt/Māori 1) } \\
\text { "best teams are not just academic criteria...we're expecting to see } \\
\text { diversity, succession planning, capability building, } \\
\text { inter/transdisciplinary components" (BioH Mgmt/Res/Māori 1) } \\
\text { "It's horses for courses; so it's in some cases it's just who are the } \\
\text { best people doing robotics. Or data analytics, or additive } \\
\text { manufacturing - who are the best people?" (SfTI } \\
\text { Mgmt/Res/Māori 1) } \\
\text { they're rare beasts and we always try and get a hold of them." } \\
\text { (SfTI Res/Māori 1) } \\
\text { "the right kind of researchers, who had not only the right skill-set } \\
\text { but actually have this cultural context." (SfTI Res/Māori 1) } \\
\text { and work well together" (BioH Mgmt/Māori 1) }\end{array}$ \\
\hline
\end{tabular}




\begin{tabular}{|l|l|}
\hline "we do have that capability within and they're highly useful \\
because it means they can bring together the 'glue', different \\
people and skills from across different communities or disciplines \\
together" (BioH Mgmt/Res/Māori 1) \\
"there is a reliance on what you'd call Māori intermediaries, who \\
understand the science technical bit or understand the Māori \\
sector and act as brokers between those two different \\
worldviews" (SfTI Mgmt/Res/Māori 1)
\end{tabular}

Views on best teams have two points of convergence, and one key divergence from the policy of 'best teams'. Common amongst perspectives is the view that 'best teams' are transdisciplinary. This is a direct reflection of the conceptualisation of mission-led research as transdisciplinary, and exemplifies a structure which supports the implementation of mission-led research conceptualisations. However, the specific composition of teams reflect similar nuances to the particular definitions of transdisciplinarity presented in the understanding of the concept. BioH for example, refers to best teams as including a broad range of non-academic groups, specifically including community and diversity:

\section{Not just having academic researchers...you want top thought leaders, top impact factor scientists, top professors...but we also want communicators, connectors, community, citizen scientist, Māori, Pacifica, industry" (BioH Mgmt/Res/Māori 1).}

This reflects their understanding of transdisciplinary research as a necessary component of their mission. SfTI, similarly, considers a transdisciplinary team as necessary, and defines the team composition through a similar deconstruction as their concept of 'big picture', focusing on the distinct parts of the project and the need to incorporate 'the best' for each part of the larger project, including industry and 'stakeholders' but without the same degree of inclusion BioH refer to:

You want to get the best, for each part of the project you want the best people to do that part of the project, but it means...the best overall team to 
do it for NZ. And that's going to include some industry people and some stakeholders. (SfTI Mgmt 4)

In addition, transdisciplinarity is viewed as not a necessity in itself, with focus placed instead on the capability and capacity of the team to succeed in their project. The result is that the 'big picture' conceptualisation and its complexities are seen to create projects that generally need a range of worldviews to address, hence transdisciplinary best teams, but that transdisciplinarity is not in itself an independent requirement of a 'best team', creating a "horses for courses" (SfTI Mgmt/Res/Māori 1) mindset:

Does it [the team] need to be interdisciplinary? I don't think that's required.

It's more about the breadth of capability that's going to be needed to deliver on that mission. (SfTI Mgmt 3)

The 'best team' concept was dismissed in several instances in favour of 'right team', particularly in the BioH Challenge:

We have been very deliberate in our new strategy that the best teams are the right teams...we'd prefer to not even use the terminology of best teams. (BioH Mgmt 1)

The key to this interpretation was the importance of a positive team dynamic within the 'best team', resulting in teams with more diverse worldviews. The idea of a 'right team' as one that prioritises the positive relationships and cooperation within the group above the specific researcher skillset is held both by BioH and SfTI. High level research skills are still seen as essential, but while a highly talented researcher without the ability to operate effectively in a team environment might exist in a best team, the 'right team' philosophy prioritises team dynamic:

Really you can have good teams and bad teams. A good team is a team that communicates well and everybody gets on...good people first, and then what kind of scientists they are or researchers or managers are second. (SfTI Mgmt/Māori 1) 
The need for a synergistic team emphasises the importance of boundary-spanners as relationship facilitators within and between teams. Boundary-spanners are seen as critical connectors between the transdisciplinary boundaries of a team:

They are highly useful...they can bring together the 'glue', different people and skills from across different communities or disciplines together" (BioH Mgmt/Res/Māori 1).

Both SfTI and BioH have successfully implemented a form of boundary-spanner that allows these cross-communications to occur, but have implemented the idea differently. BioH employs "knowledge brokers" as specialist roles which act in a role dedicated to facilitating positive relationships and engaging stakeholders where individuals within teams might lack the capability to do so effectively:

That's where our knowledge brokers came in, as we started moving on and we started hearing from industry groups that they had no idea what was happening...some project leaders just don't know how to engage with people, how to talk to anyone who's not a researcher. And so the knowledge brokers then were brought back in to help facilitate that relationship again and to start building that. (BioH Mgmt/Māori 1)

This benefits relationship facilitation and 'best teams' by having 'go to' knowledge holders who are capable of performing the relationship building role by helping to "translate for researchers who sometimes struggle to engage with stakeholders" (BioH Mgmt/Māori 1). SfTI contrasts by having a portfolio dedicated to building innovation capacity, which includes developing the ability of researchers to engage in a boundary-spanning context; referred to as building human and relational capacity. This enables researchers to fulfil a general boundary-spanner role, in comparison with the specialist boundary-spanners in $\mathrm{BioH}$; and is seen to provide benefits both in relationship building and innovating:

I often find that some of the most interesting researchers that I bring to a team are the ones who do have those skills because they can think outside their own disciplinary domain, and while they're firmly grounded in that, through conversations they actually enable us to shift thinking. (SfTI Māori/Res 1) 
Both SfTI's capacity building and BioH's knowledge brokers enable transdisciplinary 'best teams', aligning with mission-led conceptualisations of transdisciplinarity, collective benefit, and strategic science through collaboration.

The commonalities in interpretation of 'best teams' as transdisciplinary, boundary-spanning 'right teams' between SfTI and BioH suggest their usefulness in achieving mission-led goals. Slight differences in understanding, particularly of transdisciplinarity, have been aligned in the application of the 'best team' policy; this exemplifies a structure that has created a converged application of concepts, despite divergent understandings of those concepts.

\section{Vision Mātauranga}

Table 10: Buy-in to VM Policy

\begin{tabular}{|c|c|}
\hline Theme & Representative Quotes \\
\hline Engagement & $\begin{array}{l}\text { "BioH in particular has embraced the whole Mātauranga Māori quite } \\
\text { considerably...but they haven't just paid lip service to it, there's a lot of } \\
\text { Mātauranga Māori projects going on in BioH." (BioH Ind 1) } \\
\text { "how do you sell that idea to particularly Pakeha researchers who are } \\
\text { probably afraid, feel threatened, don't know the relevance" (SfTI } \\
\text { Res/Māori 1) } \\
\text { "I think the Management get the importance of VM and they're willing to } \\
\text { devote time, energy, space, money towards it." (SfTI Mgmt/Māori 1) } \\
\text { "the VM policy, it reads very extractive, and it's actually not for Māori. It's } \\
\text { been very lucky that in the implementation of it has had a Māori focus and } \\
\text { it's been used to allow Māori inroads into research" (BioH Mgmt/Māori 1) } \\
\text { "You could see Mātauranga Māori as being just one part of VM } \\
\text { itself...having VM as a policy rather than having Mātauranga Māori as a } \\
\text { we'd only been considering Mātauranga Māori" (SfTI Mgmt/Māori 1) }\end{array}$ \\
\hline
\end{tabular}


The engagement with the VM policy and its representations in the Challenges is differentiated among participants, with a number of conflicting perspectives becoming evident around the usefulness of the policy and whether or not it remains fit for purpose. However, both SfTI and BioH have embraced their own interpretations of VM, and have experienced a number of similar outcomes in its implementation. In addition, both Challenges refer to a general positivity in embedding VM practices, but that there is more that could be done in the space:

My understanding is that we've done a really good job, better than some of the other Challenges...but actually we're only starting and there's a lot more we can do I think. (SfTI Mgmt 4)

Engagement with VM is differentiated between individuals; some perspectives note its historical context as impacting its design, creating a policy that is 'extractive' in its design. These perspectives highlight the importance of managerial buy-in to VM, and the interpretation of the VM policy by management in a way that enables the positive impacts VM can achieve:

\section{VM is a government policy...designed under a government that was removing anything race based out of policy...the policy was designed to look like it was supporting non-Māori but to subtly have an inroad for Māori. So when you read the policy it's very much extractive, it's about pulling stuff out of Māori communities...So the VM policy, it reads very extractive, and it's actually not for Māori. It's been very lucky that the implementation of it has had a Māori focus and it's been used to allow Māori inroads into research, but the policy itself has flaws. (BioH Mgmt/Māori 1)}

The need for interpretation of the policy by management illustrates issues with VM and whether it is still fit for purpose. Perspectives which see it as unfit fall into two groups; those who support its reinterpretation and implementation, and those who consider that engagement with stakeholders should occur on a basis of relevance to individual projects, rather than as a result of a facilitating policy. This has similar connotations to SfTI's 
interpretation of 'best team' as including the capability needed to complete a project, rather than BioH's more generally inclusive understanding of best team:

What matters more is engaging with Māori, or Pakeha or whoever, who have a need or an interest in an area in the business, and they want to make something happen...to me it's more important that you engage with Māori businesses or entrepreneurs...without thinking VM per se. (SfTI Mgmt/Ind 1)

Table 11: Implementation of Vision Mātauranga

\begin{tabular}{|l|l|}
\hline Theme & Representative Quotes \\
\hline Implementation & $\begin{array}{l}\text { "people were sensitive to issues around tikanga Māori but didn't know } \\
\text { how to enact them" (SfTI Res/Māori 1) } \\
\text { "where those projects didn't know how to do it, we put in ways and } \\
\text { pathways to facilitate that input" (BioH Mgmt/Res/Māori 1) } \\
\text { "The key to it is...to hand hold them and walk them through in a safe space } \\
\text { where they can ask you anything without fear of judgement" (SfTI } \\
\text { Māori/Ind 1) }\end{array}$ \\
\hline
\end{tabular}

An additional theme evident regarding VM in both $\mathrm{SfTI}$ and $\mathrm{BioH}$ was the issue of practical application of Mātauranga Māori by researchers who lacked confidence in doing so. The general positivity of buy-in was inhibited be the difficulty of enacting VM principles in the research context:

"everybody thinks it's a great thing; but thinking it and then actually enacting that are two different things" (SfTI Mgmt/Res/Māori 1)

Both SfTI and BioH indicate this to be an issue, and both Challenges recognise the importance of tutoring those who are willing to learn VM processes in its application. They also reiterated the need for those in leadership positions to buy-in to VM, citing the ability of management and project leaders to implement VM tools and embed its use in to the mission-led process through learning processes: 


\section{"if you have really open minded, inclusive, eager to learn programme leaders or project leaders, you can do it really easily. Because at the end of day if they're open to learning and asking questions they'll find a way to embed Mātauranga Māori” (BioH Mgmt/Māori 1)}

The VM policy is generally well accepted by stakeholders of these Challenges, but faces critical challenges; particularly in the belief that it isn't entirely fit for purpose, and in a lack of confidence in its implementation. However, interpretation and implementation by BioH and SfTI both facilitate an aligned application within their projects; this is more apparent in $\mathrm{BioH}$, whose VM criteria ensure that projects must align with VM policies in their application, regardless of divergent levels of buy-in.

\section{Reporting}

Table 12: Reporting as Unrepresentative

\begin{tabular}{|l|l|}
\hline Theme & Representative Quotes \\
\hline Unrepresentative & $\begin{array}{l}\text { "I'd have thought then that you might develop KPIs that reflect that } \\
\text { dynamism if you like, rather than just following a sort of more } \\
\text { standard template" (SfTI Mgmt 3) } \\
\text { "the frustration would be the focus still on those quantitative } \\
\text { measures, and not on some of the qualitative stuff" (BioH } \\
\text { Mgmt/Māori 1) } \\
\text { "the other big problem is the time problem...I suspect that some of } \\
\text { our KPIs have a timeframe that is longer than our likely length of } \\
\text { existence" (SfTI Mgmt 2) } \\
\text { "they need KPIs. They need to demonstrate delivery. They're } \\
\text { spending taxpayers money, but at the same time MBIE have been } \\
\text { quite flexible for us" (BioH Mgmt 1) }\end{array}$ \\
\hline
\end{tabular}

Where 'best teams' and VM both represent structures which reflect the conceptualisations of mission-led research and encourage an alignment of perspectives toward achieving 
research goals, reporting is a construct which has been co-opted from non-mission-led contexts, and appears to fail to reflect the understandings stakeholders have of mission-led research.

The format of NSC reporting is criticised by both SfTI and BioH as inadequate. There is a general opinion that the reporting framework used has been adopted from a source that fails to reflect the conceptualisations and processes of mission-led research as understood by its participants:

What they do is exactly the same as they require the CRIs to do. They treat the NSCs in exactly the same way. So CRI reporting is at the end of the year and the middle of the year. They treat the NSCs identically. (SfTI Mgmt/Ind 1)

This generates frustration from participants, as they feel they are unable to meaningfully report on key aspects of mission-led processes; primarily that of relationship building, which is seen to have a time frame for benefits that exceeds the scope of reporting formats and is a qualitative outcome. The frustration appears to be a result of a misalignment between mission-led conceptualisations, such as the necessity of relationship building in transdisciplinary research, and the reporting structure that has been implemented:

\section{You've got to build that relationship, build trust with iwi/whanau/hapū before you can even start to think about what research you're doing...so how do I report that. (BioH Mgmt/Res/Māori 1)}

This perceived inadequacy of the reporting process is addressed by management through Challenge-specific KPIs that exist separately to those implemented by MBIE. BioH, for example, has introduced the VM scale, which has been deliberately implemented to promote the VM policies implementation as interpreted by the BioH management group:

we use the VM scale, 1-5...and we won't fund a project unless it meets a 3, 4 , or 5 in that scale. So if your project isn't 3+ then we just aren't interested. (BioH Mgmt/Māori 1).

A broader example of the benefits of Challenge-specific KPIs is the increase in qualitative reporting and 'story-telling' in internal reporting. This has improved the ability of projects to 
indicate progress that isn't represented through quantitative formats; building relationships, transfer of tacit knowledge, and potential for long-term benefits are more easily conveyed through qualitative reporting. There have been some issues apparent with researchers who aren't familiar with qualitative reporting but the general perception seems to be that it facilitates communication both internally and externally of meaningful but non-quantitative outcomes.

Story-telling is incredibly important - how do I tell the story of the journey to find this person, and then what does that mean for the larger project. (SfTI Res/Māori 1)

There is a broad acknowledgement of the need MBIE has for quantitative reporting criteria however, particularly in regard to providing ongoing support to the NSCs through political cycles. This has been indicated as a 'flexibility' afforded to the Challenge management that allows them room to deliver on a broader range of outcomes:

They need KPIs. They need to demonstrate delivery. They're spending taxpayer's money, but at the same time MBIE have been quite flexible for us, in not holding us too strongly to some detail. They've allowed us to respond to change as we go - it's been quite good for us. (BioH Mgmt 1)

The overall perception of reporting in the NSCs is that it is necessary, but inadequately formatted to represent the conceptualisations of mission-led research. This is overcome, similarly to the structures of VM and best teams, through interpretation and implementation by Challenge management, who have the flexibility afforded to them to introduce Challenge-specific KPIs that can better represent the qualitative outcomes of mission-led projects and align the mission-led structure with mission-led conceptualisations. 


\section{Funding}

Table 13: Negotiation of Funding

\begin{tabular}{|c|c|}
\hline Theme & Representative Quotes \\
\hline Negotiation & $\begin{array}{l}\text { "we've kinda flipped the conversation from 'this is about a funding pool } \\
\text { that you bid for' and turned it into a 'we're gonna use our funding to get to } \\
\text { the goal, the best way to connect you into that bigger picture framework'." } \\
\text { (BioH Mgmt 1) } \\
\text { "We decide if the proposal is good enough to fund, and we go back to them } \\
\text { and we ask them to improve the milestones, budget, team, and everything, } \\
\text { as we want changes - we kinda then negotiated it" (SfTI Mgmt 4) } \\
\text { "You negotiate around what it is that you're doing, that's what it } \\
\text { means....they've [MBIE] got a pot of money and they need to get rid of it, } \\
\text { and it's for such and such a purpose but they don't know the details." (SfTI } \\
\text { Mgmt/Res/Māori 1) }\end{array}$ \\
\hline Limitations & $\begin{array}{l}\text { "it's really hard to get detailed expertise, given that you want to do a range } \\
\text { of projects in those areas, so inevitably we might get persuaded to put } \\
\text { money into things...that have already been done" (SfTI Mgmt 2) } \\
\text { "the Challenges...don't necessarily have long term funding and long term } \\
\text { projects" (BioH Ind 1) } \\
\text { "initiatives in that space around long-term funding, but it hasn't quite met } \\
\text { that yet. It needs better - they're tweaking as they go but they still have a } \\
\text { long-way to go for mission-led science." (BioH Mgmt/Res/Māori 1) }\end{array}$ \\
\hline
\end{tabular}

While the reporting structure is characterised as unrepresentative of mission-led research concepts, requiring interpretation by management to align it with mission-led values, negotiated funding structures are perceived as naturally enabling mission-led processes. This is primarily through the use of negotiation; which provides a natural tool for NSC 
management in refining proposal content. Negotiation is seen as advantageous by all parties; researchers are given feedback by Challenge management in how to adapt proposals to better meet funding criteria, which both satisfies researcher desire for feedback and management ability to direct content:

\section{We decide if the proposal is good enough to fund, and we go back to them and we ask them to improve the milestones, budget, team, and everything, as we want changes - we kinda then negotiated it (SfTI Mgmt 4)}

The use of negotiation by management also allows the implementation of other structures; support for emerging researchers, embedding of VM policies, and a focus on team composition are all highlighted as benefits of negotiation, and are representations of mission-led concepts. The result is that projects with research merit, but lacking focus on mission-led concepts, can be negotiated into a format that captures their academic benefit while aligning with understandings of mission-led frameworks.

The negotiated framework is advantageous as a concept for the NSCs, but carries particular risks through context. Because of the broad nature of the research being proposed, management have identified a risk of funding research already being undertaken in other frameworks or institutions. Broad research areas also make it unlikely that specialist knowledge on projects will always be held in the selection group; although this has been addressed by SfTI by employing advisors with the relevant specialist knowledge:

\section{If there's a mission or an approach to that that we're not familiar with, we can get a little bit of expertise that we haven't got ourselves to help us make those calls. (SfTI Mgmt 2)}

The most prominent frustration with the funding process is a result of the political context that the NSCs exist within, and the misalignment of political cycles with the need for longterm funding. There is recognition of the political reality creating a need to "demonstrate delivery, they're spending taxpayers money" (BioH Mgmt 1) but the result is that funding doesn't necessarily support long-term conceptualisations of mission-led research. This is particularly evident in the $\mathrm{BioH}$ Challenge, who indicate that the funding fails to reflect the nature of their goals: 


\section{We're trying to reverse the decline of NZs biodiversity and have got six years of funding to do so. We can get started but aren't gonna get very far}

\section{(BioH Ind 1)}

The negotiated funding process is seen as largely reflective of mission-led concepts. There is an overall sense of satisfaction toward its formatting, particularly in the negotiation of project proposals to improve direction. However, it is limited by political contexts and retains a legacy of short-term funding relative to some of the missions being targeted.

Project Creation/Selection

Table 14: Project Co-creation

\begin{tabular}{|l|l|}
\hline Theme & Representative Quotes \\
\hline Co-creation & $\begin{array}{l}\text { "industry saying, 'that's something that could have commercial good or } \\
\text { something that could have value to NZ'. Yet the researchers are saying this } \\
\text { is where we need to push the envelope" (SfTI Mgmt 2) } \\
\text { "The feeling is that even if industry wrote, modified, suggested changes } \\
\text { into those proposals, quite often they were lost, [industry modifications] } \\
\text { weren't reflected in the final proposal." (SfTI Mgmt/Ind 1) } \\
\text { "So any criticism they offer now is frustrating because they forget that they } \\
\text { had so much control then" (BioH Mgmt/Māori 1) } \\
\text { "we tried the mission-lab approach where we've deliberately gone out and } \\
\text { sought external input as to what our research agenda should be, and that I } \\
\text { think is working really well" (SfTI Mgmt 3) }\end{array}$ \\
\hline
\end{tabular}

SfTI has implemented a 'mission-lab' process of project co-creation, incorporating transdisciplinary practices through the input of industry advisors at the project creation stage. This is seen to enable collaboration between researcher and stakeholder perspectives, as opposed to a competitive process of bidding projects for funding: 
Part of that is that there's that kind of co-creation at the front end rather than just a bidding process. So it's more about being collaborative with industry and with researchers, so you've actually got a different process at the front end. (SfTI Mgmt 2)

This is seen to enable project understanding of the real world context of their eventual outputs. BioH has a similar process of co-creation that reflects a similar dynamic, but has not implemented formal 'mission-labs':

Some of our research teams have key industry people in their bid. They're factored in...they might be part of research design or their expertise has been recognised or they're part of the project team. (BioH Mgmt/Res/Māori 1)

However, there are issues in the execution of the mission-lab process that inhibits its usefulness as a transdisciplinary process. Industry cite frustrations at the degree to which their input is meaningfully incorporated, with a view that their contributions are neglected both in BioH and SfTI:

The feeling is that even if industry wrote, modified, suggested changes into those proposals, quite often they were lost, they weren't reflected in the final proposal. (SfTI Mgmt/Ind 1)

Contrastingly, researchers consider industry input as "very influential on how we do things" (SfTI Res 1), evidencing disconnection in expectations between the two stakeholders. Cocreation represents a process that directly enables mission-led concepts but the successful implementation of which remains difficult, and is inhibited by a misalignment of stakeholder expectations.

Table 15: Project Selection: Ballot Selection

\begin{tabular}{|l|l|}
\hline Theme & Representative Quotes \\
\hline Ballot & "we're looking for projects that are hopefully going to deliver on a range of \\
Selection & outcomes...in the end you apply a fairly holistic view" (SfTI Mgmt 3) \\
\hline
\end{tabular}




\begin{tabular}{|l|l|}
\hline "people curse against Marsden...even if you're near the top of it, you realise \\
that it's pretty much a lottery of which reviewers you get, whether they like \\
you or not." (SfTI Res 1) \\
"it's the one that people can complain about the least. It's open, it's absolutely \\
obvious, you can't manipulate it, it's done properly" (SfTI Mgmt/Ind 1) \\
$\begin{array}{l}\text { "It has come up with a situation that people go into the lottery once, and they } \\
\text { either succeed or they fail, its fine. And if they fail they'll put in for the second } \\
\text { year and they'll go into the lottery again, and they could fail again based on the } \\
\text { lottery" (SfTI Res 1) } \\
\text { "what people don't like is when it's really picky, when you seem to be } \\
\text { measuring things that are easily measured and actually not the things that we } \\
\text { all really care about." (SfTI Mgmt/Res/Māori 1) }\end{array}$
\end{tabular}

As an alternative to traditional assessment, proposals in the SfTI Challenge which meet funding criteria are entered into a ballot, and those drawn out are funded; this is not a system that has been implemented in $\mathrm{BioH}$, but provides an interesting point of discussion. A ballot provides a transparent process of selection, and is seen to reflect the realities of decision making:

No pretence of being this is the best project, this is the second, this is the third. None of that, much more real (SfTI Mgmt/Ind 1)

This process of ballot selection is predicated on the basis that assessing project proposals can only be done to a relatively low level of granularity, where the differences between project proposals of similar fundability are insufficient to reasonably justify selection for funding:

So once we finalise the list that are really good we then just pull them out of a hat. Because we sort of say being able to discern at that level of granularity just isn't possible. (SfTI Mgmt 3) 
There is an acknowledgement of potential disengagement for researchers whose proposals are repeatedly entered in the ballot without success; this is a risk that was raised by several perspectives, but the improvements of transparency and realistic process are seen to provide a system of project selection that is advantageous over typical selection processes.

\subsection{Section 3: Stakeholder Interactions}

The conceptualisations and structures discussed in sections one and two illustrate the importance of an alignment between the two; where structures may not represent conceptualisations, there is a risk of frustration from stakeholders. The third aspect to this dynamic is the interaction between the stakeholders themselves, and how each perspective views the others in the NSC framework. Typically, interactions were referred to in context of mission-led concepts, or in relation to a mission-led structure. In this section, the perspectives of all stakeholder groups are amalgamated to represent the dominant theme of discussion referred to in reference to how the group in question interacted with other perspectives in the Challenge context. In reference to Researchers, stakeholders predominantly discussed topics that fell under a theme of transdisciplinary collaboration; Industry was typically talked about in terms of how their commercial reality dominated their interaction; Māori perspectives were frequently discussed in regards to their futureoriented and communitarian perspective, and in issues of capability and capacity; and Management were generally discussed as the facilitators and enablers of relationships.

Researchers

Table 16: Transdisciplinary Researcher Collaboration

\begin{tabular}{|l|l|}
\hline Theme & Representative Quotes \\
\hline Transdisciplinary & $\begin{array}{l}\text { "recognising the people with technical knowledge exist not just in } \\
\text { academic institutions but in regional councils, in museums, in industry, } \\
\text { primary industries." (BioH Mgmt/Res/Māori 1) }\end{array}$ \\
& $\begin{array}{l}\text { "The willingness to collaborate, the willingness to share ideas, the } \\
\text { willingness to write joint papers and stuff, that seems fine." (SfTI Res 1) }\end{array}$ \\
\hline
\end{tabular}




\begin{tabular}{|l|l|}
\hline "the first projects were funded basically to the researchers who got \\
enough speaking time - you know, the loudest voices or the strongest \\
reputations got the funding." (SfTI Mgmt 3) \\
"we've been very lucky we've had some very inspirational, kind \\
individuals who were happy to step back." (BioH Mgmt 1) \\
$\begin{array}{l}\text { "it's quite a new process for everybody. So perhaps it's the nature of } \\
\text { the space that's allowed the younger researchers to put forward their } \\
\text { ideas as well." (SfTI Mgmt/Res/Māori 1) } \\
\text { "the classic MBIE best team has often been...your big important } \\
\text { professors who publish in Nature and Science with the big CVs you } \\
\text { can't argue with. We recognise that...but we're looking at best team in } \\
\text { a much more diverse way" (BioH Mgmt/Res/Māori 1) }\end{array}$ \\
\hline
\end{tabular}

The dynamics of interaction between researchers and other stakeholder groups, as well as within researchers, can largely be considered within the theme of transdisciplinary cooperation. The recognised need for transdisciplinarity in mission-led contexts establishes the context for the relationships researchers build, and highlights some of the dynamics that exist within the researcher group that conflict with transdisciplinary practices.

Researchers are largely supportive of the transdisciplinary mode of working in the NSCs. They suggest reasons of improved efficiency, access to new techniques and knowledge sets, and reduced duplication of effort as some of the benefits that are realised in collaborative work with industry, as well as an improved ability to focus on areas of interest:

So for me not having to go out and take tens of thousands of forestry data sets because...Scion has already done it, means I can just concentrate on what I'm interested in. And similarly the feedback is actually you don't want to take photos of that particular forest, you want to take photos of that particular forest. You want to do this so we can pass back and forwards ideas. (SfTI Res 1) 
Despite this support for transdisciplinary work, managing the dynamic between stakeholders presents a relational challenge to those involved. For example, one of the benefits noted above is the removal of the need to personally collect field data; however, some industry perspectives note that individuals who are more willing to embed themselves in the field are easier to build relationships with, suggesting a balance needs to be struck between the efficiencies of transdisciplinary processes and the relationships that facilitate them.

\section{Academics need to put their gumboots on and go walk in the forest. The academics that do that are fantastic to work with, the ones who don't are hard work (SfTI Māori/Ind 1).}

One of the key dynamics brought up by participants in reference to the dynamic of relationships in the NSCs was that of emerging and established researchers. There is a perception of a tendency for established researchers to naturally dominate conversations, and a corresponding need to facilitate collaborative processes to prevent emerging researchers from being shut out of the process (although some perspectives note the awareness of established researchers who deliberately stepped down to allow increased diversity and emerging researchers in teams).

\section{People felt again it was the louder voice in the room, the senior people same-old same-olds that you see everywhere else who were mature in the system and know what they're doing and who can out-dominate. (BioH Mgmt/Res/Māori 1)}

The facilitation of emerging researchers is generally seen as successful in both BioH and SfTI, but the 'loud voices' dynamic suggests that collaborative processes must be well managed in order to ensure they are truly collaborative. Some perspectives note that a novel research environment, that has no established specialists, will help to equalise the power dynamic. The need to facilitate transdisciplinary relationships is evidenced both between researchers, as above, and between institutions. One perspective describes a contractual relationship that effectively prioritises one organisation above another; which is seen to introduce a 'pecking order' that prevents true collaboration: 


\section{It's not equal collaboration, and the fact that we're sub-contracted...means there's a pecking order already. (SfTI Res/Māori 1)}

Transdisciplinary collaboration is seen as a necessity of mission-led research, and is a driving force behind the dynamic of researchers in the NSCs, but there is a need to manage the relationships and facilitate conversations to prevent established individuals and organisations from dominating the relationship and enable effective collaboration.

\section{Industry}

\section{Table 17: Industry's Commercial Reality}

\begin{tabular}{|c|c|}
\hline Theme & Representative Quotes \\
\hline $\begin{array}{l}\text { Commercial } \\
\text { Reality }\end{array}$ & $\begin{array}{l}\text { "sometimes the industry people get a little bit too focused...they come with } \\
\text { a particular perspective and a particular set of experiences...and sometimes } \\
\text { that can be a little bit too narrow or too short-term" (SfTI Mgmt 3) } \\
\text { "a lot of the industry rep who liaise, who straddle that divide between } \\
\text { industry and science, a lot of them have come out of science, so it's always } \\
\text { frustrating that they don't; they know how science operates and they know } \\
\text { we need time - science doesn't happen overnight you know, it takes a } \\
\text { while, it takes two years sometimes for even a draft outcome." (BioH } \\
\text { Mgmt/Māori 1) } \\
\text { "a lot of industry - they're there to make a profit and that can drive short- } \\
\text { term thinking" (SfTI Mgmt 2) } \\
\text { "When you get industry leading, most of the time it's all focused on today's } \\
\text { problems. And therefore you don't get stretchy science" (SfTI Mgmt/Ind 1) } \\
\text { do things." (SfTI Res 1) }\end{array}$ \\
\hline
\end{tabular}




\begin{tabular}{|l|l|}
\hline "We struggle to have any meaningful involvement in advisories \\
there...we've got a couple of people involved but even then it's not \\
completely satisfying" (BioH Ind 1) \\
the industry perspective is very much around IP, so everything coming out \\
of this is ours...whereas for Māori...we believe that it's either not owned by \\
anyone, or it's owned by us, because we have a cultural authority over it." \\
(BioH Mgmt/Māori 1) \\
$\begin{array}{l}\text { "This is high-tech, leading edge research. There is no literature - and the } \\
\text { minute the literature's written it's old." (SfTI Māori/Ind 1) } \\
\text { "for the industry people I talk to, the motivations for research are often } \\
\text { around finding ways to improve the commercial output from the } \\
\text { companies - keep people in jobs, compete, those kinds of things." (SfTI } \\
\text { Māori/Ind 1) }\end{array}$
\end{tabular}

The dynamic of industry's interaction with other stakeholder groups is characterised by their commercial context. There is a predominant view by all perspectives of industry as holding a short-term, individualistic driven by their 'commercial reality', a view which conflicts with preconceptions of mission-led processes as long-term and transdisciplinary:

\section{They [researchers] don't think industry is long term thinking enough. They think they're often too short term. (SfTI Mgmt 1)}

Industry, particularly those engaged with the SfTI Challenge, tend to agree with the view of industry as short term. However, they refer to the nature of the high tech discipline as one that rapidly evolves and requires quick decision making that long-term research isn't capable of, whereas industry are more willing to adapt the content of their research and to admit where a project has failed in order to learn from it: 


\section{An industry person who will go 'well this isn't working, we need to pivot or drop it', and just like that a decision can be made and move onto the next thing. (SfTI Māori/Ind 1)}

SfTI have recognised this aspect of industry as beneficial to their own organisational behaviour, and have introduced a 'fast fail' theme, to encourage researchers to admit research failures and allow a more rapid response and repositioning. This reframing of the concept of failure introduces an alignment between industry and researcher perspectives, although it is noted that researchers are frequently unwilling to admit failure:

Find out what things are failing, and reframing failure not as the opposite of success but as part of success...so if something doesn't work you've found that out, that's part of success, and we pivot. (SfTI Mgmt 1)

The result is an attempt to strike a balance between the long-term conceptualisations of mission-led research, and the need to align values to facilitate transdisciplinary research; both of which are seen as core functions of mission-led frameworks. This balance may reflect one of the major divergences between $\mathrm{SfTI}$ and $\mathrm{BioH}$ in their industry engagement; SfTI perspectives see industry as highly influential in their processes, a result of continuous engagement strategies targeting the incorporation of industry at the 'front-end' as well as end-users. Contrastingly, industry in BioH perceive themselves as struggling to have meaningful involvement, and key conflicts have been illustrated between industry and Māori expectations around output ownership, particularly concerning Intellectual Property:

\section{We'll have this tension where industry expectations are 'you've created the solutions that now we can turn into a product', and Māori will be like 'but you've created this solution out of our knowledge so you don't own it. No one can own it'. (BioH Mgmt/Māori 1)}

Industry's interaction with the Challenges is founded on a need for diverse perspectives and their role in commercialisation, reflecting the transdisciplinary and collective benefit conceptualisations; despite their divergence of understanding the Challenges as longterm/strategic. While SfTI have attempted to address the time-orientation aspect, there remains a perception in researchers of industry as having too short-term a viewpoint. In $\mathrm{BioH}$, the conflict is more oriented around that of collective benefit, where industry are seen 
as wanting exclusive IP rights over research outcomes, creating tension with Māori perspectives with a broader view of impact.

\section{Māori}

Table 18: Māori Orientation and Capability

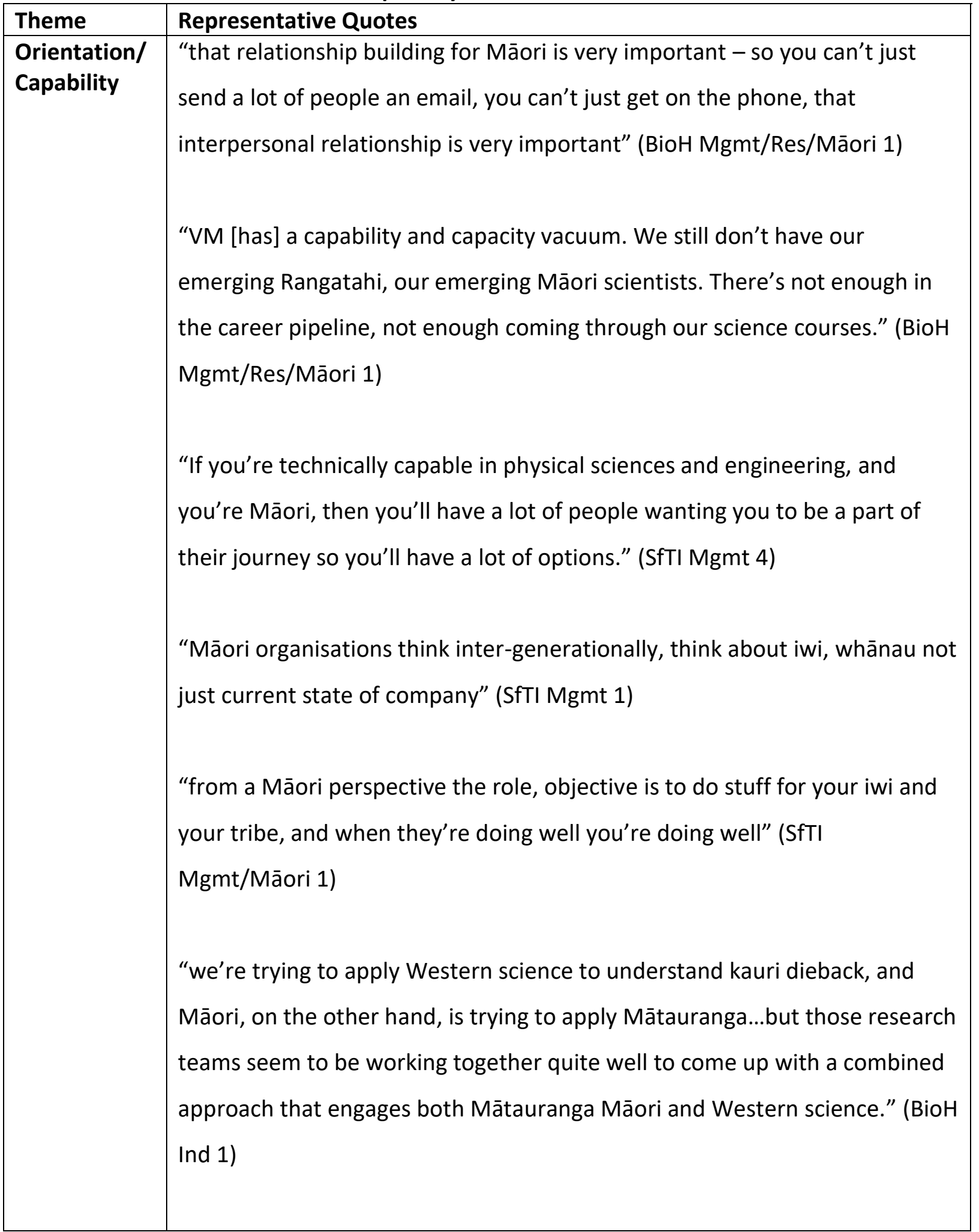




\begin{tabular}{|l|l|}
\hline "in NZ in the science and engineering space there ain't a big pool of \\
potential researchers, student researchers, available of Māori descent." \\
(SfTI Mgmt 2)
\end{tabular}

The dynamic of the Māori perspective in the NSCs is one that largely reflects a long-term, community oriented view which struggles to maintain the capacity needed to implement and embed its views. The alignment between Māori perspective characteristics and the conceptualisations of mission-led research is seen to make the inclusion of Māori values and worldviews beneficial to the achievement of mission-led goals. For example, they are seen to hold long-term perspectives with strategic orientations at a scale that mainstream science systems tend not to consider:

And they think so long term - I've been to conferences with sort of 1000 year plans. That's just how they think, so [mission-led], it's the perfect space for them. (SfTI Mgmt 1)

They are also seen to have a strong alignment with the collective benefit concept, based in their links to community and a cultural emphasis on relationship building. This, in turn, supports their ability to perform as boundary-spanners, encouraging both the incorporation of Mātauranga Māori and transdisciplinary collaboration across sectors:

\section{Most Māori have been doing it [boundary-spanning] anyway. Māori who have been brought up with a knowledge of their tikanga have been doing that (SfTI Mgmt/Māori 1)}

One of the most common issues raised regarding Māori engagement is a perceived lack of Māori capability and capacity in the science and technical space; this was seen as true for both SfTI and BioH. A lack of young Māori interest in the science and engineering disciplines creates an environment where competition for those who do come through is high between institutions. This also creates pressure on the Mãori who are engaged with the Challenges to become relatively generalists able to advise a range of topics, rather than specialist researchers in their own right:

Māori academics typically have the worst CVs....the average Māori academic is probably doing five or more projects. And on tiny bits of those 
projects. So their CVs suffer, their CVs look like...they don't focus on anything, they don't lead anything. (BioH Mgmt/Res/Māori 1)

Overcoming issues of Māori engagement is seen as largely predicated on the support of Challenge management and leadership. Several perspectives describe the benefit of having a management team that is willing to invest resources into the VM policy and to support its implementation in a way that facilitates the incorporation of Māori worldviews in a meaningful way, embedding Mātauranga Māori and tikanga into the processes of missionled research:

I think it's been upholding VM really well; and that's because I think the management get the importance of VM and they're willing to devote time, energy, space, money towards it. (SfTI Mgmt/Māori 1)

The Māori perspective is one that aligns closely with the conceptualisations of mission-led research through long-term and collective values, as well as enabling transdisciplinary processes through roles as boundary-spanners. The use of VM as a policy, and the support of those in leadership positions has facilitated the implementation of Mātauranga Māori and incorporation of Māori researchers and business, but a lack of capacity and capability held by Māori in the science and technical sectors is seen as inhibiting further success.

\section{Management}

Table 19: Management Role: Relationships and Facilitation

\begin{tabular}{|c|c|}
\hline Theme & Representative Quotes \\
\hline $\begin{array}{l}\text { Relationships } \\
\text { and Facilitation }\end{array}$ & $\begin{array}{l}\text { "A huge part again comes down to having the right team...it's about } \\
\text { having trust built relationships" (SfTI Mgmt 1) } \\
\text { "There's definitely a trust relationship between us and our } \\
\text { relationship managers" (BioH Mgmt 1) } \\
\text { "There's a good relationship, and it kinda has to be or they just } \\
\text { become a defacto funding body like MBIE" (SfTI Res } 1 \text { ) }\end{array}$ \\
\hline
\end{tabular}




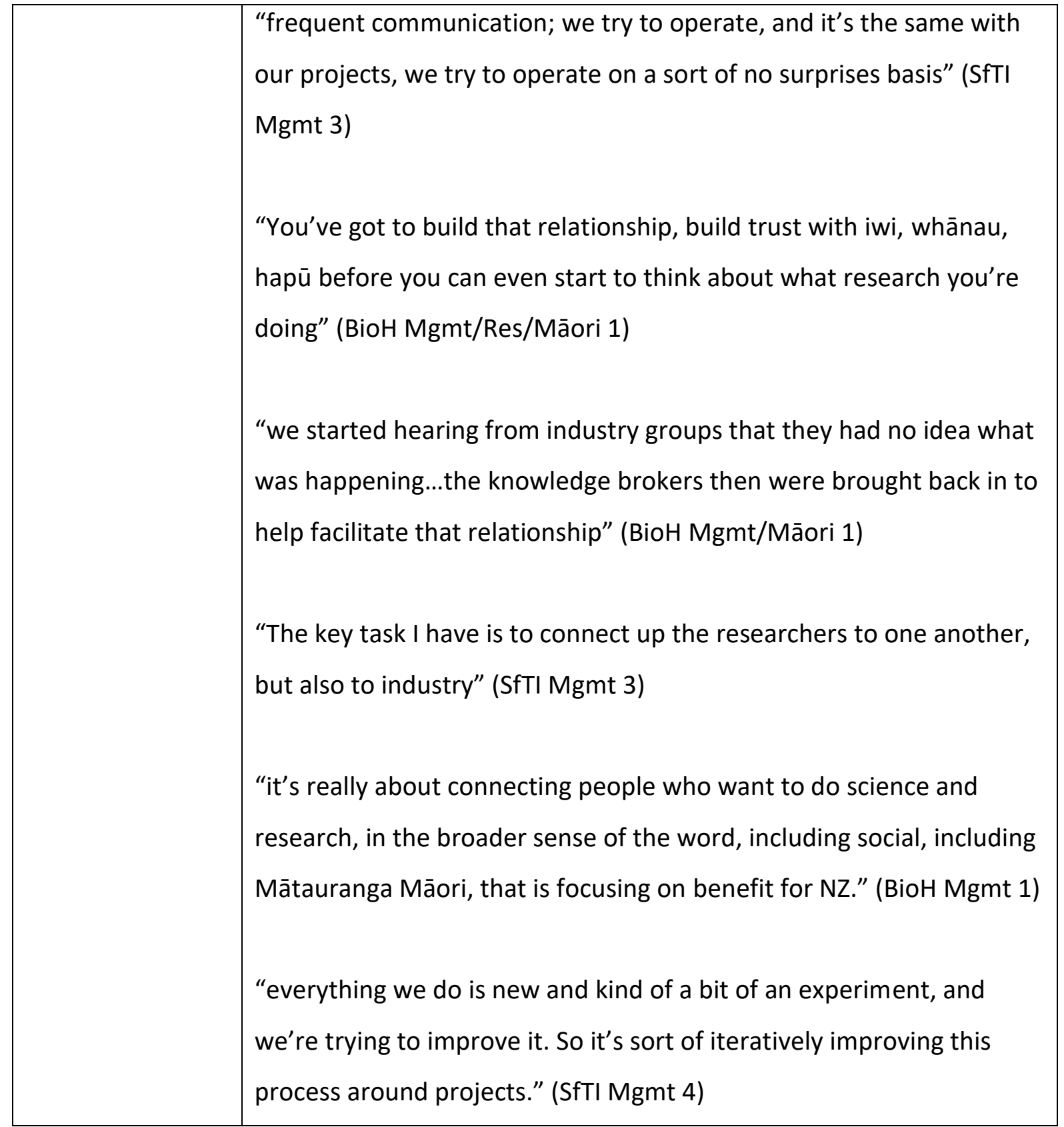

One of the primary roles of management in both BioH and SfTI is seen to be that of relationship management and facilitation. This reflects the need to align stakeholder conceptualisations of mission-led research despite variations in context and perspectives, and helps to address the tensions that those variations produce between groups. This facilitation is accomplished through both formal, structured methods, including interpretations of 'best team' and VM policies; and informal methods, such as clear communication and a trust built relationship. 


\section{It's really important that in those [transdisciplinary] projects you have good leadership. Yes you do need facilitation, and you need to develop quite a lot of trust between people. (SfTI Mgmt/Res/Māori 1)}

The relationship management aspect of the Challenges provides an ability to moderate the dynamic between stakeholders that would otherwise engage with a skewed power dynamic; facilitation of mission-labs is repeatedly given as an example where facilitation is absolutely necessary in order to achieve meaningful collaboration and prevent the dominating effect of loud voices and established researchers over emerging researchers and industry.

And the vocal people are okay for a bit, but once you've heard them then you're not getting anything new, and what you want is to hear from the quiet people...so we try to drag that out of people with good facilitation and break out groups. (SfTI Mgmt 4)

Managing the relationship between worldviews is critical for mission-led research; the interpretations of 'best team' as transdisciplinary, in addition to a focus on the introduction of boundary-spanners, are a central aspect to that management. Particular emphasis is put on building relationships between stakeholders that traditionally would not have collaborated on a project and are therefore susceptible to poor communication and misaligned expectations; this is particularly true for industry. BioH's implementation of knowledge-brokers to span the industry-researcher divide, and SfTI's continuous engagement of industry illustrates this point; management recognise and respond to the need for good communication between stakeholders with divergent expectations. An additional point that was highlighted was the view of BioH and SfTI as "learning organisations', which deliberately sought out feedback internally as to what processes were working and which were not and then reacted, reinterpreting systems where needed to better meld with stakeholder perceptions of dynamics. This reflects management's understanding of the need for trust relationships between stakeholders, where there is a belief that management is willing to listen and adapt to feedback:

It's been a really fun experience, because it's, we can be flexible, we can be adaptive, we can go nah that's just not working, and we've got to change. (BioH Mgmt 1) 
Management enable the relationships and structures that the other stakeholder groups interact with to enable mission-led research. The interpretation and implementation of mission-led structures, and the facilitation of relationships through communication and boundary-spanning, provide the basic dynamics that allow stakeholders to interact positively and cooperate to achieve research objectives despite different expectations, motivations, and contexts.

\subsection{Summary of Results}

This section describes the stakeholder perceptions of the mission-led process and their interaction within it. Conceptualisations of mission-led research, the structures that support those conceptualisations, and the dynamics of stakeholder interaction within those structures are examined from the perspective of different groups. The results suggest that within the SfTI and BioH Challenges, there are three factors that interact to enhance the success of mission-led research: common conceptualisation of mission-led frameworks; structures that reflect those conceptualisations and work to align divergent perspectives; and positive, well facilitated relationships between the stakeholder groups acting to achieve the 'mission'. 


\section{Discussion}

The National Science Challenges are organisations that support the implementation of mission-led research in New Zealand. The way in which each Challenge interprets and understands the idea of mission-led research guides the way in which they carry out their processes, the structures they introduce, and the nature of the relationships interacting within them. However, the stakeholders engaged by the Challenges have their own understandings of mission-led research, influenced by their individual contexts. Where stakeholder understandings are aligned, there is reduced tension in relationships and improved cooperation. Where understandings are divergent, tension increases and relationships are at risk of deteriorating. These dynamics were evidenced in various interviews; in particular, views of industry as individualistic and short-term created tensions between industry perspectives and those of Māori and researchers. Ensuring that this divergence of understandings doesn't inhibit effective research practice requires facilitation and relationship building between stakeholder groups; in the NSCs this has largely been enacted by Management. Managing perspective divergence may occur in three ways: first, through selection of stakeholders who already hold an aligned understanding; second, through the introduction of structures that align research practices; and third, through facilitation of positive inter-stakeholder relationships that prevent entrenched divergent understandings from negatively impacting the interactions between stakeholders.

\subsection{Mission-led Conceptualisations}

Mission-led research is conceptualised differently by different stakeholder groups. These conceptualisations largely reflect the literature's consideration of mission-led, or missionoriented frameworks. The most significant of these conceptualisations is that of 'big picture' problems; this is understood by stakeholders in a way that reflects understandings in the literature. Mazzucato (2017), for example, refers to mission-oriented policies as needing to "focus on creating system-wide transformation across many different sectors". The "big picture' conceptualisation held by many of the stakeholders is generally referred to through an understanding of mission-led problems as too large or complex to solve through a single organisation, discipline, or sector. This creates a subsequent conceptualisation of missionled research as transdisciplinary; the nature of the conceived problems are such that only 
transdisciplinary research is seen as capable of addressing them on an appropriate scale (Rasmussen, Andersen and Borch, 2010; Bromham, Dinnage, \& Hua, 2016).

'Big picture' problems are perceived as requiring long-term, strategic approaches that reflect the volume of research and scale of impact that encompass the Challenge missions. A foresight model presented by Ughetto (2007) describes the processes by which long-term, future-oriented research might benefit research policy, and emphasises the links between foresight modelling and the Triple Helix model of research policy. This similarly suggests that the long-term nature of mission-led research both reflects the 'big picture' problems of mission-led research and the inter-stakeholder dynamic within which it takes place. The final mission-led conceptualisation of collective benefit emphasises both the intended scale of dissemination of research outcomes, and the variable nature of those outcomes beyond economic growth (D'Acci, 2011; Godin \& Dore, 2004). Where notions of transdisciplinary collaboration and co-creation reflects an understanding of the scale of the problem at the 'front-end' of research, collective benefit acknowledges the scale of impact that the research will have at the 'back-end'.

These conceptualisations: Big Picture, Transdisciplinary, Long-term/Strategic, and Collective Benefit, are commonly held between perspectives, despite some contextual variation across Challenges and between stakeholder groups. Tension arises where conceptualisations are significantly different and are often driven by an individual stakeholder's context external to the mission-led environment, such as the competitive nature of industry. Understanding the dynamic between the different stakeholders is therefore an important aspect of enabling positive relationships and cooperative action; the Triple Helix Model of innovation is useful for building that understanding.

\subsection{Theoretical Context: Triple Helix, Foresight, and Duality}

Leydesdorff \& Etzkowitz's (1998) Triple Helix Model suggests that knowledge based societies will introduce a system of innovation based on an interaction between three institutional contexts; government, academia, and industry. While this fails to recognise an individual 'helix' of Māori perspective, it can be considered that the Māori perspectives involved in the Challenges introduce a reframing of the existing helices through a conceptual overlay, rather than acting as an independent group altogether; this is supported by the existence of Māori perspectives in all three of the typical 'triple helix' groups 
interviewed. The triple helix model of innovation reflects the dynamic of the NSCs, and can be used to examine how the expectations and rules of interaction are set and adhered to, particularly in the context of mission-led research. Etzkowitz $(2003$, p. 305) posits a laissezfaire model of the Triple Helix that strongly resembles the context of the NSCs; institutions are largely seen as acting competitively, and in separate institutional spheres with minimal coordination. Where interaction does occur "it takes place across strongly defended boundaries and preferably by an intermediary" (Etzkowitz, 2003, p. 306); this is strongly reminiscent of the interaction within the Challenges, with relationships between industry and non-industry generally tense and requiring either facilitation by management or the deliberate introduction of boundary-spanning skillsets in order to build positive relationships. The role of government in this laissez-faire model is limited, essentially acting as a provider of funding and in establishing the environment for cooperation; this is precisely the action taken by MBIE in setting up the NSCs. However, the Triple Helix model also suggests that as the system develops there will be a "convergence of innovation regimes" and that the separate groups will act as "relatively equal partners" (Etzkowitz, 2003, p. 307); these are both aspects that aren't fully apparent in the Challenges, with several perspectives noting an inequality in input between researchers and industry, and the need for structures that support Māori views. This suggests that the current state of the NSC dynamic is not a true Triple Helix yet. This is seen in Etzkowitz's (2003) four stages of Triple Helix emergence; helices have begun to internally transform, helices influence one another, and the "creation of a new overlay of trilateral networks and organisations" is exemplified by the existence of the NSCs, but this is a recent adoption. The fourth stage, a recursive effect of networks on society and themselves, is not immediately apparent and may not have had sufficient time to take effect.

Ughetto's (2007) discussion of the "process benefits of foresight", as described by Martin and Irvine (1989), draws comparisons between the "process benefits" of long-term research and the Triple Helix Model. These are: Communication; Long-term focus; Co-ordination through networking; Consensus; and Commitment. Of particular note are the ideas of convergence and consensus; both Etzkowitz (2003) and Ughetto (2007) mention the importance of an aligned understanding of goals. Ughetto $(2007$, p. 16) frames it as "the attainment of a common vision for the future" and refers to the need for 'commitment' in 
contribution toward that common vision. The internal dynamic between stakeholders in the Challenges reflects these ideals to a degree; where there is a divergence rather than consensus in understanding of mission-led conceptualisations, tension between groups becomes apparent. There is therefore a need to align the understanding of stakeholders to build a 'common vision', without losing the benefits of diversity in worldview and transdisciplinary collaboration; a balance that can be equated to Sutherland \& Smith's (2011) Duality Theory. This describes a process of maintaining a balance between dynamism and stability that captures the benefits of both states; this is evidenced in some stakeholder perspectives of the stakeholder relationship. For example, diversity in thought and transdisciplinarity, or dynamism, is seen to be a key to the innovative potential of missionled researchers; "those moments of translation are the moments of innovation" (SfTI Res/Māori 1). However, where translation is ineffective or perspectives are overly divergent, tension arises and stability in management is needed. Managing these tensions through maintaining a "conceptual distinction" rather than an antagonistic separation (Sutherland \& Smith, 2011) allows the maintenance of this transdisciplinarity while allowing the convergence of conceptualisations toward mission-led research and a 'consensus' toward common future goals.

The Triple Helix Model understood through Duality Theory necessitates an understanding of each 'helice' and its motivations. These can also be assessed through a cultural lens such as that of Trompenaars and Hampden-Turner (2012), highlighting the specific discrepancies between perspectives and the areas that are most likely to need relationship facilitation.

\subsection{Cultural Dimensions of Mission-led Research}

The perspectives of different stakeholders set the context for their conceptualisations of mission-led research. These perspectives can be identified through cultural dimensions presented by Trompenaars and Hampden-Turner (2012), particularly those of individualismcommunitarianism and orientations in time. While each stakeholder group exists in the same national setting, their contexts within that national culture drive distinctions between perspectives that are equivalent to divergent sub-cultural perspectives. The NSCs themselves can be identified as a communitarian context, considered by Trompenaars and Hampden-Turner (2012) through Parsons and Shils (1951) as a "prime orientation to common goals and objectives"; this strongly aligns with the mission-led conceptualisations 
of collective benefit and transdisciplinarity, as well as the over-riding 'big picture'. The NSCS also present a context with a predominantly "future orientation" (Trompenaars and Hampden-Turner, 2012) of time, aligning with conceptualisations of long-term and strategic research. A future-oriented, communitarian context for research presents a unique challenge in reconciling the views of stakeholders with conflicting cultural dimensions toward a common goal. The future-oriented, communitarian context is reproduced in the perspective of management, who provide a representation of the mission-led context and its cultural dimensions.

Researchers in general are perceived as holding a future-oriented, individualistic perspective. However, the national context of the New Zealand science system, and perceptions of the NSCs, have introduced dynamics that select for individual researchers who hold a more communitarian perspective. This was evidenced through the view that many of those engaged with the Challenges had "a different view of the world and want to be doing something that's of benefit to communities and of benefit to the country" (BioH Mgmt/Māori 1). This 'self-selection' seems to be largely driven by the lack of buy-in from researchers who were either unfamiliar with the Challenges and their value proposition, or were more attracted by individualistic styles of work. The implication is that while researchers in general hold an individualistic view, those who joined these Challenges were already more closely oriented with the 'communitarian' perspective because of individual variation, resulting in a pre-alignment with the transdisciplinary and collective benefit conceptualisations of mission-led research.

The future orientation of researchers is given relative to the 'present' orientation of industry, with many participants referring to the need for industry to remain adaptable, and the tensions this generates between, primarily, researchers and industry. There is a sense that industry fails to recognise the necessarily slower 'pace' of academic research, despite the large numbers of industry participants who hold academic backgrounds; similarly, industry perceive researchers as failing to recognise the urgency of industry to obtain applicable knowledge in order to remain competitive. The competitive, reactive nature of industry's commercial context creates a short-term perspective, increasing tension with longer-term perspectives. Similarly, the competitive nature of industry drives a motivation for engaging based on the creation of competitive advantage, an inherently individualistic 
concept. This individualism conflicts with communitarian perspectives that the remainder of the stakeholders hold; this is particularly emphasised in the interaction with Māori perspectives.

Māori views are seen to strongly align with the cultural dimensions presented in the NSC context, particularly the communitarian aspects of Māori culture. The use of the whānau as the core social unit (Best \& Love, 2010, p. 14) as opposed to the Western 'individual' introduces an orientation toward work that benefits the collective, aligning with conceptualisations of the NSCs as working for collective benefit. This "collectivism" (Best \& Love, 2010, p. 14) introduces networking and relational capabilities that facilitate transdisciplinarity; several perspectives note the ability of Māori to act as boundary spanners and facilitate relationships, and the importance of establishing meaningful relationships over time. However, the collectivism, or communitarianism (Trompenaars \& Hampden-Turner, 2012) aspects of Māori culture create tension with the individualistic tendencies of industry; outputs of research that industry seek to take ownership over which have been created using Mātauranga Māori are seen as collective resources becoming individualised and commercialised. Māori perspectives are also seen to be inherently futureoriented, partially owing to the communitarian aspects of Māori culture; this is seen to be applied intergenerationally: "communities are speaking about kaitiakitanga and the intergenerational end-point" (BioH Mgmt/Res/Māori 1), acknowledging the needs of future generations with a deliberate consideration for how present-day actions and research might affect them. Both the long-term and communitarian characteristics of Māori culture, reflect general conceptualisations of mission-led research, creating tension with views of industry. Industry stakeholders are the group who are most likely to conflict with the futureorientation and communitarian dimensions of NSCs; a tension attributed to 'commercial reality'. The need to maintain competitive advantage, react to technological innovation, and a resource-based view introduce cultural dimensions, particularly in the technological sector, of present-orientation and individualism. This is not universal: "a lot of people are willing to provide their time because it is the 'NZ good' perspective" (SfTI Mgmt 2) but it is a prevalent view of the industry dynamic. It is a set of characterisations that both industry and other perspectives recognise as legitimate, citing a focus on current problems that drive a short-term, industry-focused view. The result is a risk of a short-term, individualistic 
stakeholder operating in a future-oriented, communitarian culture with stakeholders who otherwise generally align with those values. This isn't necessarily a negative or detrimental situation, with Duality theory (Sutherland and Smith, 2011) and the Triple Helix Model (Etzkowitz, 2003) both describing the benefits of a transdisciplinary, diverse system of cooperative innovation, but it does require a certain degree of consensus and convergence toward a common goal, or common understanding of the framework within which they operate.

\subsection{Stakeholder Alignment: Structures and Boundary Spanners}

Resolving the incongruities between stakeholder conceptualisations of mission-led research and cultural discrepancies is central to the establishment of a common vision of the future and successful transdisciplinary projects (Nurius, Kemp, Köngeter \& Gehlert, 2017). The $\mathrm{BioH}$ and SfTI Challenges present examples of possible ways of addressing the conflicting perspectives, and illustrate the importance of relationship building and facilitation as a solution.

The primary issue to be addressed is the potential for tension between industry's shortterm, individualistic perspective and the long-term, communitarian perspectives of other stakeholders. Both BioH and SfTI management refer to the importance of building positive relationships with stakeholders. The use of industry leaders in the SfTI board provides a legitimacy to the Challenge, and the deliberate engagement of industries through advisory boards and co-creation processes indicates a desire to meaningfully incorporate industry beyond their role as end users. The co-creation of projects between researchers and industry exemplifies a 'front-end' engagement intended to guide the real world application of research outcomes, and industry's likely position as end users of outputs creates a need to incorporate industry input meaningfully. However, this continuous engagement is seen as unsatisfactory for industry, some of whom feel they struggle to have the level of influence over research direction that would provide them with a reasonable degree of engagement. This directly conflicts with some researcher and Māori perspectives, who can perceive industry "to have far more influence compared to what they're contributing" (BioH Mgmt/Māori 1). However, the use of boundary-spanners (Mangematin, O'Reilly, and Cunningham, 2014) by both SfTI and BioH help to remediate the potentially negative aspects of industry's engagement. All stakeholders acknowledge the value of individuals who cross 
worldviews as translators and moderators, and their engagement is seen to have an immediately apparent positive influence on stakeholder relationships. Structures that improve boundary-spanning, whether in the specialised 'knowledge-broker' role in BioH or as a generalised improvement in relational and human capacity in SfTI, enable the positive relationship needed to align industry, Māori, and researcher perspectives.

\section{Boundary-Spanning through Vision Mātauranga}

Enabling boundary-spanners is a side-effect of several of the major structures within BioH and SfTI. Vision Mātauranga as implemented by Challenge management enables Māori researchers and Māori business to engage in the Challenges through a deliberate and meaningful relationship. In BioH particularly, the VM criteria require that projects overcome a lack of Māori capacity and capability in the research space. In the short term, this has driven Māori researchers towards a generalist work style, advising multiple projects and missing the opportunity to specialise in a particular discipline. However, it has created opportunities dedicated to developing Māori capability in the long-term, particularly for "young emerging researchers who self-identify as Māori" (SfTI Res 1). These opportunities provide an attraction to the Challenges for emerging Māori researchers; although there are significant challenges in lack of emerging Māori capability. But the ability of Māori researchers to act as boundary spanners is significant (Mason, 2003); whakawhānaungatanga, relationship building, provides a tendency toward communitarian culture which is immediately conducive toward building capability in boundary-spanning; this is noted by one SfTI perspective: "most Māori have been doing it [boundary-spanning] anyway, Māori who have been brought up with a knowledge of their tikanga have been doing that" (SfTI Mgmt/Māori 1). The result is that VM, supported by criteria, funding, and reporting processes, enables the incorporation of Māori perspectives. This subsequently attracts individuals pre-disposed to boundary-spanning roles, who emphasise the building ofpositive relationships.

\section{Boundary-spanning through Best Teams}

The second structure that enables boundary-spanning is that of 'best teams'; but only when there has been a reinterpretation of 'best teams' toward 'right teams'. This encourages focus to move away from the individualistic practice of picking the seemingly most talented individuals, and towards a communitarian focus on cooperation, diversity, and 
communication first, and "what kind of scientists they are or researchers or managers they are second" (SfTI Mgmt/Māori 1). These 'right teams' create an immediate focus on the ability of individuals to build positive relationships and act cooperatively across disciplines and sector boundaries. Managerial facilitation of the relationships in these teams both builds connections and moderates them by reducing the dominant voices in a conversation, and allowing the emergence of diverse perspectives in conversations where they might otherwise not have been made apparent. Facilitation through management therefore helps to enable the meaningful incorporation of transdisciplinary worldviews by moderating power dynamics between and within stakeholder groups, removing barriers to boundaryspanning and positive relationship building within teams (Ratcheva, 2009).

The core benefit of boundary-spanning as a tool in the NSCs is in the building of relationships and understanding between stakeholders of their divergent expectations and motivations. Relationship building through boundary spanning provides a means of implementing Duality Theory (Sutherland \& Smith, 2011); rather than attempting to align the values of different stakeholder groups, it allows a cross-boundary understanding of perspectives; researchers understand the perspective of industry and vice versa, for example. This provides a generalised common vision of the overall conceptualisations of the missions, regardless of the individual contexts of each stakeholder perspective. Additionally, the building of meaningful relationships through boundary-spanning individuals allows for a degree of compromise and engagement that facilitates the transdisciplinary cooperation agreed to be necessary for mission-led outcomes. It does not resolve all conflicts of expectation and motivation; it provides an understanding of expectations and motivations, facilitating communication and relations within the mission-led context.

\subsection{Alignment of Criteria, Reporting, Funding}

Modes of alignment which have a basis outside that of relationship building are also used to produce, if not a conceptual consensus, then a convergence of practices that reflect the general understanding of mission-led research. This is most apparent in the use of Challenge specific, internal KPIs that reflect qualitative reporting, and in the interpretation of VM and best teams for proposal criteria. The use of qualitative reporting in particular is seen to improve the ability of research teams to engage in processes that support their conceptualisations of mission-led research, but which don't have the quantitative outcomes 
expected through typical reporting formats. For example, engaging in relationship building is widely recognised as a central process in mission-led research, but participants noted that it was difficult to report on those processes within quantitative formats. Conversely, the use of qualitative reporting was met with some issues; primarily through researchers who were unfamiliar with the process, and had been embedded in frameworks with predominantly quantitative reporting. Despite this, the ability to tell stories and report in a less standardised way is seen to improve the 'dynamism' of reporting to better reflect the reality of the Challenges. Frustrations with reporting are generally directed at formats that fail to reflect mission-led conceptualisations; reporting which is short-term or doesn't allow for qualitative reporting on a meaningful scale is seen as failing to recognise the nature of the Challenges and doesn't necessarily reflect meaningful progress. This was not a universal view; some perspectives noted that MBIE had provided enough flexibility to the Challenge management in reporting that they were capable of reporting sufficient qualitative measures of their success. However, the perspectives which were satisfied with reporting were generally satisfied with the level of qualitative reporting; thus where their conceptualisation of mission-led frameworks was mirrored in the reporting process, there was less tension. Those who had a different understanding in the nuances of mission-led concepts were sometimes less satisfied, because reporting failed to reflect those understandings.

The idea of Negotiated Funding was generally not strongly understood as a policy framework, but the perspectives who did emphasise it suggested it allowed management to provide some direction to project proposals regarding their direction and milestones. These were identified most clearly in the implementation of VM criteria by $\mathrm{BioH}$, which requires a level of Māori engagement in project proposals that would meaningfully incorporate Mātauranga Māori and kaupapa into the overall process. BioH also uses the negotiated funding tool to move deliberately away from the use of funding as a motivator, encouraging the engagement of researchers who are motivated by the work itself, rather than a funding source - this was a tactic noted as desirable in some SfTI interviews. The implication is that Negotiated funding encourages the alignment of project proposals with mission-led conceptualisations; this has become even more pronounced with the use of mission-labs and capability bids in SfTI as an alternative to proposal bid in processes that highlights the 
emphasis on transdisciplinary and cooperative practices throughout the research process. Similarly to reporting structures, the negotiated funding process is seen as beneficial where its interpretation and implementation by management aligns with the stakeholder conceptualisations of mission-led research. Where it fails to align, such as in the short-term nature of funding through political cycles, there is a tension where participants perceive a structure that doesn't reflect their needs.

The use of processes such as reporting, criteria, and funding to create an organisational environment that reflects mission-led conceptualisations has provided the opportunity for stakeholders to enact research in a format consistent with those concepts. The result is that even where stakeholder understandings diverge, or relationships aren't facilitated strongly, the basic framework of the Challenges requires that the processes enacted by those stakeholders have a basic alignment with the underlying concepts of mission-led research.

\subsection{Theoretical Contribution and Research Question}

This thesis attempts to answer the research question: How do stakeholder relationships, funding mechanisms, and selection processes that facilitate mission-led processes impact the ability of the National Science Challenges to achieve their objectives? The answer lies in the way each of the factors works to align stakeholders toward a common understanding of the context of their research and the 'mission' they are undertaking. In short, stakeholder relationships and mission-led processes impact the ability of the National Science Challenges to achieve their objectives by providing a means of aligning the understandings of the different stakeholders toward a common vision of what mission-led research means and how they can interact to achieve their overarching objectives.

The implications of this research for the literature are oriented around three points. 1) How mission-led research is conceptualised by stakeholders; 2) How stakeholder conceptualisations of mission-led research are realised and interact during research processes; 3) How conceptualisations are aligned through mission-led structures to facilitate the research process. The basic premise of these implications are that an alignment of understanding of mission-led research between groups will facilitate positive relationships and collaboration, enabling successful research outcomes. 
How stakeholders envisage mission-led characterisations of: Big Picture, Transdisciplinary, Long-term, and Collective benefit are based on each stakeholder's frame of reference, which can be understood as sub-cultural characteristics. Stakeholders with a frame of reference that encourages a convergent understanding of mission-led research with that of other stakeholders will tend have a relationship with less tension; stakeholders whose frame of reference promotes an understanding which is divergent from that of other stakeholders will have greater tension in their relationships. The recruitment of stakeholders into a mission-led institution depends partially on the buy-in of stakeholders to the concept of mission-led research; the level of buy-in can also be partially attributed to the stakeholder conceptualisations. Those whose conceptualisations are divergent will tend not to buy-in, and introduce a self-selection of individuals who have a pre-existing conceptual alignment with the characterisations of mission-led research.

Following recruitment, there are two further opportunities for creating an alignment of understanding; the first through relational alignment. This recognises that the tension created by divergent understandings can be eased through effective relationship management; in the NSCs, this occurs primarily through the use of boundary-spanning skillsets and advisory councils. Stakeholders interactions moderated by effective facilitation and translation are likely to have reduced tension through recognition of the legitimate contexts of other groups. As well as reducing tension of divergent understandings, well facilitated relationships enable greater transdisciplinary collaboration and cross-boundary acceptance of motivations and expectations. This creates a dynamic of relationships which are aligned through mutual understanding of each other's context, helping to overcome the tension introduced through different understanding of mission-led research. The second opportunity for alignment is structural; where stakeholder conceptualisations are divergent through context and boundary-spanning skillsets are insufficient to create a common understanding of other contexts. Structural alignment takes place through the use of reporting, criteria, and funding; these can be interpreted and implemented by management to enforce the practical application of common mission-led concepts, despite a lack of conceptual or relational alignment. For example, the VM criteria of BioH necessitate the integration of Mātauranga Māori values into project proposals, including those submitted by stakeholders who might not have a conceptual perspective that values its inclusion; this 
promotes transdisciplinary collaboration, long-term impact, and collective benefit even where those are not the understandings of the stakeholders engaged in the project.

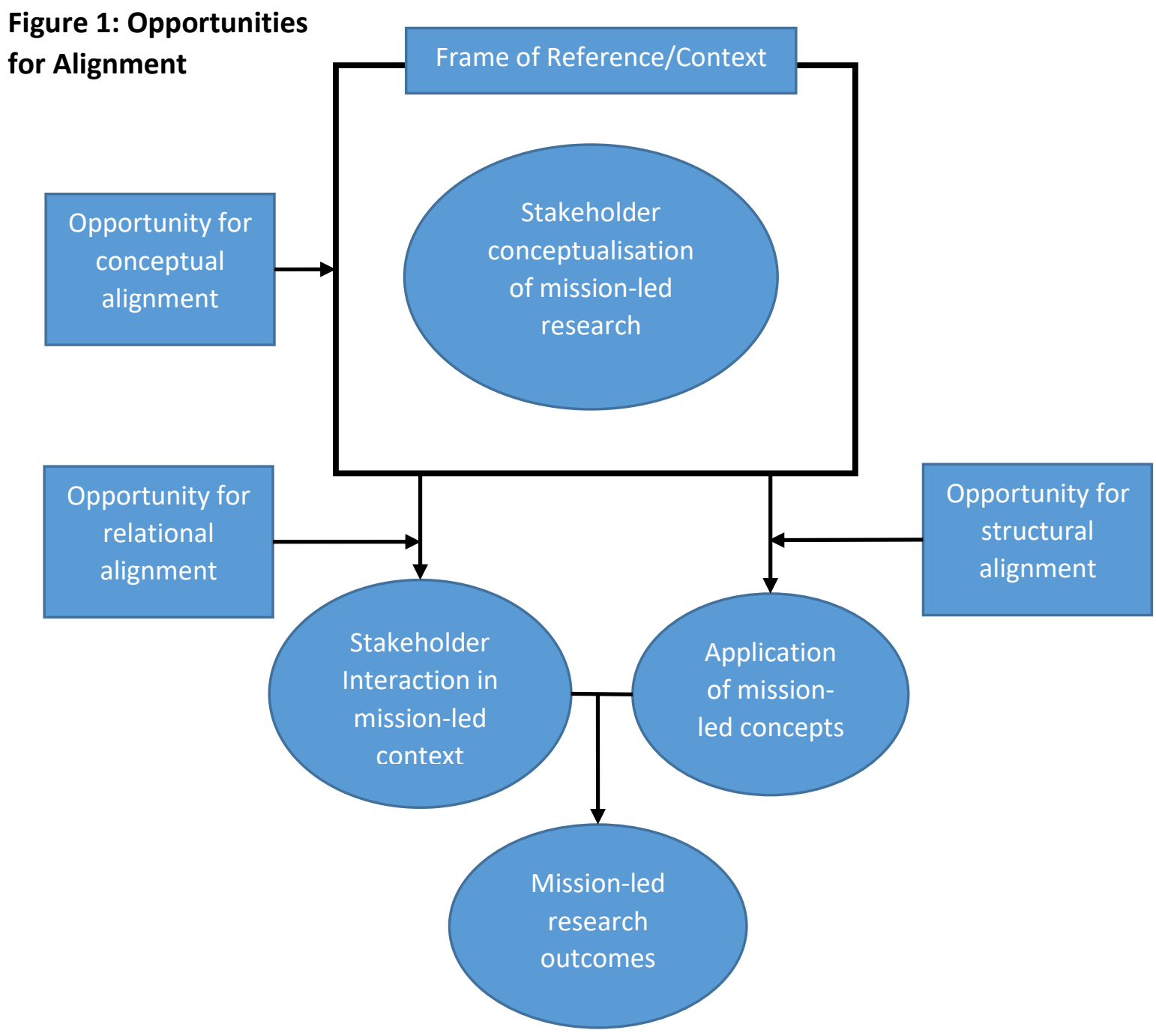

Figure 1 illustrates the opportunities for alignment as suggested by the discussion above. Stakeholder conceptualisations are influenced by their context, or frame of reference. An opportunity for conceptual alignment exists in the recruitment of individuals whose context predisposes them toward a particular conceptualisation of mission-led research. The interaction of stakeholders is then an opportunity for relational alignment, and their application of mission-led concepts in research practice is an opportunity for structural alignment. Interaction of stakeholders, and application of concepts, drives the creation of mission-led research outcomes. 


\subsection{Practical Implications}

The practical implications of this research target the management of mission-led research organisations. Ensuring that stakeholders with different understandings of their research context are aligned either conceptually, structurally, or relationally, will help to improve collaboration and reduce tension between stakeholder groups. The introduction of clear statements on what mission-led frameworks mean for the organisation can provide a conceptual framework that can be used to align stakeholders, and allow the self-selection of those who have a value set that reflects those meanings.

An emphasis on establishing boundary-spanning skillsets is crucial to the success of transdisciplinary research, and subsequently mission-led frameworks. This can be done in multiple ways, as demonstrated by the SfTI NSC, who deliberately train individuals in improving their human and relational capacity, or through BioH's use of knowledge brokers, who specialise in the boundary-spanning role and translating across boundary obstacles. It is likely that a combination of the two methods will prove most effective in achieving both general understanding and effective specific translation.

Lastly, the use of structures that promote the application of mission-led concepts even where understandings are divergent ensures that the implementation of research practices are aligned with the intended nature of outcomes. This can take place through the negotiation of proposal content at the funding stage, the setting of criteria that ensures milestones and direction are appropriate, and reporting formats that reflect the framework and context of research. 


\section{Limitations of Research}

This research was limited primarily in the nature of the sample of participants. The use of SfTI and BioH as exemplars of mission-led frameworks provided a useful comparison between the commonalities of successful organisations, but meant it was impossible to draw comparisons of the differences between successful and unsuccessful organisations. This meant that the issues identified by $\mathrm{SfTI}$ and $\mathrm{BioH}$ were the main sources of investigation, which may not reflect those of unsuccessful Challenge organisations. Similarly, all participants interviewed held the perspective of stakeholders currently engaged by the National Science Challenges; this was particularly limiting in determining the possible causes of reduced buy-in and disengagement from Challenges, although some participants were still able to lend insight into those areas by relaying opinions of colleagues.

Another limitation was in the semi-structured interview methodology; although this proved essential in adapting content of interviews to better reflect the realities of stakeholder perspectives and exploring unconsidered routes of investigation, it also led to a discrepancy in the nature of data collected between early and later interviews. This created a dearth of data from some perspectives in issues raised in later interviews, particularly regarding gender inequality issues and the more precise distinctions between mission-led conceptualisations.

Lastly, several concepts of Māori culture are referred to in this thesis; lacking a background in Te Ao Māori, I held informal discussion with knowledgeable individuals in an attempt to represent the concepts respectfully and accurately, but acknowledge that I may be biased by being grounded in Western values and this is likely to have influenced my discussion. 


\section{Future Research}

Future research of relationships within the National Science Challenges as a policy framework should consider exploring the Duality Theory in more depth. Examining the paradox of achieving a convergent understanding of context while maintaining the diversity of thought that allows for effective transdisciplinarity would provide an interesting insight into how an innovative tension can be maintained while avoiding the conflict in the interaction of stakeholder groups with different expectations and motivations; further exploration of theories of boundary-spanning and competence-based trust may provide some insight here.

Another potential avenue for future exploration is a comparison of equality and diversity across different Challenges. The SfTI and BioH Challenges both emphasised the incorporation of Vision Mātauranga, but it was evident that ongoing tensions existed in three key areas: emerging and established researchers, Māori and non-Māori perspectives, and gender. Gender, in particular, was an issue raised in later interviews of this study that unfortunately could not be reasonably incorporated, but it was apparent that the issue was salient to some perspectives. Examining how diversity has changed over time across different Challenges may provide an insight into how important this is to the success of mission-led research. 


\section{Conclusion}

One of the core dependencies on which the success of the NSCs depends is the alignment of mission-led conceptualisations and practice by different stakeholders. Characterisations of each stakeholder group, including their motivations, expectations, and relationships within the NSC context, create frames of reference within which stakeholders form their individual understandings of mission-led concepts. Stakeholder conceptualisation creates specific interactions as they are applied practically; for example, a stakeholder with an understanding of mission-led frameworks as future-oriented will have a more tense interaction with present-oriented stakeholders than if the two were aligned. The introduction of structures designed to improve alignment of understandings helps to avoid tension; project creation, funding, and reporting can be used in this way. Additionally, the VM and 'best team' policies can be used as tools to promote boundary-spanning practice, facilitating positive stakeholder relationships. Where stakeholder characteristics create divergent conceptualisations of mission-led research, there is divergence in modes of practice, which creates tension in stakeholder interactions and inhibits the success of mission-led research. Where conceptualisations of mission-led research are aligned, and modes of application are well structured and facilitated, there is positive stakeholder interaction and successful mission-led outcomes are more likely.

The result is that where conceptualisations of mission-led research and nature of application of those concepts are aligned between stakeholders, relationships are more positive and outcomes more likely to be successful. Alignment can occur in three modes; conceptual, structural, and relational. Conceptual alignment might occur through selection of individual stakeholders with a pre-existing common conceptualisation of mission-led research. Structural alignment may occur through funding, selection, and policy processes that promote a common mode of concept application. Relational alignment can be enacted through relationship facilitation and communication. Maintaining a consensus of understanding between stakeholders toward their research context and a common objective, while acknowledging the value of diverse schools of thought through conceptual, structural, and relational alignment, enables mission-led research in the NSCs. 


\section{References}

Belgrave, L. L., \& Seide, K. (2018). Grounded Theory Methodology: Principles and Practices. Handbook of Research Methods in Health Social Sciences, 1-18.

Best, P., \& Love, M. (2010). Māori Values for Māori Business Cultural Capital in Indigenous Organisations. Wellington, NZ. Victoria Management School

Boon, W., \& Edler, J. (2018). Demand, challenges, and innovation. Making sense of new trends in innovation policy. Science and Public Policy, 1, 13.

Bornmann, L. (2013). What is societal impact of research and how can it be assessed? a literature survey. Journal of the American Society for Information Science and Technology, 64(2), 217-233.

Bornmann, L., Wallon, G., \& Ledin, A. (2008). Does the committee peer review select the best applicants for funding? An investigation of the selection process for two European molecular biology organization programmes. PLoS One, 3(10), e3480.

Bozeman, B. (2000). Technology transfer and public policy: A review of research and theory. Research Policy, 29(4), 627-655.

Bozeman, Rimes, \& Youtie. (2015). The evolving state-of-the-art in technology transfer research: Revisiting the contingent effectiveness model. Research Policy, 44(1), 34-49.

Bromham, L., Dinnage, R., \& Hua, X. (2016). Interdisciplinary research has consistently lower funding success. Nature, 534(7609), 684.

Brown, R., Deletic, A., \& Wong, T. (2015). How to catalyse collaboration. Nature, 525(7569), 315-317.

Cole, S., Cole, J., \& Simon, G. (1981). Chance and consensus in peer review. Science, 214(4523), 881-886.

D'Acci, L. (2011). Measuring Well-Being and Progress. Social Indicators Research, 104(1), 4765.

DeTombe, D. (2001). Introduction to the field of methodology for handling complex societal problems. European Journal of Operational Research, 128(2), 231-232.

Detombe, D. (2017). Societal problems more complex than presumed: The Compram methodology. Journal of Systems Science and Systems Engineering, 26(3), 303-320.

Dhansay, T., Serper, A., Linol, B., Ndluvo, S., Perumal, L., \& De Wit, M. (2015).

Transdisciplinarity within South Africa's global change research: How (well?) are we doing? South African Journal of Science, 111(5/6), 1-4.

Durie, M. (2004). Exploring the interface between science and indigenous knowledge. In 5th APEC Research and Development Leaders Forum, Christchurch, New Zealand. 
Este, P., Rentocchini, F., Grimaldi, R., \& Manjarrés-Henríquez, L. (2013). The relationship between research funding and academic consulting: An empirical investigation in the Spanish context. Technological Forecasting \& Social Change, 80(8), 1535-1545.

Etzkowitz, H. (2003). Innovation in Innovation: The Triple Helix of University-IndustryGovernment Relations. Social Science Information, 42(3), 293-337.

European Commission (EC). (2012). The Grand Challenge. The design and societal impact of Horizon 2020. Luxembourg: Publications Office of the European Union.

Foray, D., Mowery, D., \& Nelson, R. (2012). Public R\&D and social challenges: What lessons from mission R\&D programs? Research Policy, 41(10), 1697-1702.

George, G., Howard-Grenville, J., Joshi, A., \& Tihanyi, L. (2016). Understanding and Tackling Societal Grand Challenges through Management Research. Academy of Management Journal, 59(6), 1880.

Godin, B., and Dore, C. (2004). Measuring the Impacts of Science: Beyond the Economic Dimension. CSIIC Working Paper, CSIIC, Canada (2004). Retrieved from:

http://www.csiic.ca/PDF/Godin Dore Impacts.pdf

Given, L. M. (2008). The SAGE encyclopedia of qualitative research methods (Vols. 1-0). Thousand Oaks, CA: SAGE Publications Ltd. DOI: 10.4135/9781412963909

Grimpe, C. (2012). Extramural research grants and scientists' funding strategies: Beggars cannot be choosers? Research Policy, 41(8), 1448-1460.

Holbrook, J. (2010). The use of societal impacts considerations in grant proposal peer review: A comparison of five models. Technology, 12(3), 213-224.

Kelman, A., \& Cook, J. (1996). The role of a competitive research grants program for agriculture, food, and natural resources. BioScience, 46(7), 533-540.

Kubler, J. (2013). Strengthening the mechanisms of competitive research and peer review in Africa. Regional and Thematic Papers on Research Management; RIMI4AC. Retrieved from: https://www.acu.ac.uk/publication/download?publication=534

Kuhlmann, S., \& Rip, A. (2014). The challenge of addressing Grand Challenges: a think piece on how innovation can be driven towards the "Grand Challenges" as defined under the prospective European Union Framework Programme Horizon 2020. European Research and Innovation Area Board (ERIAB).

Leydesdorff, L., \& Etzkowitz, H. (1998). The Triple Helix as a model for innovation studies. Science and Public Policy, 25(3), 195-203.

Leydesdorff \& Meyer. (2006). Triple Helix indicators of knowledge-based innovation systems: Introduction to the special issue. Research Policy, 35(10), 1441-1449.

Lundberg, H. (2013). Triple Helix in practice: The key role of boundary spanners. European Journal of Innovation Management, 16(2), 211-226. 
Maasen, S., Lengwiler, M., \& Guggenheim, M. (2006). Practices of transdisciplinary research: Close(r) encounters of science and society. Science and Public Policy, 33(6), 394-398.

Maguire M., \& Delahunt B. (2017). Doing a thematic analysis: A Practical, Step-by-Step Guide for Learning and Teaching Scholars. Aishe-J, 8(3)

Mangematin, V., O’Reilly, P., \& Cunningham, J. (2014). PIs as boundary spanners, science and market shapers. The Journal of Technology Transfer, 39(1), 1-10.

Marsden Fund Council. (2017). Marsden Fund Investment Plan 2018-2020. Retrieved from: https://royalsociety.org.nz/assets/Uploads/Marsden-Fund-Investment-Plan.pdf

Martin, B., \& Irvine, J. (1989). Research foresight: Priority-setting in science. London; New York: Pinter.

Mason, R. (2003). Culture-Free or Culture-Bound? A Boundary Spanning Perspective on Learning in Knowledge Management Systems. Journal of Global Information Management (JGIM), 11(4), 20-36.

Materia, Pascucci, \& Kolympiris. (2015). Understanding the selection processes of public research projects in agriculture: The role of scientific merit. Food Policy, 56, 87-99.

Mazzucato, M. (2017) 'Mission-oriented Innovation Policy: Challenges and Opportunities', UCL Institute for Innovation and Public Purpose Working Paper, (2017-1).

Mills, A. J., Durepos, G. \& Wiebe, E. (2010). Encyclopedia of case study research. Thousand Oaks, CA: SAGE Publications Ltd. doi: 10.4135/9781412957397

Ministry of Business, Innovation and Employment (MBIE). (2013). National Science Challenges: Key Messages Regarding Challenge Principles. Retrieved from: http://www.mbie.govt.nz/info-services/science-innovation/national-sciencechallenges/documents-image-library/key-documents/NSC-principles-key-messages-nov2013.pdf

Ministry of Business, Innovation and Employment (MBIE). (2015a). National Statement of Science Investment. Retrieved from: https://www.mbie.govt.nz/info-services/scienceinnovation/funding-info-opportunities/document-imagelibrary/NSSI\%20Final\%20Document\%202015.pdf

Ministry of Business, Innovation and Employment (MBIE). (2015b). National Science Challenges: Performance Framework Guidance Document (1). Retrieved from: http://www.mbie.govt.nz/info-services/science-innovation/national-sciencechallenges/documents-image-library/key-documents/NSC-performance-frameworkguidance-document.pdf

Ministry of Business, Innovation and Employment (MBIE). (2016a). Review of Crown Research Institute Core Funding. Retrieved from: https://www.mbie.govt.nz/infoservices/science-innovation/agencies-policies-budget-initiatives/researchorganisations/pdf-document-library/cri-core-funding-review.pdf 
Ministry of Business, Innovation and Employment (MBIE). (2016b). Principles for National Science Challenge development and implementation. Retrieved from:

http://www.mbie.govt.nz/info-services/science-innovation/national-sciencechallenges/documents-image-library/key-documents/NSC-20-principles-Nov-2013.pdf

Ministry of Business, Innovation and Employment (MBIE). (2017a). National Science Challenges Terms of Reference for Mid-Way Reviews. Retrieved from:

http://www.mbie.govt.nz/info-services/science-innovation/national-sciencechallenges/documents-image-library/national-science-challenge-mid-way-review.pdf

Ministry of Business, Innovation and Employment (MBIE). (2017b). Briefing for the Incoming Minister of Research, Science and Innovation. Retrieved from:

http://www.mbie.govt.nz/about/who-we-are/our-publications/briefings-to-incomingministers/2017-bims/research-science-innovation.pdf

Ministry of Business, Innovation and Employment (MBIE). (2017c). Endeavour Fund Investment Plan 2017-2020. Retrieved from: https://www.mbie.govt.nz/endeavour-fundinvestment-plan.pdf

Ministry of Research, Science, and Technology (MRST). (2005). Vision Mātauranga: Unlocking the Innovation Potential of Māori Knowledge, Resources, and People. Retrieved from: http://www.mbie.govt.nz/info-services/science-innovation/pdf-library/vmbooklet.pdf

Morandi, V. (2013). The management of industry-university joint research projects: How do partners coordinate and control R\&D activities? The Journal of Technology Transfer,38(2), 69-92.

Mowery, Nelson, \& Martin. (2010). Technology policy and global warming: Why new policy models are needed (or why putting new wine in old bottles won't work). Research

Policy, 39(8), 1011-1023.

National Science Challenges: Aging Well. (2013). Vision Mātauranga in Practice: Aging Well. Retrieved from: https://www.ageingwellchallenge.co.nz/wp-

content/uploads/2017/11/Ageing-Well-Vision-M\%C4\%81tauranga-improving-outcomes-forMāori-people.pdf

National Science Challenges: Aging Well. (2018). Vision Mātauranga. Retrieved from: https://www.ageingwellchallenge.co.nz/about-us/vision-Mātauranga/

New Zealand's Biological Heritage (BioH). (2018a). Vision Mātauranga. Retrieved from: http://www.biologicalheritage.nz/about/vision-Mātauranga

New Zealand's Biological Heritage (BioH). (2018b). Parties \& Affiliates. Retrieved from: http://www.biologicalheritage.nz/about/parties 
National Science Challenges: Science for Technological Innovation (SfTI). (2018a). Vision Mātauranga. Retrieved from: https://www.sftichallenge.govt.nz/vision-Mātauranga

National Science Challenges: Science for Technological Innovation (SfTI). (2018b). Challenge Background. Retrieved from: https://www.sftichallenge.govt.nz/challenge-background

National Science Challenges: Science for Technological Innovation (SfTI). (2018c). Capacity Development. Retrieved from: https://www.sftichallenge.govt.nz/capacity-development National Science Challenges: Sustainable Seas. (2017). Performance Measurements for Sustainable Seas National Science Challenge. Retrieved from:

http://sustainableseaschallenge.co.nz/sites/default/files/201712/Challenge\%20KPIs\%202014-2019.pdf

National Science Challenges: Sustainable Seas. (2018). Strategy for Phase II (2019-2024). Retrieved from: https://sustainableseaschallenge.co.nz/sites/default/files/201804/2018.04.06 DRAFT Strategy\%20for\%20Phase\%20II\%20for\%20Consultation REVISEDdia grams.pdf

The New Zealand Gazette No. 12. 31/1/2014. Ministry of Business, Innovation and Employment: Criteria for Proposals for National Science Challenge Funding. Retrieved from: https://www.gazette.govt.nz/notice/id/2014-go548

New Zealand Gazette. No. 91. (12/9/2017). Criteria for Proposals for Second Period National Science Challenge Funding. Retrieved from: https://gazette.govt.nz/assets/pdfcache/2017/2017-go4685.pdf?2017-09-14\%2011:08:04

Nurius, P., Kemp, S., Köngeter, S., \& Gehlert, S. (2017). Next generation social work research education: Fostering transdisciplinary readiness. European Journal of Social Work,20(6), 907-920.

O'Leary, Z. (2014). Doing your Research Project ( $2^{\text {nd }}$ ed). London, United Kingdom. SAGE Publications Ltd.

Parker, S, (2015). Researching the values of participants attending strategic boards in public services: Semi-structured interviews, documentary research and observation. SAGE Research Methods Cases. 10.4135/978144627305014558049

Parsons, T. \& Shils, E. (1951). Toward a General Theory of Action. Cambridge, MA: Harvard University Press.

Perkmann, M., \& Walsh, K. (2009). The two faces of collaboration: Impacts of universityindustry relations on public research. Industrial and Corporate Change,18(6), 1033-1065.

Pregernig, M. (2006). Transdisciplinarity viewed from afar: Science-policy assessments as forums for the creation of transdisciplinary knowledge. Science and Public Policy, 33(6), 445455. 
Prussing, \& Newbury. (2016). Neoliberalism and indigenous knowledge: Māori health research and the cultural politics of New Zealand's "National Science Challenges". Social Science \& Medicine, 150, 57-66.

Rasmussen, B., Andersen, P., \& Borch, K. (2010). Managing Transdisciplinarity in Strategic Foresight. Creativity and Innovation Management, 19(1), 37-46.

Ratcheva, V. (2009). Integrating diverse knowledge through boundary spanning processes The case of multidisciplinary project teams. International Journal of Project Management. 27(3), 206-215.

Rekers, J., \& Hansen, T. (2015). Interdisciplinary research and geography: Overcoming barriers through proximity. Science and Public Policy, 42(2), 242-254.

Robles, C, (2014). A qualitative approach to understanding the complexity of curriculum reform: Considering the case of Bhutan. SAGE Research Methods Cases.

10.4135/978144627305013507676.

Rosenberg, N. (2009). Some critical episodes in the progress of medical innovation: An Anglo-American perspective. Research Policy, 38(2), 234-242.

Rylance, R. (2015). Grant giving: Global funders to focus on interdisciplinarity. Nature, 525(7569), 313-5.

Sadler, H. (2007). Mātauranga Māori (Māori Epistemology). The International Journal of the Humanities: Annual Review, 4(10), 33-46.

Sievanen, L., Campbell, L., \& Leslie, H. (2012). Challenges to Interdisciplinary Research in Ecosystem-Based Management. Conservation Biology, 26(2), 315-323.

Sutherland, F., \& Smith, A. (2011). Duality theory and the management of the changestability paradox. Journal of Management and Organization, 17(4), 534-547.

Tisdell, C. (1997). Public Funding of Agricultural Research: Competitive Versus NonCompetitive Mechanisms. Prometheus, 15(2), 197-208.

Trompenaars, A., \& Hampden-Turner, C. (2012). Riding the waves of culture : Understanding diversity in global business / Fons Trompenaars and Charles Hampden-Turner. (Rev. and updated 3rd ed.). London: Nicholas Brealey.

Ughetto, E. (2007). Foresight as a triple helix of industry, university and government relations. Foresight, 9(5), 14-22.

Bibliography

Barriball, L. (2015). Outside In: End to End; Tangata Whenua Focus Group. Deliverable 11: Western Science and Mātauranga Māori Discussion Document.

Boyatzis, R. (1998). Transforming qualitative information: Thematic Analysis and code development. Thousand Oaks, CA: Sage Publications Ltd. 
Cheah, S., \& Yu, C. (2016). Assessing economic impact of research and innovation originating from public research institutions and universities-case of Singapore PRIs. Triple Helix, 3(1), 1-36.

Cormack, D., Harris, M., Ricci B., \& Stanley, J. (2013). Investigating the Relationship between Socially-Assigned Ethnicity, Racial Discrimination and Health Advantage in New Zealand. PLOS ONE, 8(12), E84039.

Department of Education, Science and Training (DEST). (2006). Research Quality Framework: Assessing the quality and impact of research in Australia - Research Impact. (Report by the RQF development advisory group). Canberra: Commonwealth of Australia.

Donovan, C. (2008). The Australian Research Quality Framework: A live experiment in capturing the social, economic, environmental, and cultural returns of publicly funded research. New Directions for Evaluation, 2008(118), 47-60.

Driscoll, C., Lambert, K., Stuart Chapin, F., Nowak, D., Spies, T., Swanson, F., Kittredge, D., Hart, C. (2012). Science and Society: The Role of Long-Term Studies in Environmental Stewardship. Bioscience, 62(4), 354-366.

European Commission (EC). (2015). In-depth Report: Indicators for Sustainable Cities. Science for Environment Policy. Issue 12. DOI: 10.2779/61700

Exeter, D. J., Zhao, J., Crengle, S., Lee, A., \& Browne, M. (2017). The New Zealand Indices of Multiple Deprivation (IMD): A new suite of indicators for social and health research in Aotearoa, New Zealand. PLOS ONE, 12(8).

Fischer, M., \& Varga, A. (2003). Spatial knowledge spillovers and university research: Evidence from Austria. The Annals of Regional Science, 37(2), 303-322.

George, I. \& Vergragt. (1994). The social management of environmental change. Futures, 26(3), 323-334.

Harmsworth G., Awatere S. (2013). Indigenous Māori knowledge and perspectives of ecosystems. In: Dymond JR ed. Ecosystem services in New Zealand: conditions and trends. Lincoln, New Zealand, Manaaki Whenua Press. Pp. 274-286.

Hikuroa, D., Slade, A., \& Gravley, D. (2011). Implementing Māori indigenous knowledge (mātauranga) in a scientific paradigm: Restoring the mauri to te kete poutama. MAl Review (Online), Issue.3.

Hong, B. (2014). National cultural indicators in New Zealand. Cultural Trends, 23(2), 93-108. Lambert, S. (2012). Innovation, Māori and the Māori Economy: A flat or lumpy world? International Indigenous Development Research Conference 2012. Retrieved from: http://ndhadeliver.natlib.govt.nz/delivery/DeliveryManagerServlet?dps pid=IE15479357 Mansfield, E. (1991). Academic research and industrial innovation. Research Policy, 20(1), 112. 
Merck, V. (2003). Communication across cultures: From cultural awareness to reconciliation of the dilemmas. St. Louis: Federal Reserve Bank of St Louis. Retrieved from https://search.proquest.com/docview/1698029423?accountid=14782

National Institutes of Health (NIH). (2010). STAR METRICS: New Way to Measure the Impact of Federally Funded Research. Retrieved from: https://www.nih.gov/news-events/newsreleases/star-metrics-new-way-measure-impact-federally-funded-research OECD (2011). Public Research Institutions: Mapping Sector Trends. OECD Publishing. http://dx.doi.org/10.1787/9789264119505-en.

Orozco, J., \& Ruiz, K. (2010). Quality of interactions between public research organisations and firms: Lessons from Costa Rica. Science and Public Policy, 37(7), 527-540.

Prettner, K., Werner, K. (2016). Why it pays off to pay us well: The impact of basic research on economic growth and welfare. Research Policy. 45(5), 1075-1090.

Royal, T. (2012). Politics and knowledge: Kaupapa Māori and Mātauranga Māori. New Zealand Journal of Educational Studies, 47(2), 30-37

Salter A., Martin B. (2001). The economic benefits of publicly funded basic research: a critical review. Research Policy, Volume 30, Issue 3, Pages 509-532

Scottish Government. Scottish Index of Multiple Deprivation (SIMD). (2012). Methodology Visual Guide. Retrieved from:

http://www.gov.scot/Topics/Statistics/SIMD/BackgroundMethodology/MethodologyVisual2 012. Last Accessed March 7, 2018. Edinburgh: Scottish Government, 2012.

Sternthal, M., Slopen, N., \& Williams, D. (2011). Racial Disparities in Health. Du Bois Review: Social Science Research on Race, 8(1), 95-113.

United Nations Development Programme (UNDP). (2016). Table 1: Human Development Index and its Components. Retrieved from: http://hdr.undp.org/en/composite/HDI Accessed 5/3/2018

World Health Organisation (WHO). (2017). World Health Statistics 2017: Monitoring health for the SDGs. Annex B. p. 86. Retrieved from:

http://www.who.int/gho/publications/world health statistics/2017/EN WHS2017 AnnexB .pdf?ua=1

Zakkar, M., \& Sedig, K. (2017). Interactive visualization of public health indicators to support policymaking: An exploratory study. Online Journal of Public Health Informatics, 9(2), E190. 